LIQUID BASED DIURNAL THERMAL STORAGE

by

\author{
Mojtaba Asgarian \\ Bachelor of Engineering (Mechanical) \\ Azad University \\ Tehran, Iran, 2008
}

\begin{abstract}
A Major Research Project
Presented to Ryerson University

in partial fulfillment of the requirements for the degree

of Master of Engineering in the program of

Mechanical Engineering
\end{abstract}

Toronto, Ontario, Canada, 2016

CMojtaba Asgarian 2016 


\section{Author's Declaration}

I hereby declare that I am the sole author of this major research project. This is a true copy of the major research project, including any required final revisions, as accepted by my examiners.

I authorize Ryerson University to lend this major research project to other institutions or individuals for the purpose of scholarly research.

I further authorize Ryerson University to reproduce this major research project by photocopying or by other means, in total or in part, at the request of other institutions or individuals for the purpose of scholarly research.

I understand that my major research project may be made electronically available to the public. 


\title{
LIQUID BASED DIURNAL THERMAL STORAGE
}

\author{
Mojtaba Asgarian \\ Master of Engineering \\ Department of Mechanical and Industrial Engineering \\ Ryerson University, Toronto, Ontario, Canada, 2016
}

\begin{abstract}
A comprehensive study of using thermal energy storage (TES) tank was performed. In this report, the comprehensive literature review of various options of storing thermal energy in buildings was discussed. The objective of the project was to evaluate charging and discharging performance of a storage tank with and without phase change material (PCM) blocks. The general format of the energy balance for the storage tank considering losses, input energy, inlet and outlet mass flow rates, and PCM blocks was developed.
\end{abstract}

Charging performance was analyzed by three different approaches. Initially, constant input thermal energy rate was considered to be delivered to the tank by different heat pumps from 4.5 kW to $9 \mathrm{~kW}$ heating capacity. Charging time, phase change process, and stored energy were analyzed under constant thermal energy rate input mode for charging process. Then, the effect of constant coil temperature on charging process was studied and results were compared to previous cases. Also, a solar assisted heat pump was implemented into the model to verify the effect of solar radiation on pre-heating the air for heat pump and how this process improves the overall charging progress of storage tank. 
Moreover, discharge procedure was discussed to evaluate various discharge modes based on different water draw flow rates. Based on this analyses developing a complete TRNSYS model of the tank is recommended in order to do whole building energy simulation. 


\section{Acknowledgements}

Firstly, I would like to thank my wife and my daughter and my parents for their support over the past few years while I was taking courses and working on this project in order to complete my Master of Engineering degree.

Secondly, I would like to thank Dr. Alan Fung for providing all the guidance and support on this project; and for setting high standards on the research quality. I also thank Dr. Ziad Saghir for serving on the examination committee and providing valuable comments

Last but not least, I would also like to thank my colleagues and my friends for their support.

This work is dedicated to my daughter, JASMINE and my MOM 


\section{Table of Contents}

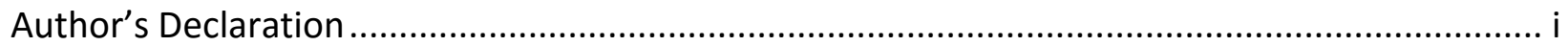

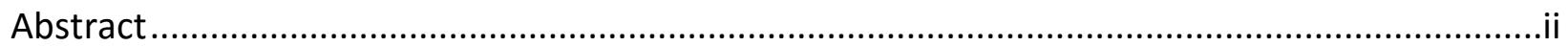

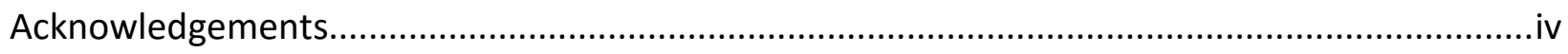

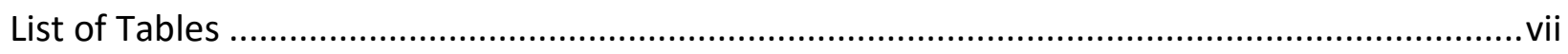

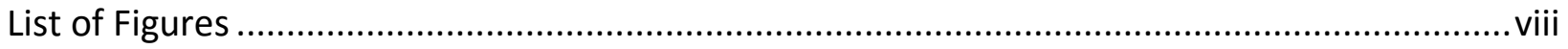

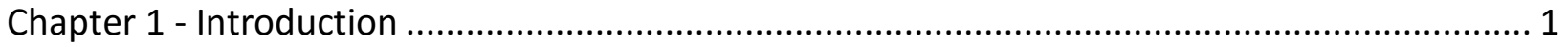

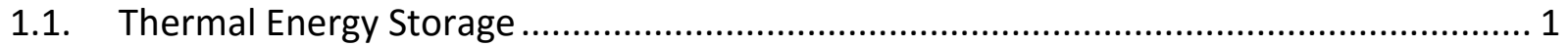

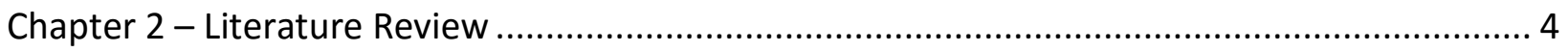

2.1. Classification of Thermal Energy Storage …................................................................ 4

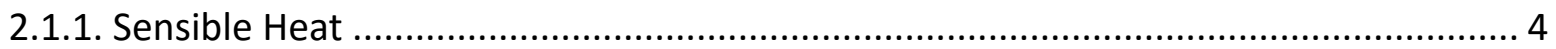

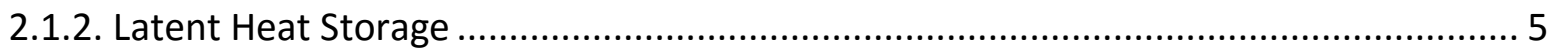

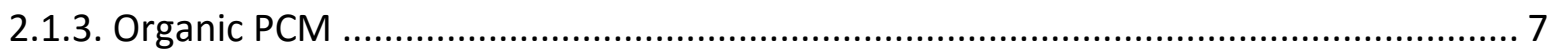

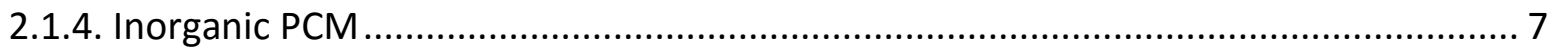

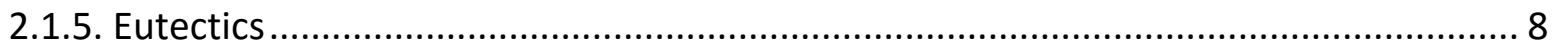

2.1.6. Long Term Stability for PCM at Low Temperatures............................................. 8

2.1.7. Phase Change Thermal Storage for Peak Load Shifting ......................................... 8

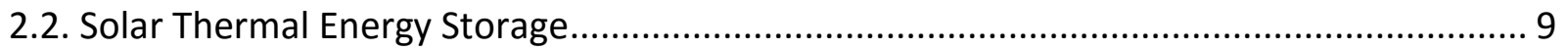

2.2.1. Water-based Sensible Heat Thermal Storage ...................................................... 11

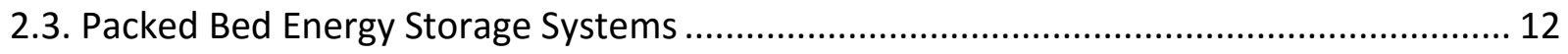

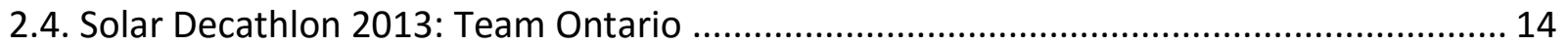

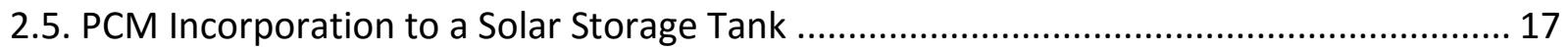




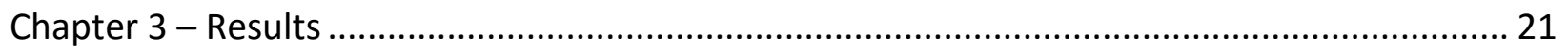

3.1. Charging Process with Constant Energy Rate ............................................................ 23

3.2. Charging Process with Constant Coil Temperature .................................................. 28

3.3. Charging Process with Solar Assisted Heat Pump ..................................................... 36

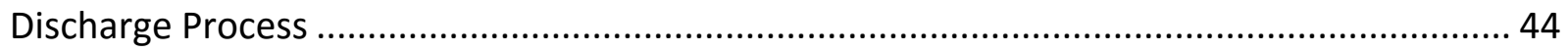

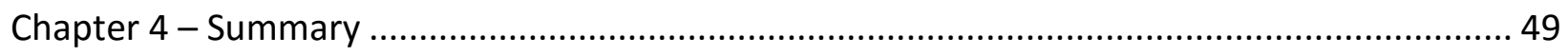

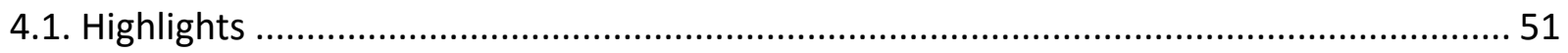

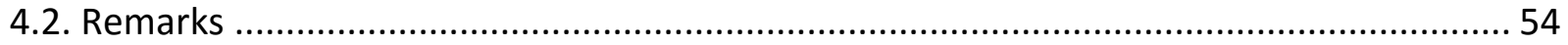

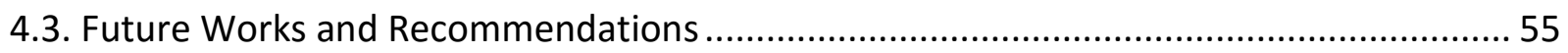

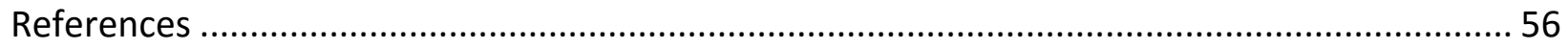

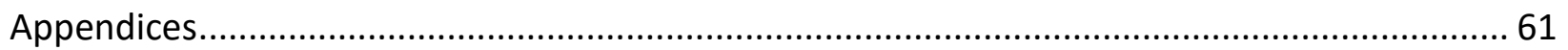

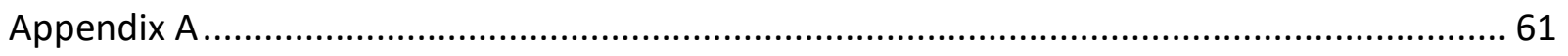

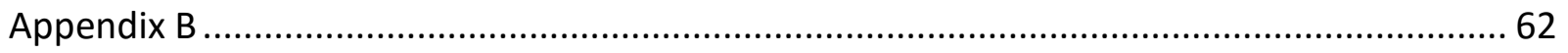

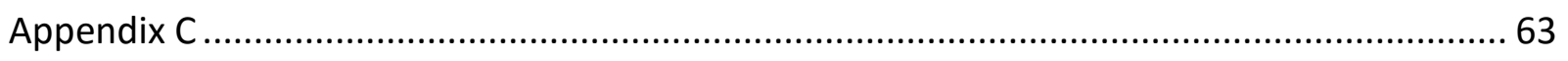

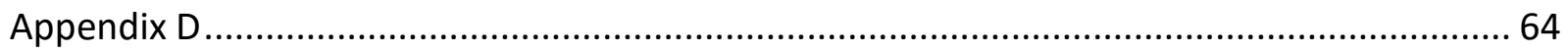

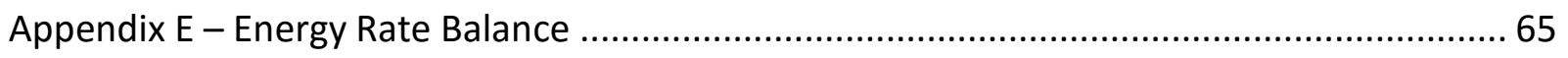

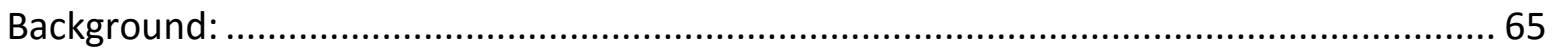

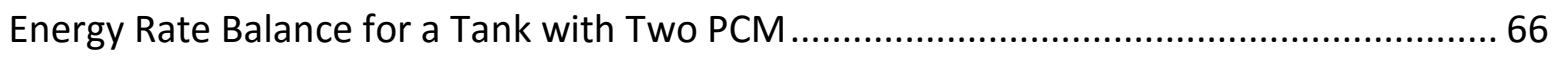

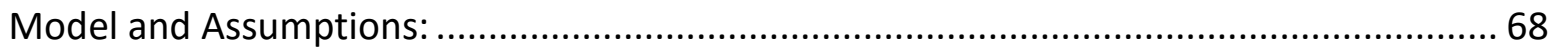




\section{List of Tables}

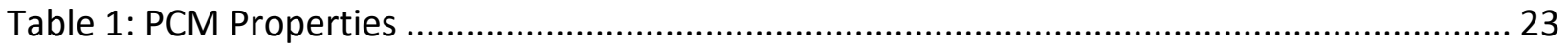

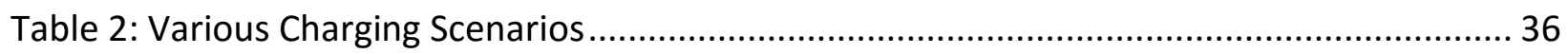




\section{List of Figures}

Figure 1: Classification of thermal energy storage (Fernandez et al., 2010)..... 4

Figure 2: Classification of latent heat storage materials for thermal energy storage (Sharma et al., 2009) 6

Figure 3: Application of thermal storage in a solar heating system. (Duffie and Beckman, 2006).9

Figure 4: Schematic of: (a) typical indirect "pumped" SDHW system and (b) an indirect SDHW system utilizing a natural convection heat exchanger (NCHE) (Cruickshank and Harrison, 2006)

Figure 5: Schematics of a packed bed thermal storage system (Castell et al., 2007) ................ 14

Figure 6: Schematic of solar assisted heat pump system (Chu et al., 2014) ........................... 15

Figure 7: The system performance with varying tank sizes(Chu et al., 2014) .......................... 16

Figure 8: Cross sectional view of the tank with PCM containers (Sharif et al., 2015)................ 17

Figure 9: Charging the tank with a 200 liter Salt-Hydrate $\$ 46$ by a $9 k W$ heat pump................. 24

Figure 10: Charging process with three different heat pump ............................................. 25

Figure 11: Charging process of a tank with three different PCM blocks by a 7kW heat pump ... 26

Figure 12: Charging process of a tank with two different PCMs ........................................ 27

Figure 13: Charging a tank with two PCM blocks by three heat pump ................................ 28

Figure 14: Charging the tank with 200L PCM S46 with constant coil temperature $\left(65^{\circ} \mathrm{C}\right) \ldots \ldots . . .29$

Figure 15: Charging the tank with 200 PCM S46 with a constant coil temperature $\left(55^{\circ} \mathrm{C}\right) \ldots \ldots \ldots . . .30$

Figure 16: Charging process with fixed temperature and different PCM blocks ..................... 31

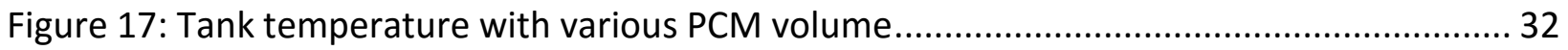


Figure 18: Charging process with $100 \mathrm{~L}$ and 200l Poly-Ethylene-Glycol (PEG) E600 lower

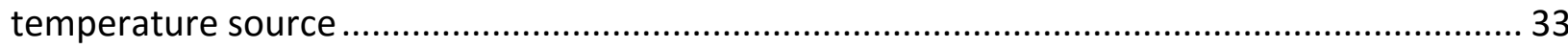

Figure 19: Charging the tank with 200 L PCM PEG-E low and high coil temperature ................. 34

Figure 20: Charging process with bigger PCM blocks ........................................................ 35

Figure 21: $5 \times 5$ roof mounted solar panel array (Kamel and Fung, 2014) .............................. 36

Figure 22: Temperature of air before and after BIPV/T (Kamel and Fung, 2014) ..................... 38

Figure 23: Performance of the heat pump with and without BIPV/T (Kamel and Fung, 2014) ... 39

Figure 24: Charging process with a solar assisted heat pump............................................. 40

Figure 25: Tank temperature when charged by ASHP and BIPV/T+ASHP ............................ 41

Figure 26: Charging process with various start times..................................................... 42

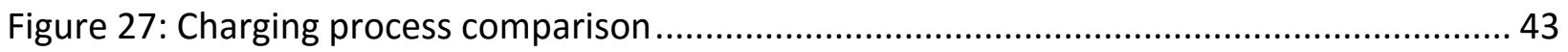

Figure 28: Charging process comparison with various PCM volumes ................................... 44

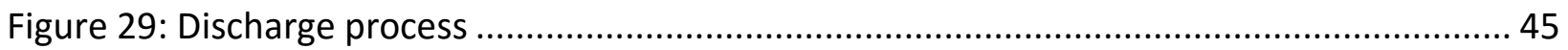

Figure 30: Discharge process with different mass flow rates ........................................... 46

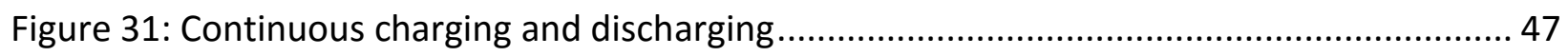

Figure 32: Charging duration for different settings ....................................................... 48

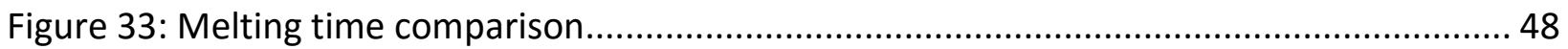

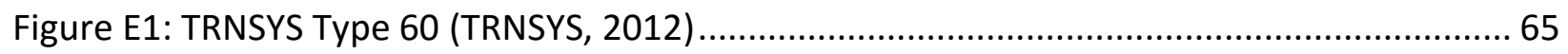

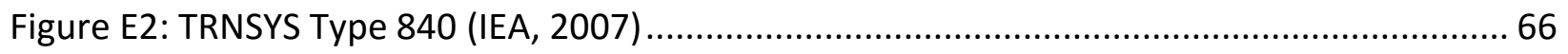

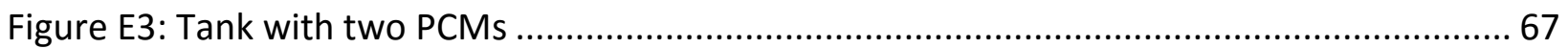




\section{Chapter 1 - Introduction}

\subsection{Thermal Energy Storage}

The continuous increase in the level of greenhouse gas emissions and the infatuations in fuel prices are the main driving forces behind efforts to more effectively utilize various sources of renewable energy. Rapid worldwide population growth has put a heavy burden on conventional energy resources, such as; fuel, coal and oil, which are estimated to run out in several decades (Basecq, 2013). These conventional resources are also blamed for $\mathrm{CO}_{2}$ and other harmful gas emissions that lead to climatic change problems such as global warming and damaging of the ozone layer. All of these severe consequences are leading people into reconsidering what are truly acceptable and sustainable development patterns. In recent years, considerable progress in renewable energy development has made new energy resources very competitive with conventional energy resources in terms of both efficiency and reliability. Solar energy, as a pollution-free, inexhaustible and affordable energy resource, has received extensive study and numerous applications throughout the world. However, one of the barriers to the use of solar energy as a resource lies in the noticeable misalignment between energy supply and consumption. The use of solar energy for thermal applications such as water heating, space heating, cooking, and drying can be unreliable as this resource is variable in nature and unpredictable (Braun et al., 1981). Therefore, the effective use of this resource necessitates a thermal energy storage system that stores the energy whenever it is available and allows utilizing the energy during non-solar hours. Thermal energy storage systems will reduce the imbalance between the demand and the supply of energy, hence improving the performance of the system 
and reducing energy loss, which translates to cost saving. The energy storage idea is proposed as a solution to the problem of inconsistent energy supply.

The idea of thermal energy storage (TES) was first discussed and further studied to address the energy shortage crisis in the 1970s. Owing to this concept, intermittent solar energy can be utilized not only meet the demands of space heating and domestic water supply but also to offer a high grade heat source all year round regardless of timing or seasonal constraints (Cabeza et al., 2006 \& 2013). (Speyer et sl., 1959) discussed the theoretical approach of possibility of long term thermal storage by storing the excess thermal energy in summer and extracting it during winter which, later was implemented in Sweden in 70's (Ochs et al., 2009).

Energy storage can be classified into short-term storage and long-term storage based on the difference in the duration of the storage time. In this regard, Seasonal Thermal Energy Storage (STES) is a practice that fits under the long-term category and can basically be described as the method of storing solar energy in summer to compensate for the heat supply insufficiency in the wintertime.

The focus of many literatures are on the design of incorporation PCM to solar storage tank or the result of energy saving and efficiency of this component. However it is clear for author that there is a great potential for studying the new design of storage water tank with using different Phase Change Materials in different temperatures as Thermal Energy Storage (TES) system. This design will bring a new innovative design for integrated mechanical systems. Proposed system may enhance and improve the performance of the overall mechanical system for heating purposes in 
variety of temperature ranges. Incorporating two different concept in one design would define a new thermal storage system with higher efficiency and lower capital cost. 


\section{Chapter 2 - Literature Review}

\subsection{Classification of Thermal Energy Storage}

Thermal energy can be stored as sensible heat, latent heat or as chemical storage based on the specific heat capacity, latent heat and chemical reactions of the material. Basic classification of thermal energy storage is given in Figure 1.

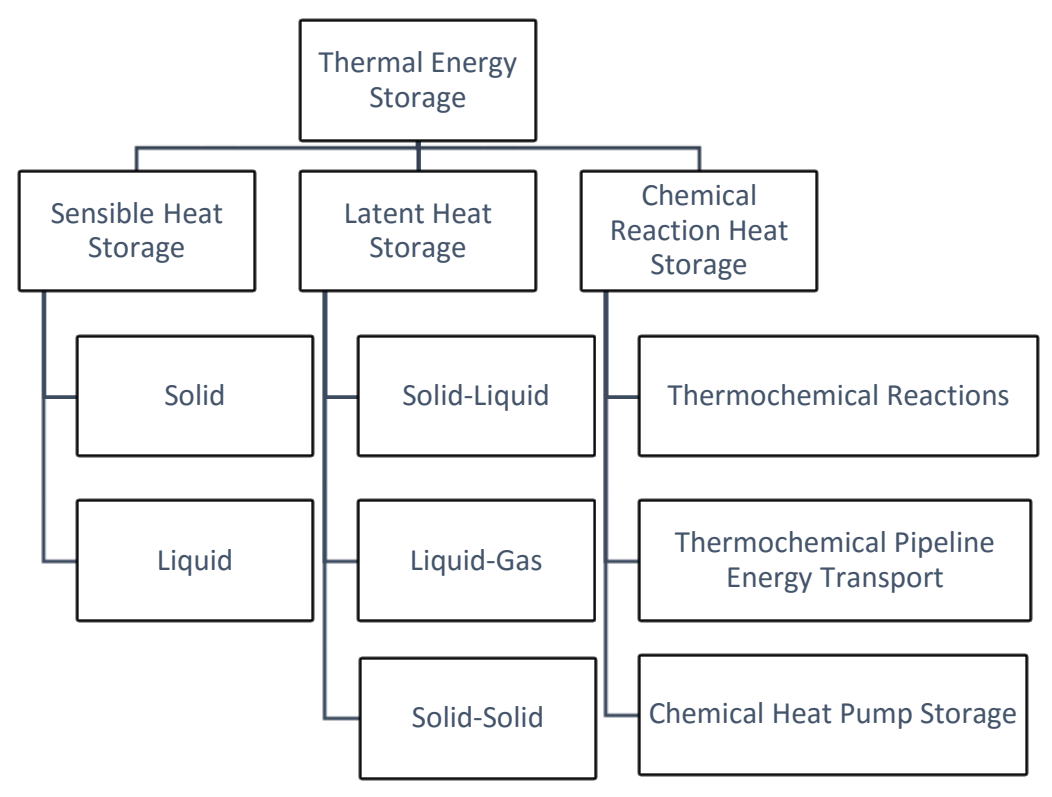

Figure 1: Classification of thermal energy storage (Fernandez et al., 2010)

Sensible and latent thermal storage systems will be discussed here but chemical reactions are out of the scope of this report.

\subsubsection{Sensible Heat}

In sensible heat storages, thermal energy is stored based on the specific heat capacity of the material. The temperature of the material in these storage systems fluctuates and never 
undergoes any phase transformation during charging/discharging cycles. The amount of energy stored in this category of storage systems are given by Equation 1.

$$
\mathrm{Q}=\int_{\mathrm{T}_{\mathrm{i}}}^{\mathrm{T}_{\mathrm{f}}} \mathrm{mC}_{\mathrm{p}} \mathrm{dt} \Rightarrow \mathrm{Q}=\mathrm{mC}_{\mathrm{p}}\left(\mathrm{T}_{\mathrm{f}}-\mathrm{T}_{\mathrm{i}}\right) \quad \text { Equation } 1
$$

The amount of the heat that is stored depends on factors such as the amount of the storage material, specific heat of the medium and difference between the change in temperature at initial and final stage. Some examples of the solid and liquid sensible heat storage medium are given in Appendix A.

\subsubsection{Latent Heat Storage}

In latent heat storage system, the process of storing and retrieving the thermal energy is based on the latent heat of fusion, where storage medium undergoes a phase transformation. The heat stored during the phase change process of the material is called latent heat. As the source temperature increases, the chemical bonds in the phase changing materials (PCM) break up which leads to the transformation from one phase to other (Farid et al., 2004; Nkwetta et al., 2014; Lane, 1980). Here the temperature is almost constant with significantly less temperature swing. Energy stored in latent heat storage medium is given by Equation 2. 


\section{Equation 2}

$$
Q=\int_{T_{i}}^{T_{m}} m C_{p} d t+m a_{m} \Delta h_{m}+\int_{T_{m}}^{T_{f}} m C_{P} d t=m\left[C_{s p}\left(T_{m}-T_{i}\right)+a_{m} \Delta h_{m}+C_{l p}\left(T_{f}-T_{m}\right)\right]
$$

Phase transformation of the material can be solid-solid, solid-liquid, or liquid-gas. Transformation of crystalline nature from one to other will be observed in solid-solid latent heat storage material whereas phase change of the material will be used to store thermal energy in other two methods of the latent heat storage materials. Solid-solid has an advantage of small change in volume and greater design flexibility but small latent heat compared to solid-liquid and liquid-gas which has larger latent heat and larger volume changes. Latent heat storage materials can be classified based on temperature, phase transition and compounds used as shown in Figure 2.

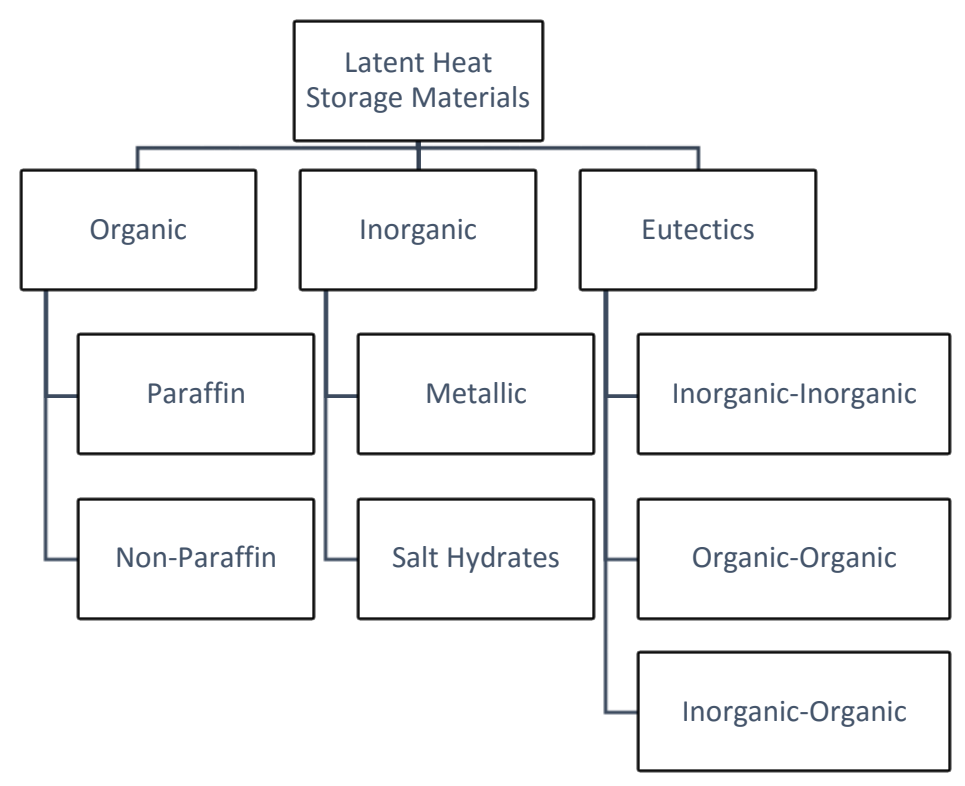

Figure 2: Classification of latent heat storage materials for thermal energy storage (Sharma et al., 2009) 


\subsubsection{Organic PCM}

A phase change material which contains carbon atom is known as organic PCM. It is classified under paraffin and non-paraffin. PCM materials with the general chemical formula of $\mathrm{Cn}_{n} \mathrm{H}_{2 n+2}$ are categorized under paraffin, where the heat of fusion and melting point increases with the increasing value of carbon atom number. Non-paraffin PCM is the compounds which contain functional groups such as alcohols, glycols, esters and fatty acids. Organic PCM's are available for a wide range of temperatures which are stable up to $300^{\circ} \mathrm{C}$. Examples of organic PCM are shown

in Appendix B. Few of the advantages of using organic PCM are no tendency to segregate, chemical stability, high heat of fusion, no tendency of supercooling and compatibility with all containers except plastic in high temperatures. Some of the disadvantages are low thermal conductivity, high cost, and in some cases flammability and being mildly corrosive (Pinel et al., 2011; Kousksou et al., 2008; Dincer et al., 2011).

\subsubsection{Inorganic PCM}

Inorganic PCMs are materials which consist of salt hydrates, nitrates and metallic. Inorganic PCM also have the advantage of being able to be used for higher temperatures of up to $1500{ }^{\circ} \mathrm{C}$. Few examples of inorganic PCMs are given in Appendix C. Inorganic PCMs are superior in terms of low cost, ease of availability, sharp melting point, high thermal conductivity, high heat of fusion and lower volume change. On the other hand, they are associated with disadvantages such as supercooling, segregation, materials degradation, corrosion of heat exchangers, low specific heat and decrease in heat of fusion after few cycles as a result of incongruent melting (Agyenim et al., 2010). 


\subsubsection{Eutectics}

Eutectic PCMs are mixture of two or more compounds at a particular percentage of composition. The compounds can be of any combination like organic-organic, inorganic-inorganic and organicinorganic. These types of PCMs melt and freeze congruently without any segregation. They freeze to an intimate mixture of crystals leaving less opportunity for the compounds to separate from one another. Similarly during melting, different compounds melt simultaneously that is also associated with a smaller probability of compound separation (Haji et al., 2010). Few examples of eutectic PCM are given in Appendix D.

\subsubsection{Long Term Stability for PCM at Low Temperatures}

The most important criteria that have limited the use of PCM in different systems is the type of container that is required for the PCM and the number of cycles it can undergo without any degradation of its properties. The long term stability of the storage materials is dependent on the stability of the material's properties and/or corrosion between the PCM and its container (Castell et al., 2010).

\subsubsection{Phase Change Thermal Storage for Peak Load Shifting}

As previously discussed, the development of an energy storage system may be one of the solutions to the mismatch problem of supply and demand. Thus, a building integrated with distributed thermal storage materials could shift most of the load coming from residential air conditioners at peak to off peak time periods. As a result, capital investment in peak power generation equipment could be greatly reduced for power utilities resulting in less expensive service to the customers. This concept is particularly beneficial where power utilities are offered 
on a time of day rate basis, as building integrated thermal storages give customers the luxury of taking advantage of lower utility rates during peak hours (Dincer et al., 2008).

\subsection{Solar Thermal Energy Storage}

Thermal energy storage (TES) is an integral component of a solar hot water system that may significantly improve its efficiency and cost effectiveness by allowing better utilization of the solar hardware and the matching of the solar resource to the load. For example, consider an idealized solar process with storage over a 3-day period, Figure 3 (Duffie and Beckman 2006). As indicated by the vertical shaded area, the collector useful gain (available energy) exceeds the load on the $1^{\text {st }}$ and $3^{\text {rd }}$ day. This excess energy is then held in the storage subsystem for use at a later time. When required, the excess energy is withdrawn from the storage to meet the load (as represented by the horizontal shaded area). If there is insufficient thermal energy in the storage, the load is met by an auxiliary energy source. The optimum choice and sizing of a thermal storage depends on many factors, including the distribution and temperature of the energy supply; the temperature requirements, magnitude and distribution of the load throughout the day or the season; the required charge and discharge rates; and the spatial limitations related to the installation and placement of the storage.

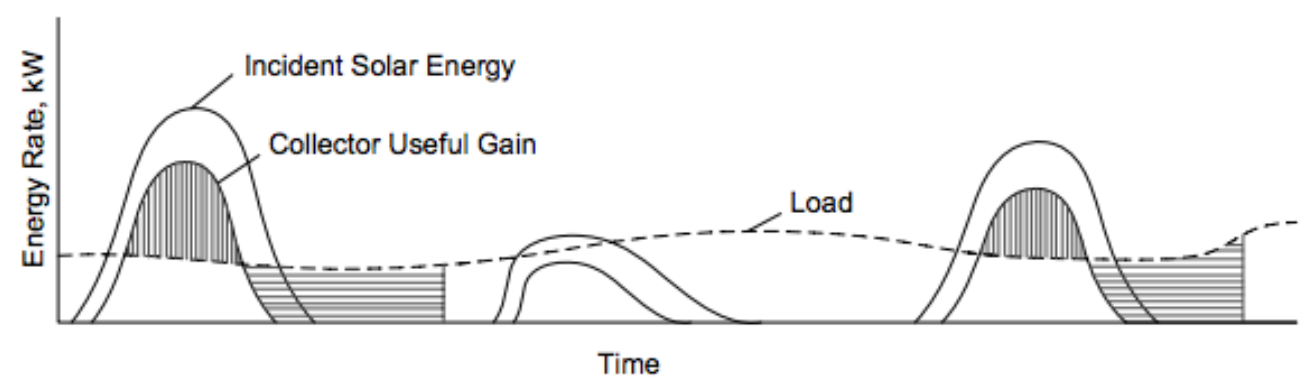

Figure 3: Application of thermal storage in a solar heating system (Duffie and Beckman, 2006) 
Most small to medium sized solar installations use diurnal storage, where energy is typically stored for one or two days, however weekly and seasonal storage is also used in certain applications. Primarily used to offset space heating loads, seasonal storage systems are designed to collect solar energy during the summer months and retain the heat in the storage for use during the winter months (Fisch et al., 1998).

Characterized by their large capacity requirement (in the order of a hundred times the capacity of a daily storage) (Dincer and Rosen, 2008), seasonal storage systems typically run at a much higher cost and require a larger storage volume than short term storages. Seasonal storages have been pilot-tested and used in a number of countries for district space and water heating (Fisch et al., 1998). Existing seasonal storage systems have been shown to meet close to $100 \%$ of annual building heating needs via absorbing solar energy (Dincer and Rosen, 2008).

Seasonal thermal storage systems may take on several physical configurations including underground aquifers, large pools (Kangas and Lund, 1994) or bore-hole buried earth storage. Because of their physical magnitude and cost, they are often custom engineered and constructed accounting for the specific load, climatic locations and soil conditions. Large-scale thermal storages of this size is not the focus of the current study.

Diurnal or short term storage is often more suitable for small-scale domestic applications. Diurnal storage is designed to store heat for up to a few days and generally consists of smaller devices that are typically manufactured and assembled off-site and subsequently delivered and installed within a building. Although short term TES systems will seldom contribute a solar fraction in 
excess of $60 \%$, they can operate on a competitive cost basis with conventional fuels (Dincer and Rosen, 2008).

\subsubsection{Water-based Sensible Heat Thermal Storage}

Water-based storage systems have been widely studied and applied in a variety of configurations. As a working fluid, water is readily available at little or no expense. Much effort has been put into maximizing the performance of water storages and minimizing the cost of the storage vessels. On the same note, small hot water heaters and storages (i.e., $180 \mathrm{~L}$ and $270 \mathrm{~L}$ ) have been produced in large quantity for the North American Market and are readily available at low cost. These systems, when coupled to an external heat exchanger as shown is Figure 4, represent a cost effective storage option for residential solar hot water heaters. However, larger storage volumes in the range of 500 to $1500 \mathrm{~L}$, are often required for multi-family residential units and small to medium-sized commercial applications. Unfortunately, suitable storage vessels of this size are only produced in limited quantities, resulting in significantly higher costs per unit of storage volume (Cruickshank and Harrison, 2006). In addition, these larger storage vessels are not well suited to retrofit situations where the storage vessel must be mobilized into a building space through the small existing door openings. Consequently, larger storages are often required to be constructed on site and be maintained at low pressure and vented to the atmosphere. This has a potential to pose a performance and health risk to occupants. 


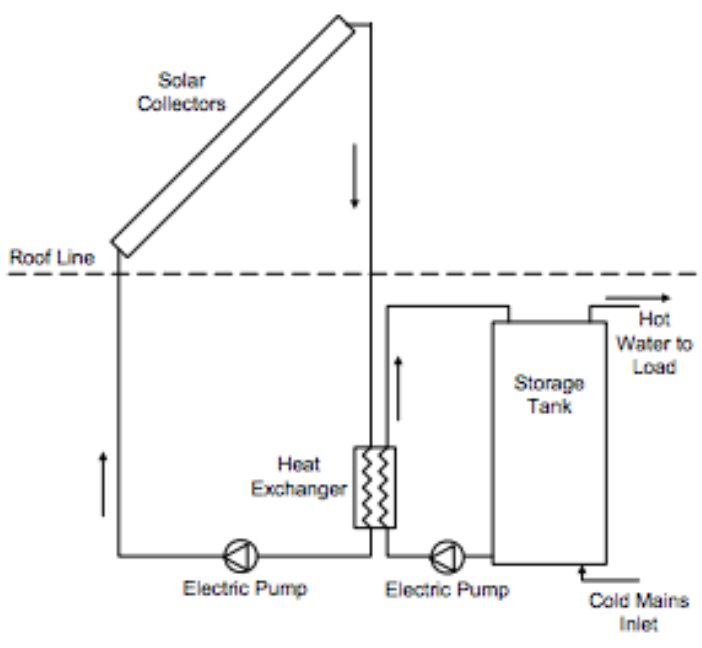

(a)

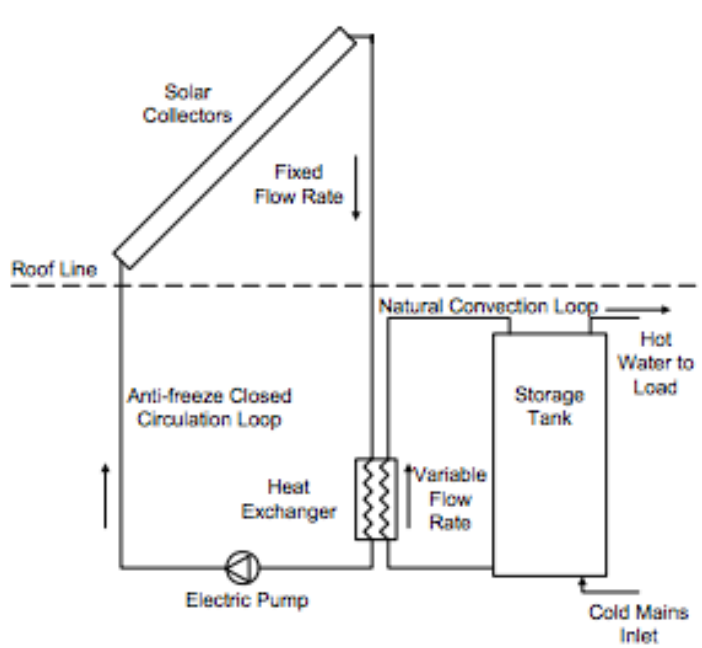

(b)

Figure 4: Schematic of: (a) typical indirect "pumped" SDHW system and (b) an indirect SDHW system utilizing a natural convection heat exchanger (NCHE) (Cruickshank and Harrison, 2006)

\subsection{Packed Bed Energy Storage Systems}

Schematic of a packed bed energy storage system is shown in Figure.5. A packed bed in a solar heating system does not operate in a normal fashion with constant temperature. During the daytime, different conditions such as solar radiations, ambient temperature, collector inlet temperature and load requirements result in a variable collector outlet temperature.

The optimum size of the storage system is a function of several system parameters such as storage temperature, material, storage heat losses, costs of the storage medium container, heat exchanger, cost of auxiliary energy and operating conditions such as insulation, ambient temperature, wind speed and solar fraction of the total heat load. Also, energy can be stored in rocks or pebbles packed in insulated vessels. This type of storage system is used very often for temperatures up to $100^{\circ} \mathrm{C}$ in conjunction with solar air heaters. It is reported that these systems are simple in design and relatively inexpensive. It is important to know that direct contact 
between the solid storage media and a heat transfer fluid is necessary to minimize the cost of heat exchange in the medium. The use of rocks for thermal storage provides advantages such as (i) rocks are non-toxic and non-flammable, (ii) rocks are inexpensive and (iii) rocks act both as heat transfer surface and storage medium. The heat transfer between air and a rock bed is considered adequate, due to the large heat transfer area, low effective heat conductance of the rock pile and small area of contact between the rocks. These factors contribute to the advantage of low heat losses from the pile.

Hasnain et al reports that solid materials such as rocks, metals, concrete, sand and brick can be used for low as well as high temperature heat storages. The pebble beds or rocks are generally used as storage material because of their low cost. Typically the size of rock used varies from 1 $\mathrm{cm}$ to $5 \mathrm{~cm}$. Also among metals, aluminum, magnesium and zinc have been claimed suitable materials for this purpose. The use of metallic media is useful where high thermal conductivity is required and the cost is of the secondary importance. On a lower level, solid industrial wastes such as copper slag, iron slag, aluminum slag and copper chips may be also be used as storage materials. All things considered, various materials ranging from metallic and refractory materials to many different types of stones can be used as storage material (Castell et al., 2007 \& 2009). 


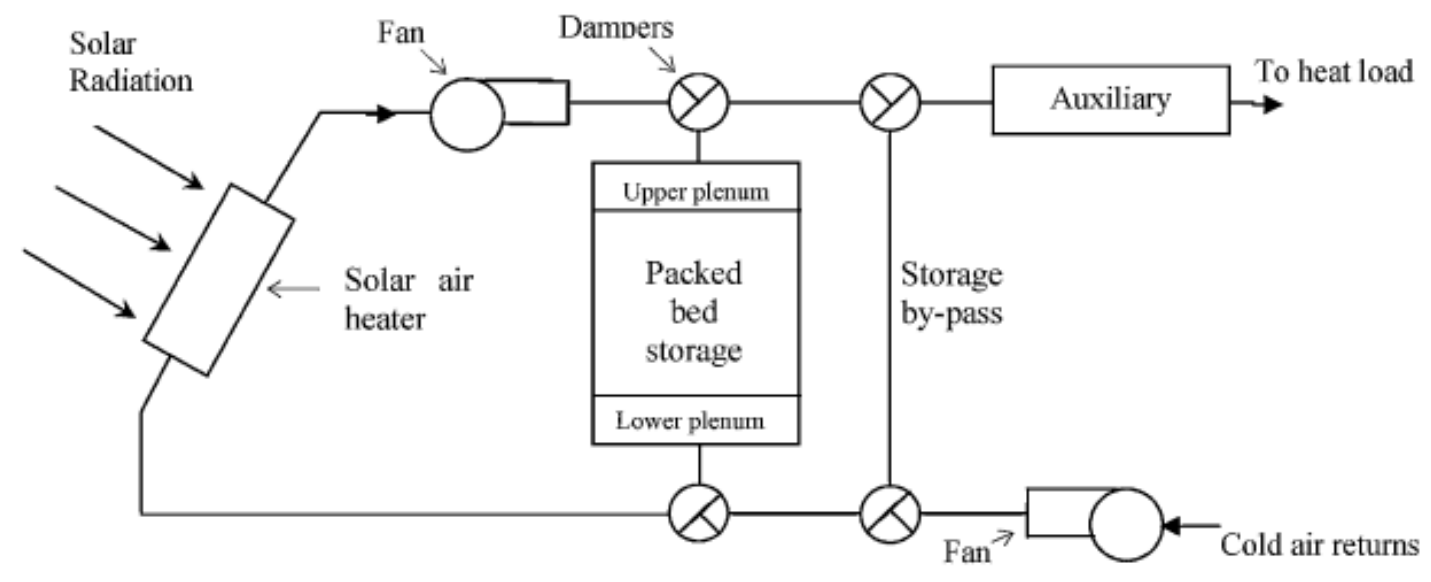

Figure 5: Schematics of a packed bed thermal storage system (Castell et al., 2007)

\subsection{Solar Decathlon 2013: Team Ontario}

The U.S. Department of Energy holds the bi-annual Solar Decathlon competition to challenge 20 teams to "design, build, and operate solar-powered houses that are cost effective, energy efficient, and attractive (U.S. Department of Energy, 2013, "Solar Decathlon," http://www.solardecathlon.gov/). Team Ontario was a collaboration of students and faculty from Queen's University in Kingston, Ontario, and Carleton University and Algonquin College in Ottawa, Ontario, Canada. This team designed an integrated mechanical system which used an indirect solar assisted heat pump as the primary system for a $960 \mathrm{ft}^{2}$ single story detached house. Two thermal energy storage tanks were used to improve the solar assisted heat pump system performance. The systems that Ontario team had used consist of solar collectors, two thermal energy tanks, and a liquid to liquid heat pump.

As shown in Figure 6 the collectors absorb solar energy that is used to charge a cold tank containing a 50/50 glycol-water solution by volume. At a preset temperature, the glycol solution 
is drawn from the top of the cold tank to the evaporator of the heat pump. The heat pump draws energy from the solution and transfers it to the hot water that is drawn from the bottom of the hot tank to the condenser of the heat pump. The heated water is returned near the top of the hot tank in order to keep thermal stratification. In the summer, the glycol solution would be used in the air handling unit for space-cooling and dehumidification. Energy recovered from spacecooling would then be transferred from the cold tank to the hot tank via the heat pump to meet DHW loads. The cooling coils within the air handler will dehumidify the air.

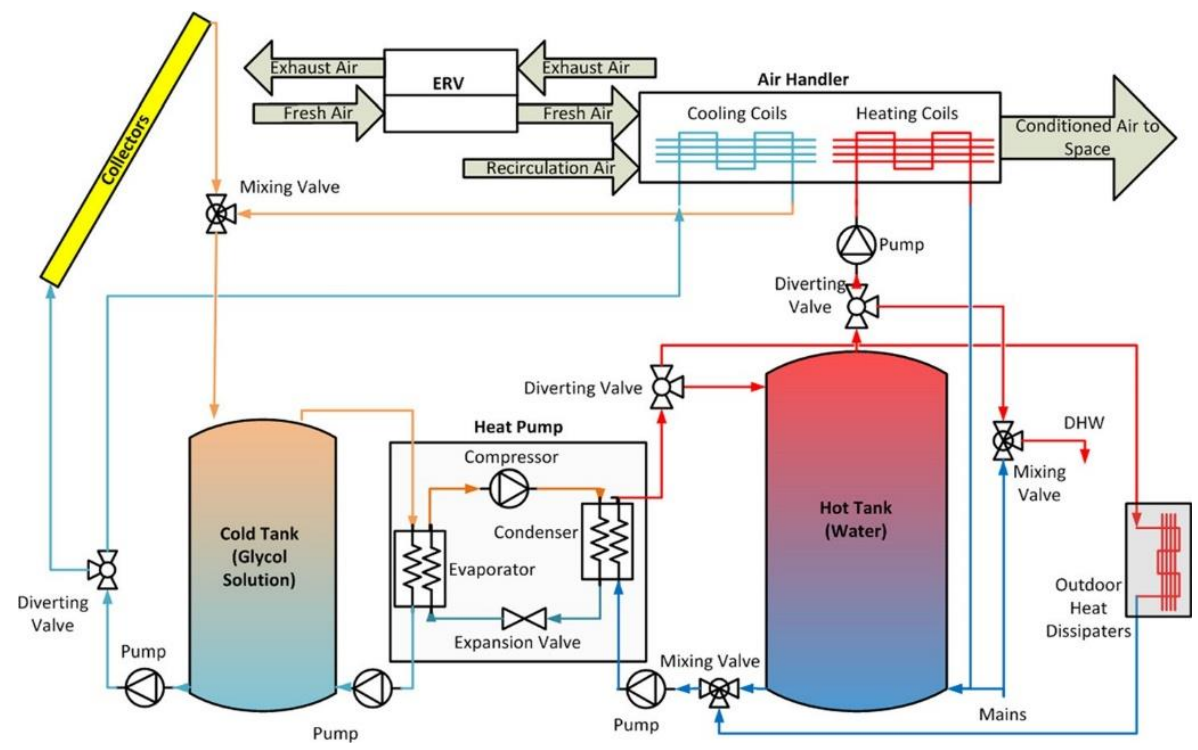

Figure 6: Schematic of solar assisted heat pump system (Chu et al., 2014)

The team modeled the house and mechanical systems in TRNSYS and run the simulation based on Ottawa weather data. They have used a 270 liter tank for cold storage and a 450 liter tank as a hot storage. A base model with $12 \mathrm{~m}^{2}$ of solar collected and a modified model with $18 \mathrm{~m} 2$ of solar collector was studied. For each study, the free energy ratio (FER) (the portion of the DHW, space-heating, and cooling loads that are met using non-purchased energy is called FER (Elliot, B. D., 2011 ) was determined for each case in order to investigate the effects of each parameter on 
the performance of the integrated mechanical system. The study suggests that a large cold tank will improve performance of the system and having a larger collector area may reduce the size of the hot water tank (see Figure 7).

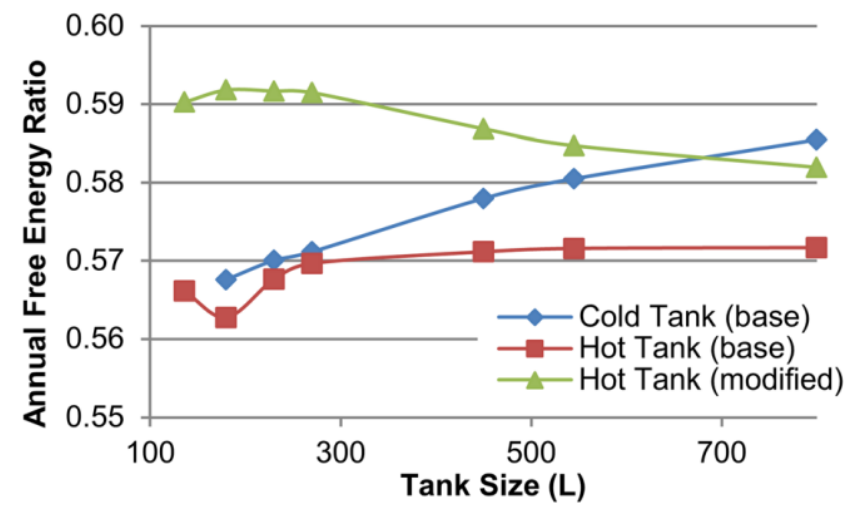

Figure 7: The system performance with varying tank sizes (Chu et al., 2014)

However, this research did not study the effect of adding PCM to tank. The study clearly lacks the analysis for the performance enhancement with PCM and having a single larger tank with two types of different phase change materials with different melting point. The studies can analysis how two different PCMs, one for cooling and another one for heating may Increase efficiency and save more energy in a single large tank. Also there was a great opportunity to do more research on other concepts.

A new concept of hot water system known as HEATPACK was developed by Martin et al., (2008). Water flowed through an extended surface tube heat exchanger in a tank with PCM as storage media. Having a compactness factor of $80 \%$, the thermal storage is able to provide hot water with a temperature of at least $40{ }^{\circ} \mathrm{C}$ for more than two hours, at average power of $3 \mathrm{~kW}$. The compactness factor (CF) is the ratio of the volume of PCM to the volume of the tank. 


\subsection{PCM Incorporation to a Solar Storage Tank}

In order to increase the heat capacity of thermal storage, PCM can be added into the hot water storage tank. Many applications are available for phase change material (PCM) thermal storage systems. In this process, typically PCM in the form of cylindrical or spherical capsules are inserted into the tank. Mehling et al. (2003) developed an effective hot water system by adding a PCM module at the top of the water tank. The hot water system is a cylindrical vertical tank that has a diameter of $20 \mathrm{~cm}$ and a height of $120 \mathrm{~cm}$. The PCM module consists of a brass cylinder with a diameter of $10 \mathrm{~cm}$ and a height of $30 \mathrm{~cm}$ filled with PCM (6\% of the total volume of the tank was PCM). Water at the top of the store was held warm at around $55^{\circ} \mathrm{C}$ for $50-200 \%$ longer and the average energy density was increased by $20-45 \%$ compared to the whole tank.

Al-Hinti et al. (2010) in Hashemite University campus in Jordan, introduced two levels of PCM into a conventional hot water storage tank that contains a total of 38 cylindrical aluminum containers. The tank is filled with $38.0 \mathrm{~kg}$ of paraffin wax. The cross sectional view of the tank is shown in Figure 8.

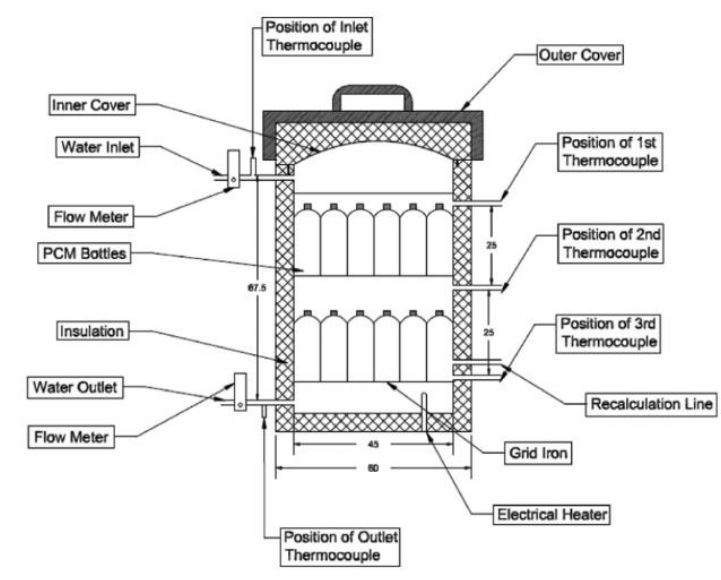

Figure 8: Cross sectional view of the tank with PCM containers (Sharif et al., 2015) 
The total volume of the PCM containers is $49.4 \mathrm{~L}$, with water occupying the remaining $58 \mathrm{~L}$ in the storage tank. PCM storage was investigated under controlled energy with an electrical heater and flat plate collectors in a closed-loop system. This system operated under both forced and natural circulation. For the conventional flat plate solar technology, the water temperature of the water-PCM storage system was maintained at over $45^{\circ} \mathrm{C}$ under all operational and climatic conditions.

Nkwetta et al. (2014) numerically studied the performance of a DHW tank integrated with different PCM types in various locations using TRNSYS simulation software. Their model was validated experimentally and used to determine the effect of PCM location on the thermal performance of the tank. The results indicated that the discharge times were consistent at the different draw-off intervals between predictions. The stored energy increased with the increase in PCM. Hence, the integration of PCM in hot water tanks improves storage capacity. Furthermore, it may provide energy, shift, and/or smooth peak power demand.

Bony and Citherlet (2007) developed a numerical model based on the enthalpy approach using TRNSYS software to examine heat transfer between the PCM and the water in DHW tanks. They also investigated different PCM capsule geometries, such as cylindrical, plate, and spherical capsules, and various PCM materials. The model was validated experimentally, and the simulated results were consistent with the monitored data.

Navarro et al. (2014) designed a storage tank for PCMs which its melting temperatures ranged from $10^{\circ} \mathrm{C}$ to $100^{\circ} \mathrm{C}$. The physical properties of the $\mathrm{PCM}$ (paraffin) were obtained, including specific heat, density, and enthalpy-temperature curve. This research group incorporated 
sensible and latent heat energy storage, and experimentally analyzed storage tank performance based on the vertical stratification of the PCM tank, effectiveness, and the total heat transfer in the tank. The findings indicated that the maximum capacity of the system reached $78 \%$ within 4 hours. Moreover, a full phase change could not be achieved during solidification at $6 \mathrm{~K}$ less than the PCM melting point.

Research completed under the International Energy Agency (IEA, 2007) Task 32 found that the storage density compared to water is strongly dependent on the temperature variation in the storage tank. For small temperature variations from 50 up to $70{ }^{\circ} \mathrm{C}$ and a $\mathrm{PCM}$ tank with immersed heat exchanger, the store can be sized about $1 / 3$ of the volume compared to water. For the same PCM material but macro-encapsulated and for a temperature variation from 25 to $85^{\circ} \mathrm{C}$ or 20 to $70{ }^{\circ} \mathrm{C}$ in solar assisted systems, the PCM store will have the same size as a water store. Thus the application of PCM in hot water systems which require a large temperature variation achieved negligible benefit with respect to store size. Therefore it is not recommended for small size tank.

\subsection{Latent Storage for Both Cooling and Heating}

Helm et al. (2013) experimentally studied the effect of latent heat storage on solar assisted heating and cooling system. They have used a single storage tank with a PCM that has a melting point which can be used both as cold and hot storage. However, it will only accommodate the higher limit of cold storage and lower limit of heat storage. Therefore it does not work very efficiently and requires a very large tank and cannot perform for many residential/commercial applications because of the temperature limit. If the temperature is too high or too low, the PCM 
is not effective and the system works almost as if there is no PCM inside the tank. However, having two separate PCM materials loaded at bottom and top of the tank with two different melting points (one for cold and one for hot storage) could increase the efficiency of the system. The heat storage works fine during the day when it is used to charge the chiller, but during transition between hot and cold and also during night time, it would not be a reliable system. 


\section{Chapter 3 - Results}

In pursuance of developing the theoretical model of the thermal energy storage tank, the complete energy rate balance of the tank including PCM blocks, heat losses, energy input and output was developed and presented in Appendix E.

In order to study the charging process of a storage tank with and without phase change material a theoretical model was developed. The model is flexible enough to be modified with various tank sizes and PCM containers. Also the model is developed in a way to be charged with a constant heat flux. However, it is designed in a way to take into account the hot water temperature in the coil instead of a fixed thermal input. It means that a fixed coil temperature can be adapted as an alternative to a fixed heat flux. Moreover, the model is able to consider a solar assisted heat pump as a heat source. In that case, the input thermal energy is changing hourly based on solar irradiation and the model will adapt the new heat source accordingly.

In this numerical model, two separate phase change material block is implemented. The size of each block inside the tank is changeable and each value can be inserted separately to study the effect of PCM blocks inside the storage tank. The model takes the physical and chemical properties of PCM materials as input and calculates the mass, heat of fusion, time of melting the block, etc. It also, shows the effect of having one or two PCMs inside the tank at the same time.

The model is able to calculate the total stored energy inside the tank with or without PCM block(s). Also, it compares different charging times based on the selected heat pump. The total power consumption and generated/stored thermal energy can also be utilized by the model. 
The following results and analyses are based on three different heat pumps. The heat pump selection was based on two market available SANYO heat pumps (4.5kW [SHP-C45DEN] \& 9kW [SHP-TH90GDN]) and the third heat pump was selected as a median between above mentioned heat pumps $(7 \mathrm{~kW})$. Both SANYO heat pumps have nominal coefficient of performance (COP) of 3.8.

Also the model was run based on a fixed coil temperature. It was assumed that instead of a fixed heat flux from heat pump, hot water at a fixed temperature is supplied by heat pump to the coil inside the tank. For this analysis supplied hot water temperature is considered to be $65^{\circ} \mathrm{C}$. Therefore, the rate of inlet thermal energy varies as the tank temperature increases.

The initial water temperature inside the tank is set at $10^{\circ} \mathrm{C}$ which is close to the inlet city water and is changeable in the model. Although, the more realistic initial temperature for the tank would be close to room temperature but in this analysis the tank is assumed to be in an unconditioned room.

All physical properties of water can be updated in the model and set to be temperature dependent but for this analysis the specific heat of water is $4182 \mathrm{~J} / \mathrm{kg} \mathrm{K}$ and water density is set to be $1000 \mathrm{~kg} / \mathrm{m}^{3}$.

As mentioned above two different PCM blocks are defined in the model and properties of the PCM's could be updated based on new materials introduced by user. This study is based on two PCM materials namely as Salt-Hydrate S46 and Poly-Ethylene-Glycol (PEG) E600. The properties of each PCM is defined in Table 1. 


\section{Table 1: PCM Properties}

\begin{tabular}{|l|l|l|l|l|}
\hline Name of PCM & $\begin{array}{l}\text { Density } \\
\left(\mathrm{kg} / \mathrm{M}^{3}\right)\end{array}$ & $\begin{array}{l}\text { Heat } \\
\text { Capacity } \\
\left(\mathrm{J} / \mathrm{M}^{3}\right)\end{array}$ & $\begin{array}{l}\text { Specific Heat } \\
\left(\mathrm{J} / \mathrm{kg}^{\circ} \mathrm{C}\right)\end{array}$ & $\begin{array}{l}\text { Melting } \\
\text { Temperature } \\
\left({ }^{\circ} \mathrm{C}\right)\end{array}$ \\
\hline Salt-Hydrate S46 & 1587 & 333000000 & 2410 & 47 \\
\hline Poly-Ethylene-Glycol (PEG) E600 & 1126 & 143227200 & 1800 & 22 \\
\hline
\end{tabular}

This study analyzes three different volumes of PCM in each block separately. Each volume is set at 100,200 , and 300 liter which correspond to $158.7,317.4$, and $476.1 \mathrm{~kg}$ of Salt-Hydrate S46 and 112.6, 225.2, and 337.8 kg of Poly-Ethylene-Glycol (PEG) E600.

\subsection{Charging Process with Constant Energy Rate}

Figure 9 is generated based on charging the 1000 liter storage tank with the $9 \mathrm{~kW}$ heat pump. The tank is occupied by a 200 liter block of Salt-Hydrate S46. There are no Poly-Ethylene-Glycol (PEG) E600 and the rest is filled with water. As Figure 9 illustrates, the tank temperature increases linearly until it reaches the melting point of the Salt-Hydrate $S 46$ at $47^{\circ} \mathrm{C}$. At this point, despite the fact that thermal energy is being added to the system, the temperature remains constant. The Salt-Hydrate $\$ 46$ goes through a phase change period and melts. Although the total thermal energy of the tank is increasing there is no temperature change during the phase change. After a complete melt down of the PCM block the tank temperature continuously increases. It takes around 2 hours to melt the whole 200 liter block of Salt-Hydrate S46 and the whole charging process to warm up the system until $50^{\circ} \mathrm{C}$ takes 7 hours and 5 minutes. 


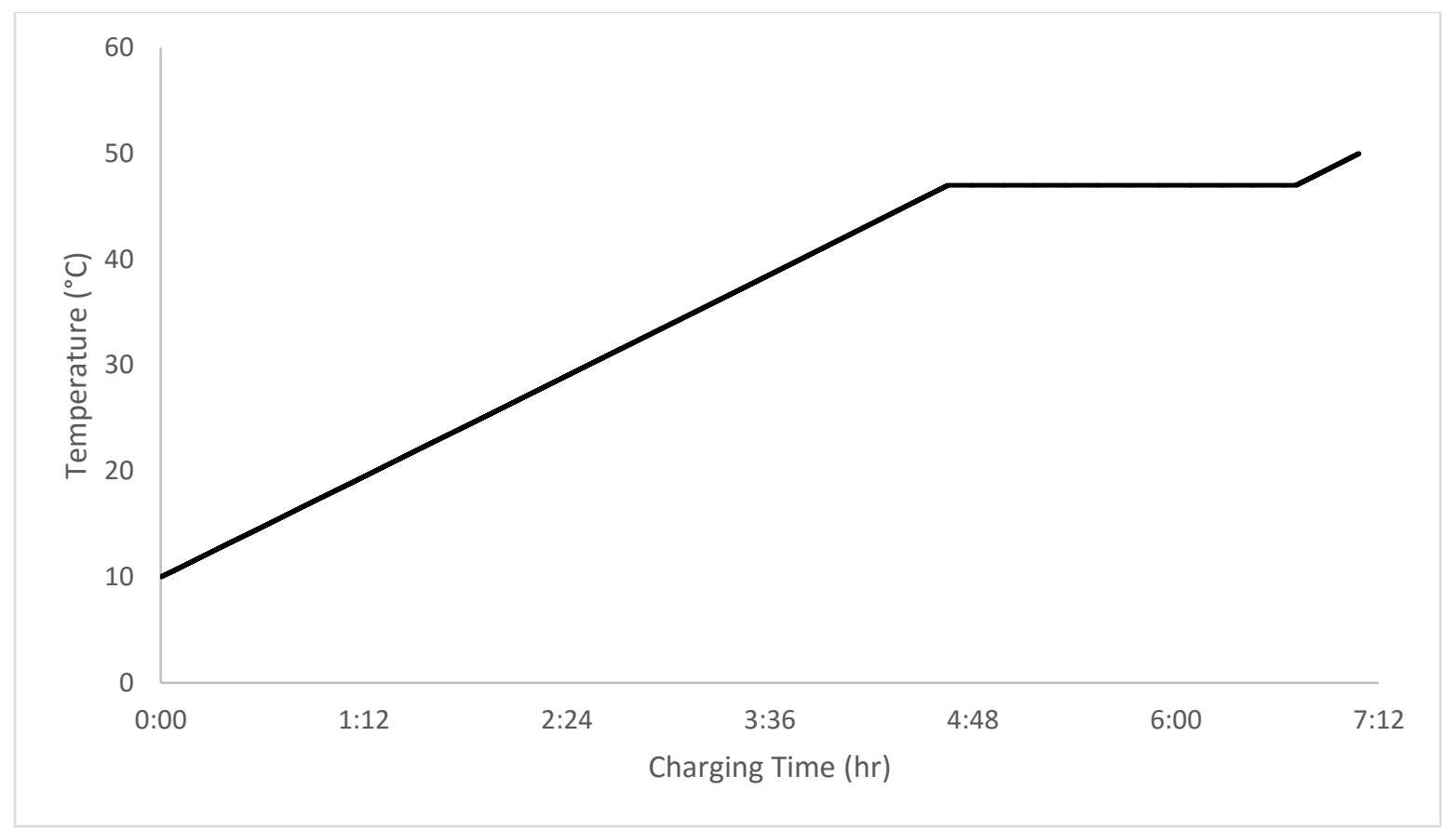

Figure 9: Charging the tank with a 200 liter Salt-Hydrate S46 by a 9kW heat pump

In order to show the effect of different heat sources in charging process, Figure 10 was generated. In this figure, charging trend of the tank again with a 200 liter Salt-Hydrate S46 by all three different heat pumps. As shown in Figure 10, temperature rise pattern during the charging process follows the same trend. However, the slope of temperature line is visibly different as expected. The graph also shows that the duration of phase change process is considerably longer in charging with a smaller heat pump. The melting times for these processes are 7400 second with $9 \mathrm{~kW}$ heat pump, 9500 second with $7 \mathrm{~kW}$ heat pump, and 14800 second with the $4.5 \mathrm{~kW}$ heat pump. Moreover, the whole charging process (heating up to $50^{\circ} \mathrm{C}$ ) is longer when the heat pump capacity is lower. The total charging time for the smaller heat pump is almost double the time to charge with 9kW heat pump. The charging times are respectively: 7:05 hr., 9:05hr, and 14:04hr. 


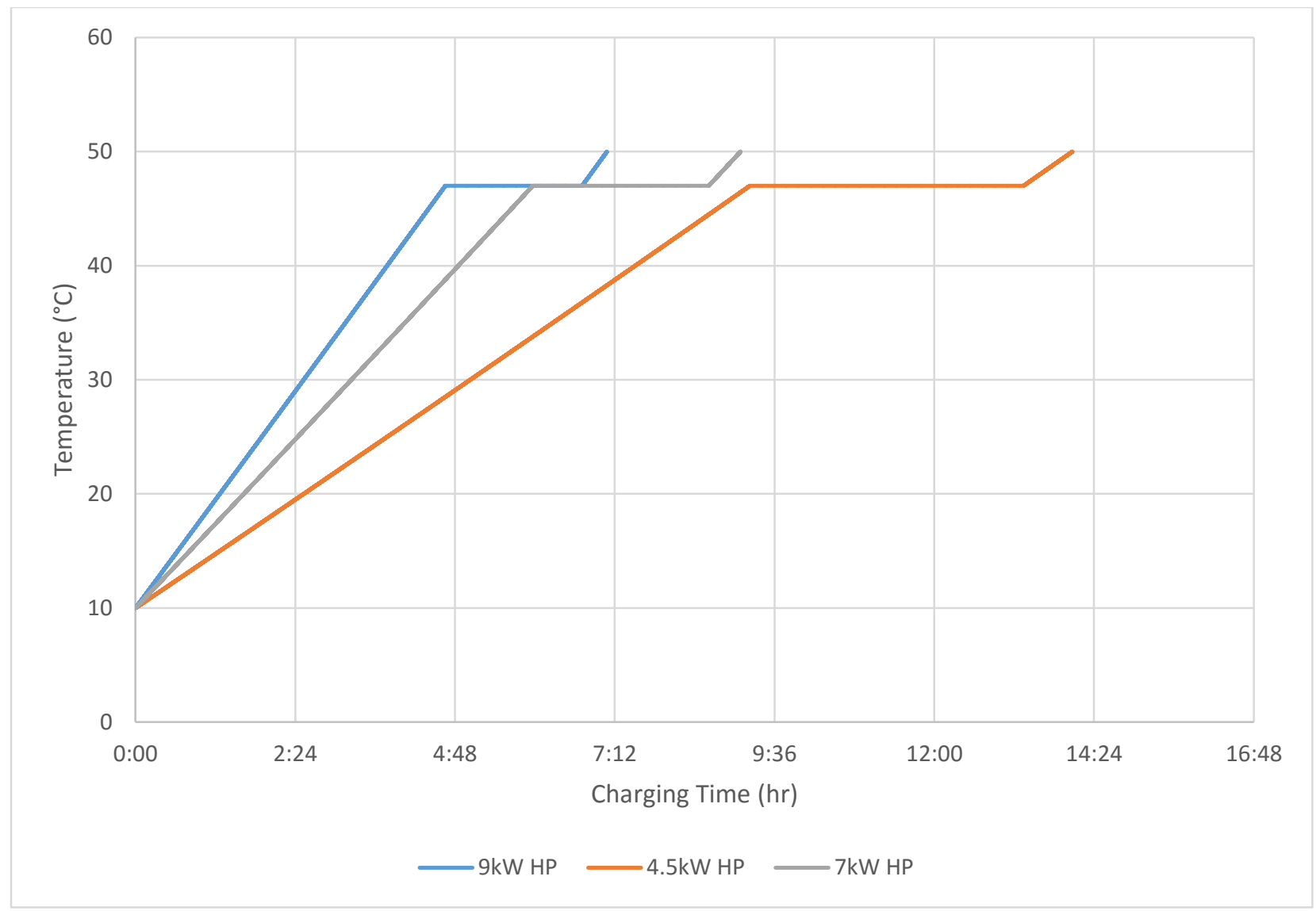

Figure 10: Charging process with three different heat pump

Figure 11 shows the charging process of the 1000 liter tank with various PCM block volumes. The heat source in this process is a 7kW heat pump. In this figure the effect of three PCM sizes of 100 , 200, 300 liter was shown. Since the physical properties of all three cases are identical the temperature rise slopes and trends are alike. The main reason to show this result is to illustrate duration of phase change process in regard to size of the PCM block inside the tank. The higher the volume of the PCM block is the longer the melting time would be. Using a $7 \mathrm{~kW}$ heat source would take 4757, 9514, and 14247 seconds to melt down 100, 200, 300 liter of Salt-Hydrate S46. Also, it affects the whole charging time. 


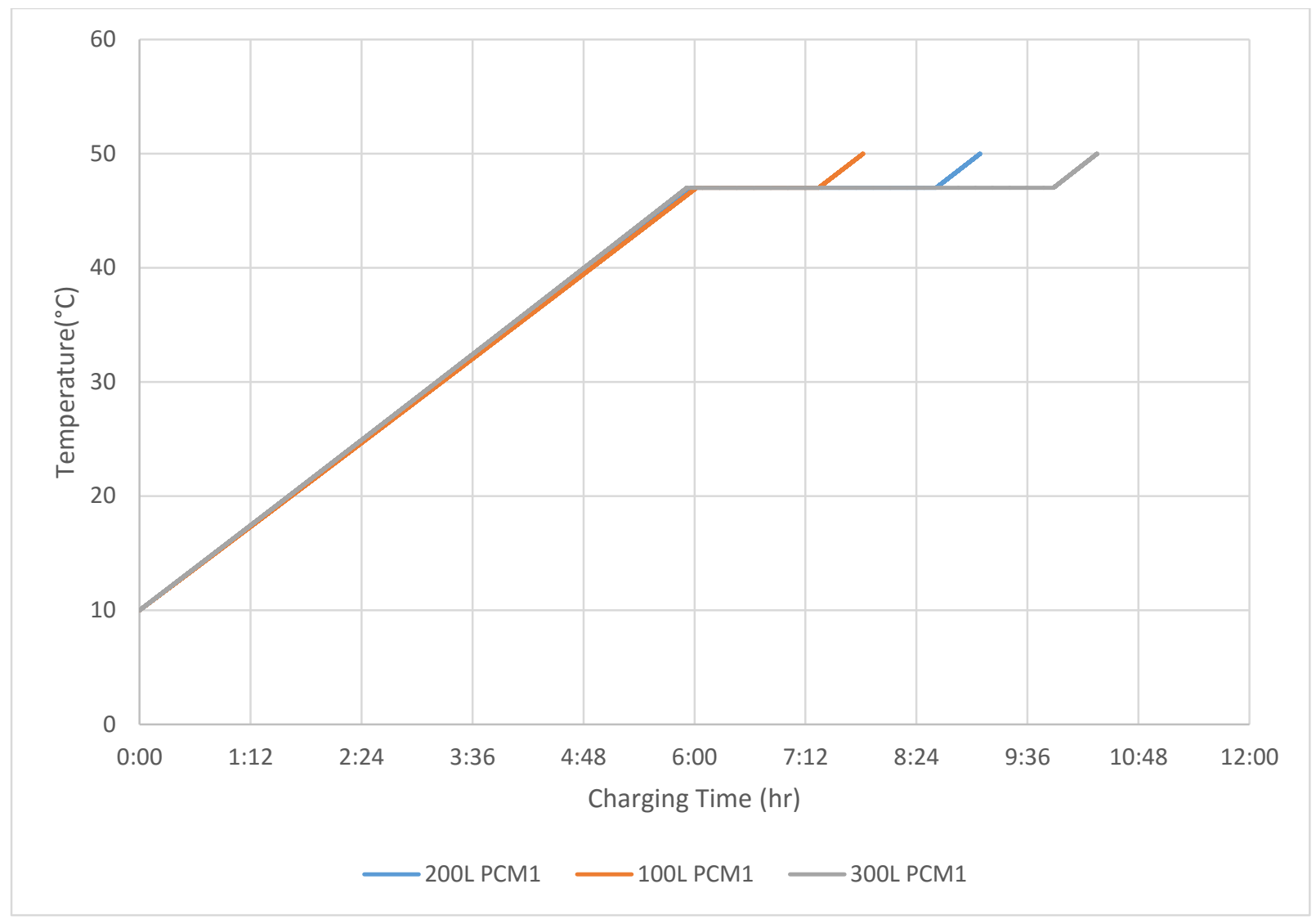

Figure 11: Charging process of a tank with three different PCM blocks by a $7 \mathrm{~kW}$ heat pump

In order to show the effect of a second PCM block inside the storage tank, Figure 12 was generated. In this analysis a 1000 liter tank with two 100 liter blocks of PCM was charged with a $9 \mathrm{~kW}$ heat pump. Since the melting point of PEG E600 $\left(22^{\circ} \mathrm{C}\right)$ is lower than the melting point of Salt-Hydrate $\mathrm{S} 46\left(47^{\circ} \mathrm{C}\right)$, there are two constant temperature lines in the figure. In general, having a second block of PCM at a lower temperature might be helpful for an incomplete charging cycle or during the time that heat source is at lower temperature. It has been shown that the melting duration for the PEG E600 was 26 minutes compare to the S46 in 1:01hr. The total energy stored during this process was $56 \mathrm{kWh}$. 


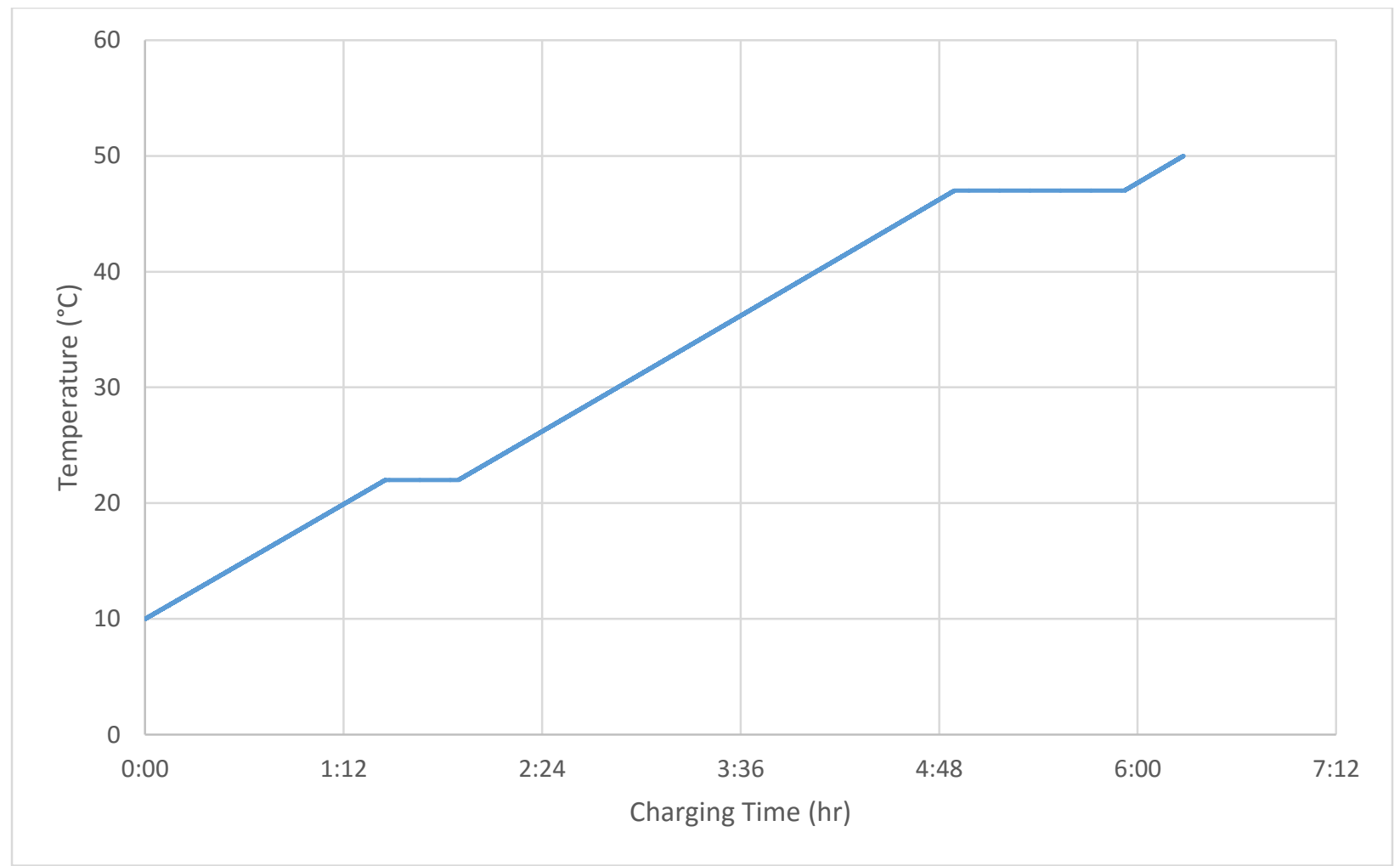

Figure 12: Charging process of a tank with two different PCMs

The same methodology was used in Figure 13 to compare the temperature response during the charging process with different heat pumps. As illustrated in the figure, it takes more than half a day to fully charge the system by the $4.5 \mathrm{~kW}$ heat pump. Also the melting time of the PCM blocks varies based on the heating source. 


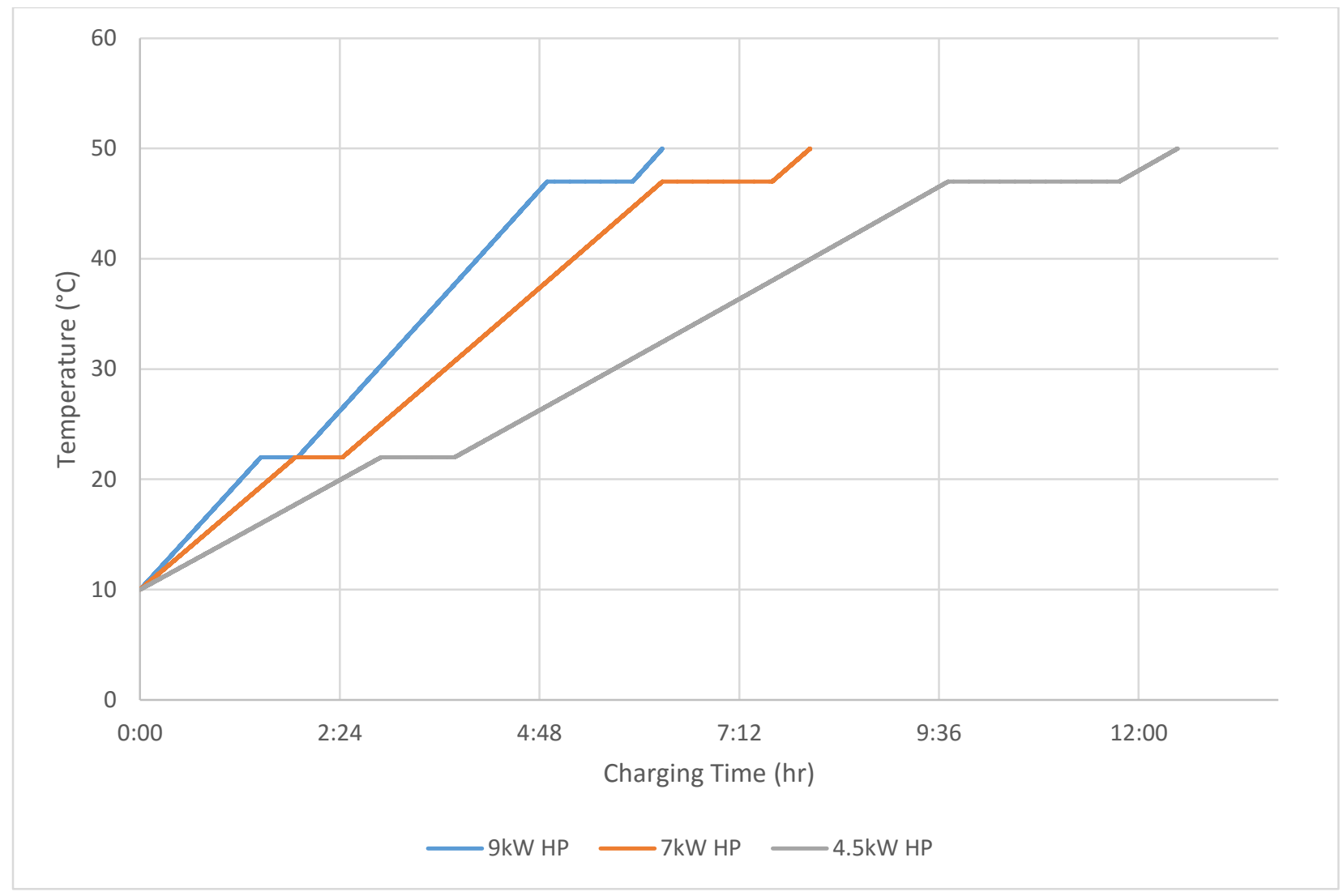

Figure 13: Charging a tank with two PCM blocks by three heat pump

\subsection{Charging Process with Constant Coil Temperature}

Although a constant heat flux with the means of fixed rate of thermal energy sources with heat pumps for the whole charging process may not be the most realistic approach, it can demonstrate the whole charging process. In that note, this study considered a fixed coil temperature instead of a fixed heat flux as well. It might be more practical to supply a fixed temperature water to the coil rather than having a fixed thermal energy input. To do so, the model was updated to take into account the flow rate, temperature, and properties of circulating fluid. Since the temperature of coil is fixed and tank temperature is increasing by time, the thermal energy input varies with time. 
Figure 14, shows charging process of a 1000 liter tank with 200 liter of Salt-Hydrate S46 as PCM block with a fixed coil temperature of $65^{\circ} \mathrm{C}$. The temperature rise is not linear anymore compare to fixed heat flux cases. The mass flowrate inside the coil is $0.2 \mathrm{~kg} / \mathrm{s}$ and the initial temperature of tank is set at $10^{\circ} \mathrm{C}$ and initial temperature difference between the coil and tank is therefore $55^{\circ} \mathrm{C}$ which corresponds to $46 \mathrm{~kW}$ of power at the beginning of the process. This number drops to $12.5 \mathrm{~kW}$ as the temperature difference between coil and tank decreases to $15^{\circ} \mathrm{C}$. The whole charging process (warm up to $50^{\circ} \mathrm{C}$ ) took $4: 45 \mathrm{hr}$ and melting process is 4420 second long.

The model is capable of analyzing different PCM materials and sizes. Also having two sets of PCMs are also applicable.

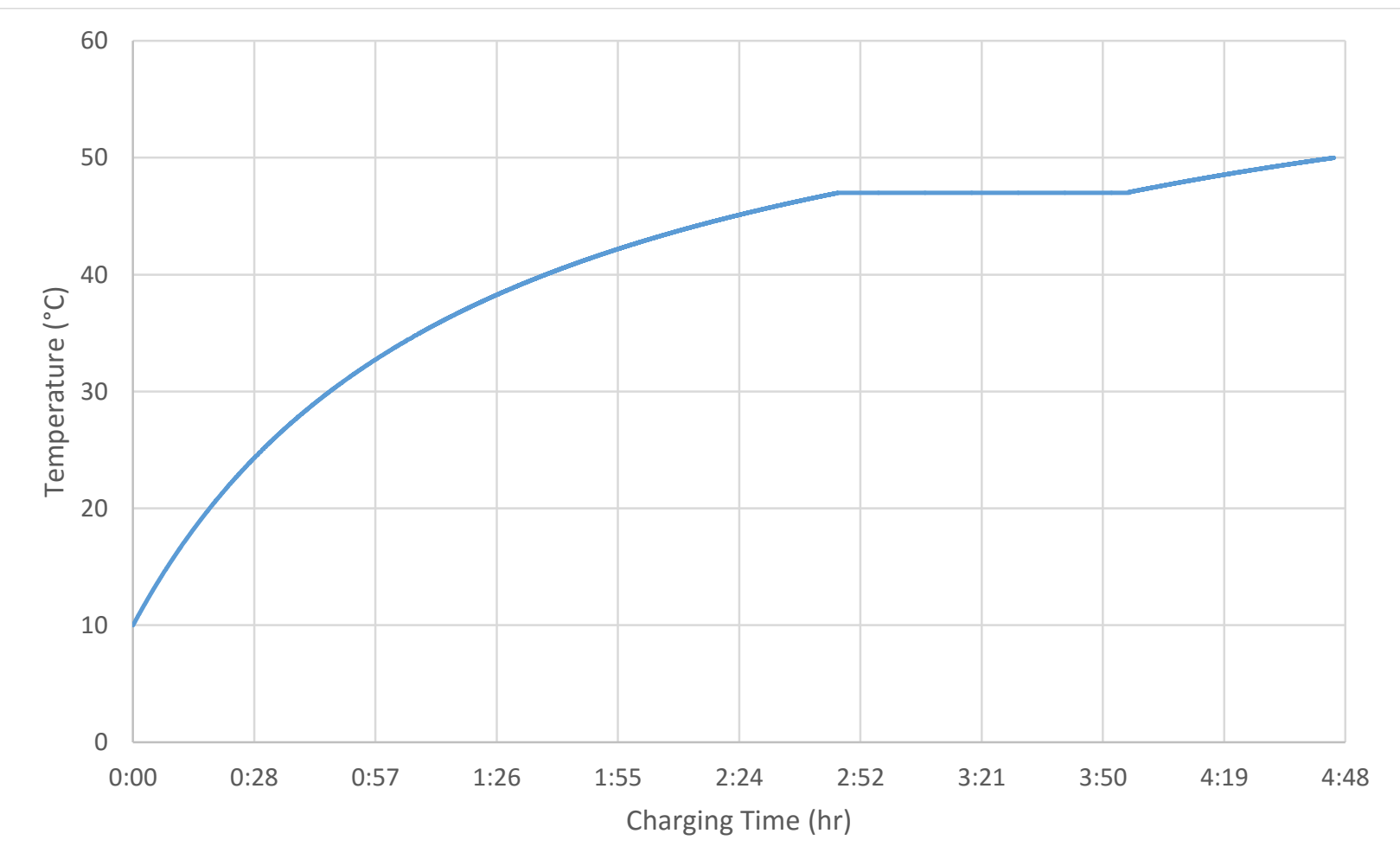

Figure 14: Charging the tank with $200 \mathrm{~L} \mathrm{PCM} \mathrm{S46} \mathrm{with} \mathrm{constant} \mathrm{coil} \mathrm{temperature}\left(65^{\circ} \mathrm{C}\right)$ 
In order to compare the charging process of the same tank with a lower coil temperature, the model was used to study the effect of constant supplied hot water at $55^{\circ} \mathrm{C}$ on the time of charging which is presented in Figure 15. Although the tank temperature rise seems to follow the same trend, the process takes much longer time to reach the tank set point at $50^{\circ} \mathrm{C}$. It has been shown that the tank temperature increases at a reasonable rate at the beginning of the process. However, temperature difference between the coil and tank decreases along the charging process to a point that charging rate is not very effective. That is the reason for initial charging rate of $37.6 \mathrm{~kW}$ and decreasing to $5.8 \mathrm{~kW}$ at the end of process. Therefore, a lower coil temperature might be more suitable when a PCM with lower melting point is used in the tank which will reduce the charging period. Also, when hot water supply is set at $55^{\circ} \mathrm{C}$, a more practical tank set point temperature would be close to $40^{\circ} \mathrm{C}$.

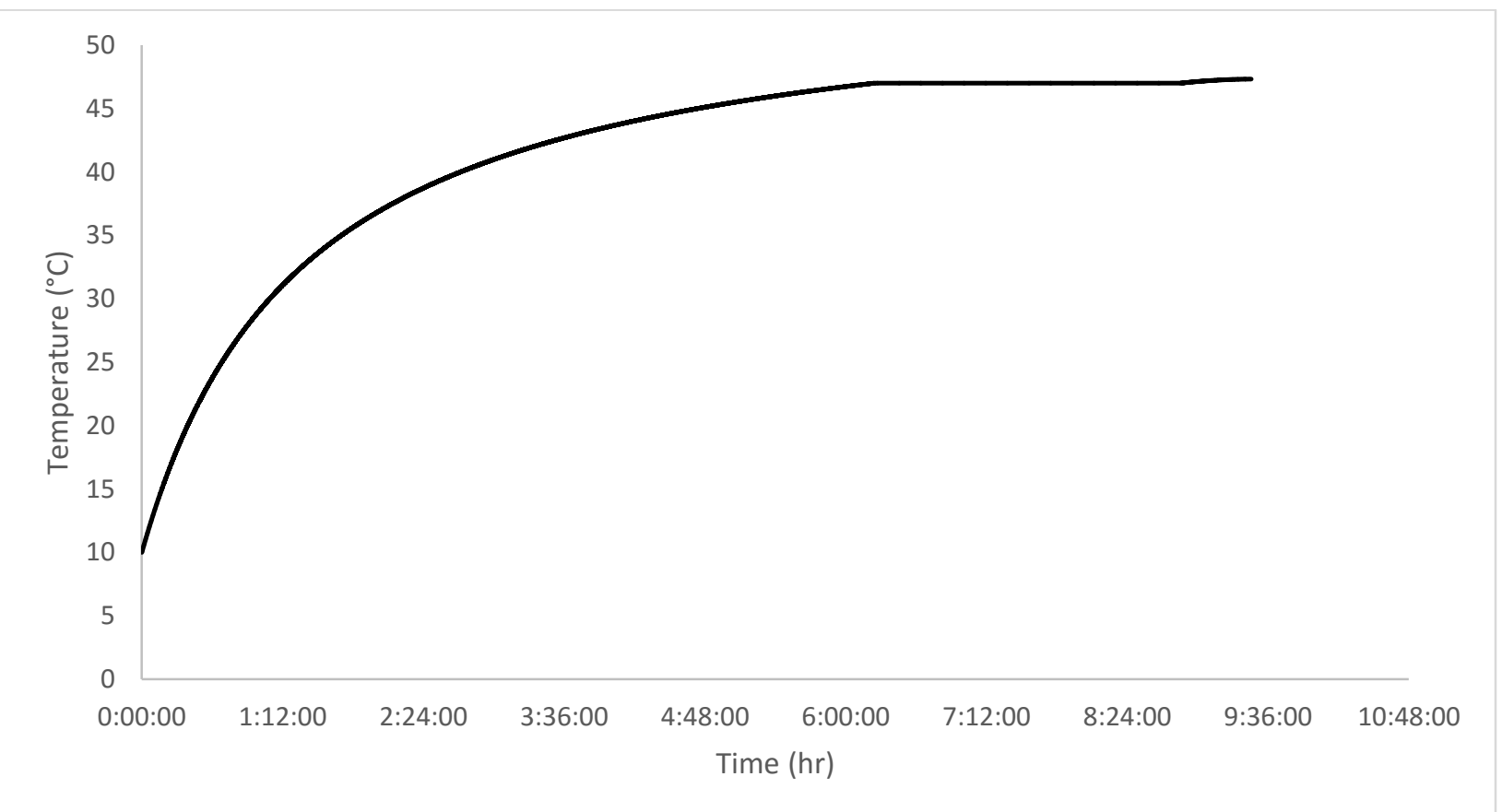

Figure 15: Charging the tank with $200 \mathrm{PCM} \mathrm{S46}$ with a constant coil temperature $\left(55^{\circ} \mathrm{C}\right)$ 
Further investigation on charging the tank with fixed coil temperature illustrates the difference between processes according to two different PCM blocks. Figure 16 shows how the tank temperature varies when it is equipped with a 100 liter Poly-Ethylene-Glycol (PEG) E600 block (dashed line) compared to a 100 liter block of Salt-Hydrate S46 (dotted line). The coil temperature was kept constant at $65^{\circ} \mathrm{C}$ for both cases. The melting temperature and heat capacity of the PCM block defines the charging time and also storage capacity of the tank. The charging period was 1:05 hour longer for the PCM with higher melting point and higher heat capacity and at the end of process the tank with Salt Hydrate S46 stored $96.7 \mathrm{kWh}$ compared to $78.3 \mathrm{kWh}$ for the PEG E600 block. Despite the equal volume of the blocks, the difference between melting time of the blocks was also remarkable. The phase changing process of PEG - E600 block took 7 minutes because of high heat transfer rate. However, it took 37 minutes for the $\$ 46$ block to be melted completely with the lower heat transfer rate as a result of high tank temperature caused.

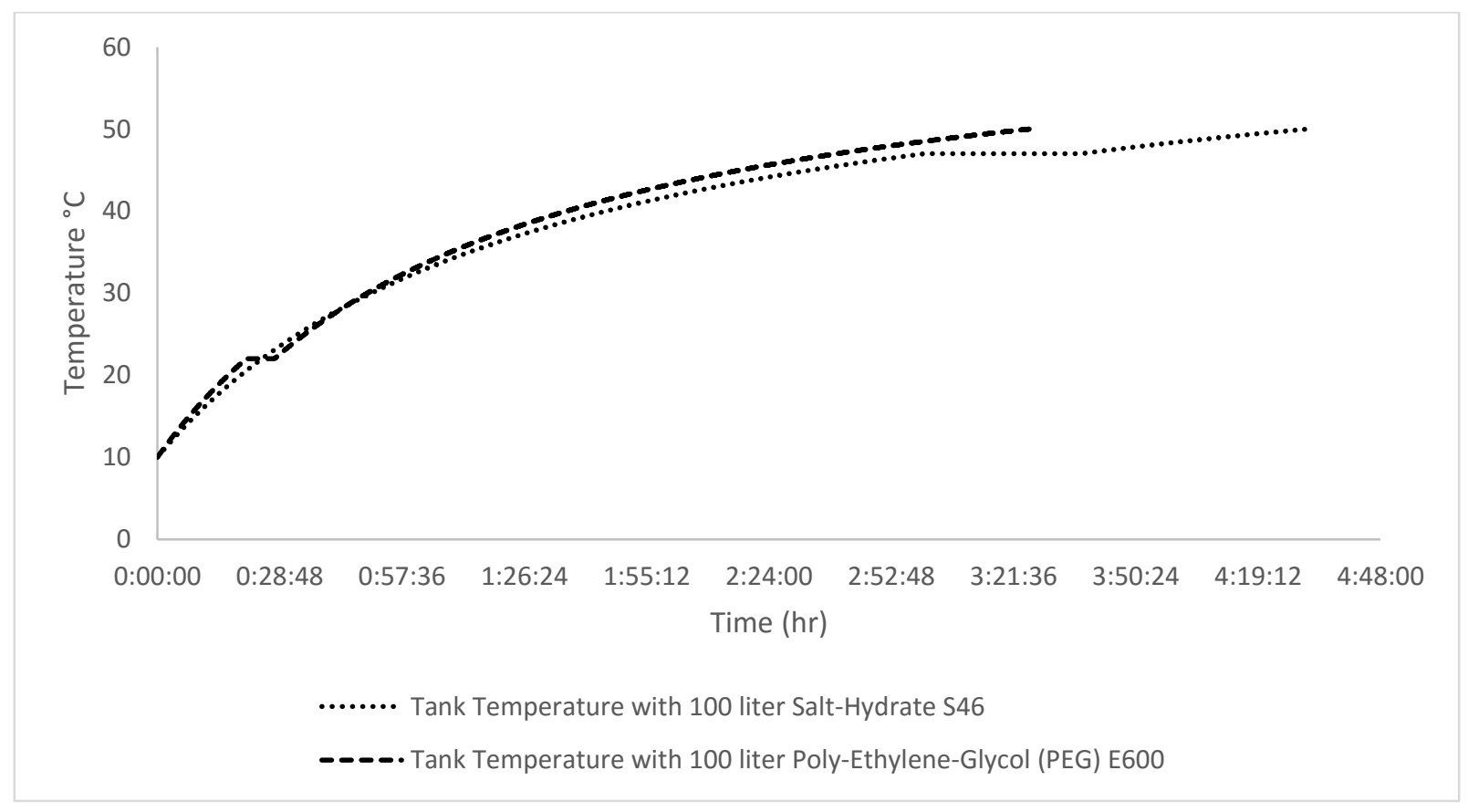

Figure 16: Charging process with fixed temperature and different PCM blocks 
The study continued investigating various options, this time by considering having two PCM blocks in the tank at the same time. The coil temperature again was kept at $65^{\circ} \mathrm{C}$. Figure 17 illustrates two possible scenarios of charging process. In the first setting the volume of each block is 100 liters (dashed line) and then it is compared with the second setting having larger blocks of 200 liters each. It has been shown that tank temperature in both settings are very close to each other and mostly the melting time of PCM blocks varies. Considering that overall heat capacity of tank is different in each case, results in slightly different slope of temperature graph. The tank with higher PCM volume took 35 minutes longer to be charged and stored $10 \mathrm{kWh}$ more thermal energy.

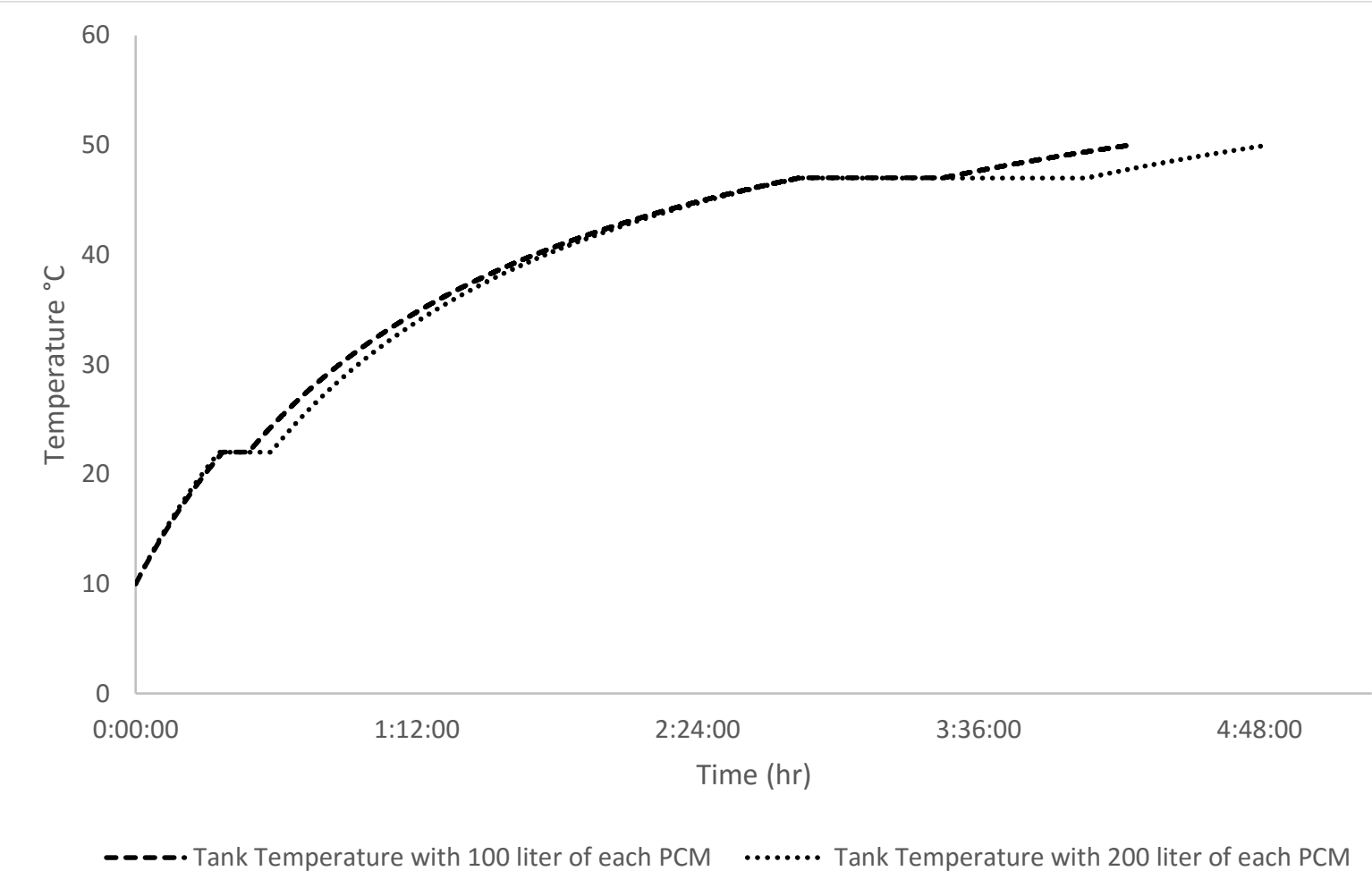

Figure 17: Tank temperature with various PCM volume 
As discussed earlier in Figure 15, it would be wiser to set the tank temperature at a lower level to fully charge the tank within reasonable time when the coil temperature is not high enough. Therefore, Figure 18 was generated to show charging performance of the system with $55^{\circ} \mathrm{C}$ with the tank set point of $40^{\circ} \mathrm{C}$. Two lines in the Figure 18 represent a tank temperature with 100 liter (dashed line) and 200 liter (dotted line) of Poly-Ethylene-Glycol (PEG) E600. Since the set point temperature is lower compared to Figure $7\left(50^{\circ} \mathrm{C}\right)$, the charging time is much shorter $(\sim 2.5 \mathrm{hr})$. Also, phase change duration for two blocks were $\sim 9$ minutes and $\sim 18$ minutes accordingly. This analysis shows that lower supplied/coil temperature is suitable for charging the storage tank for applications with low temperature requirements. However, an auxiliary source might be of use to enhance the charging performance.

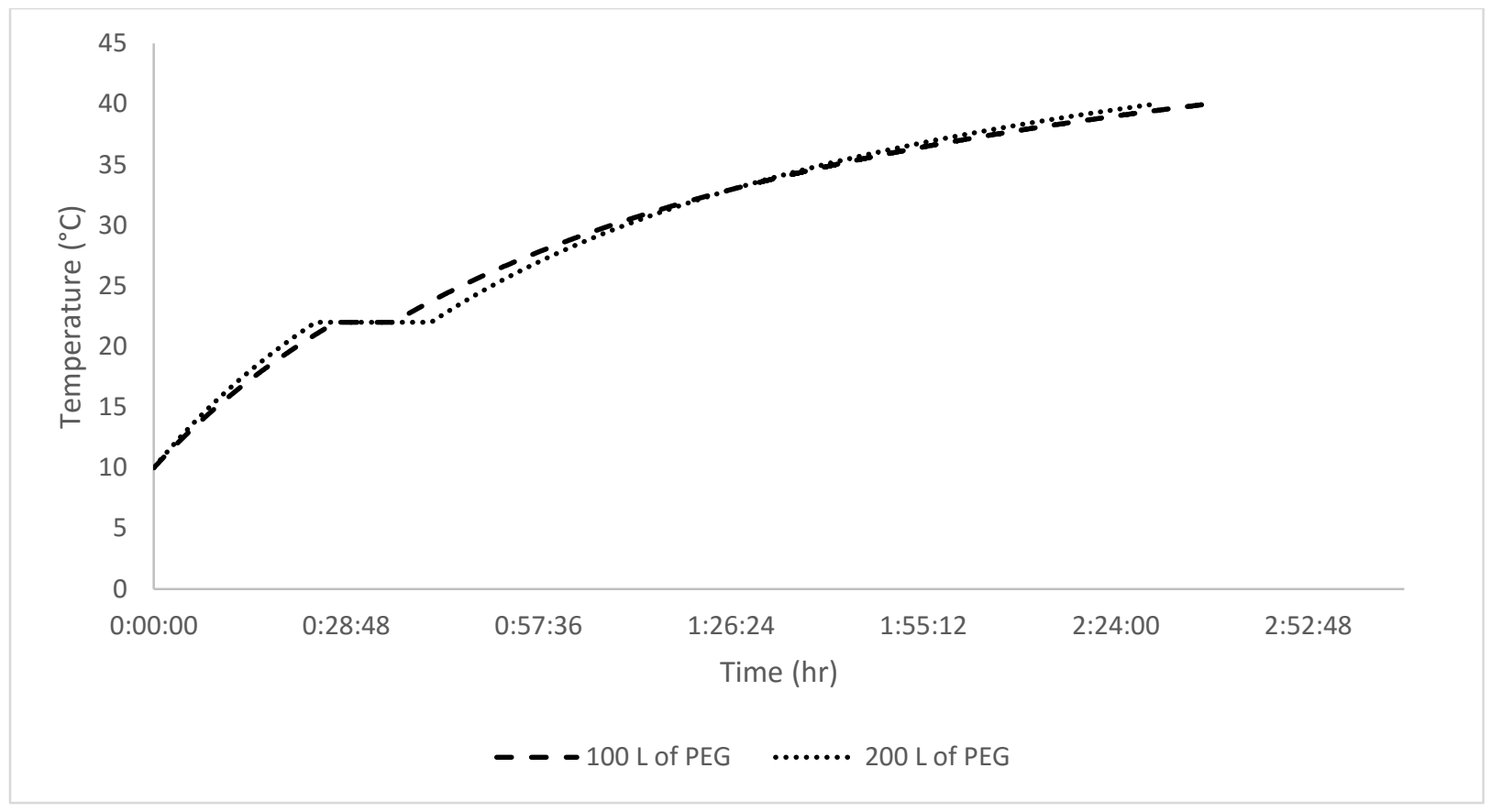

Figure 18: Charging process with $100 \mathrm{~L}$ and 200l Poly-Ethylene-Glycol (PEG) E600 lower temperature source 
Furthermore, effect of supplied temperature from the heat source on charging process was studied. Figure 19 shows the difference between charging the system with $55^{\circ} \mathrm{C}$ and $65^{\circ} \mathrm{C}$. The set point temperature of the tank is at $40^{\circ} \mathrm{C}$. From the figure the charging duration is noticeably longer for colder coil. Also it is shown that temperature rise is much faster with higher slope when the coil temperature is $65^{\circ} \mathrm{C}$. In other word, although low coil temperature would be good enough to charge the tank, the higher supplied temperature will be more effective in terms of charging duration. However, both cases proved to meet the requirement of low temperature application within reasonable time.

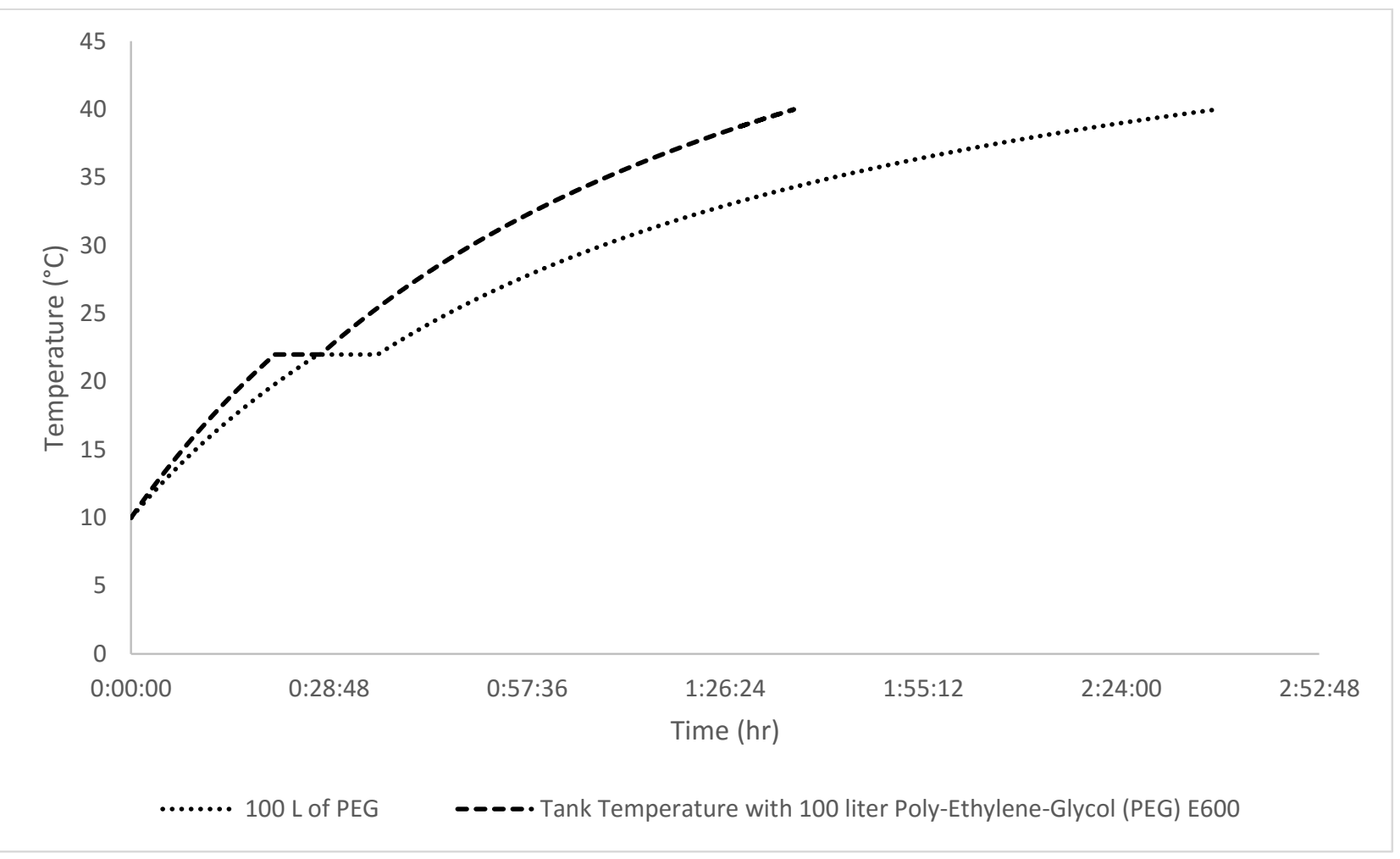

Figure 19: Charging the tank with 200 L PCM PEG-E low and high coil temperature

Additionally, in Figure 20, temperature of a tank with 200 liter of PEG-E600 heated by $55^{\circ} \mathrm{C}$ is shown and compared with the tank temperature occupied with two PCM blocks (S-46 and E66) 
each 200 liter and heat source at $65^{\circ} \mathrm{C}$. This Figure shows the temperature trend for low and high temperature requirement when the tank is filled with larger PCM blocks. Figures 14 to 20 would be of help to design control strategies for thermal storage charging process which can consider the application and decide the charging temperature and then predict and calculate the charging duration.

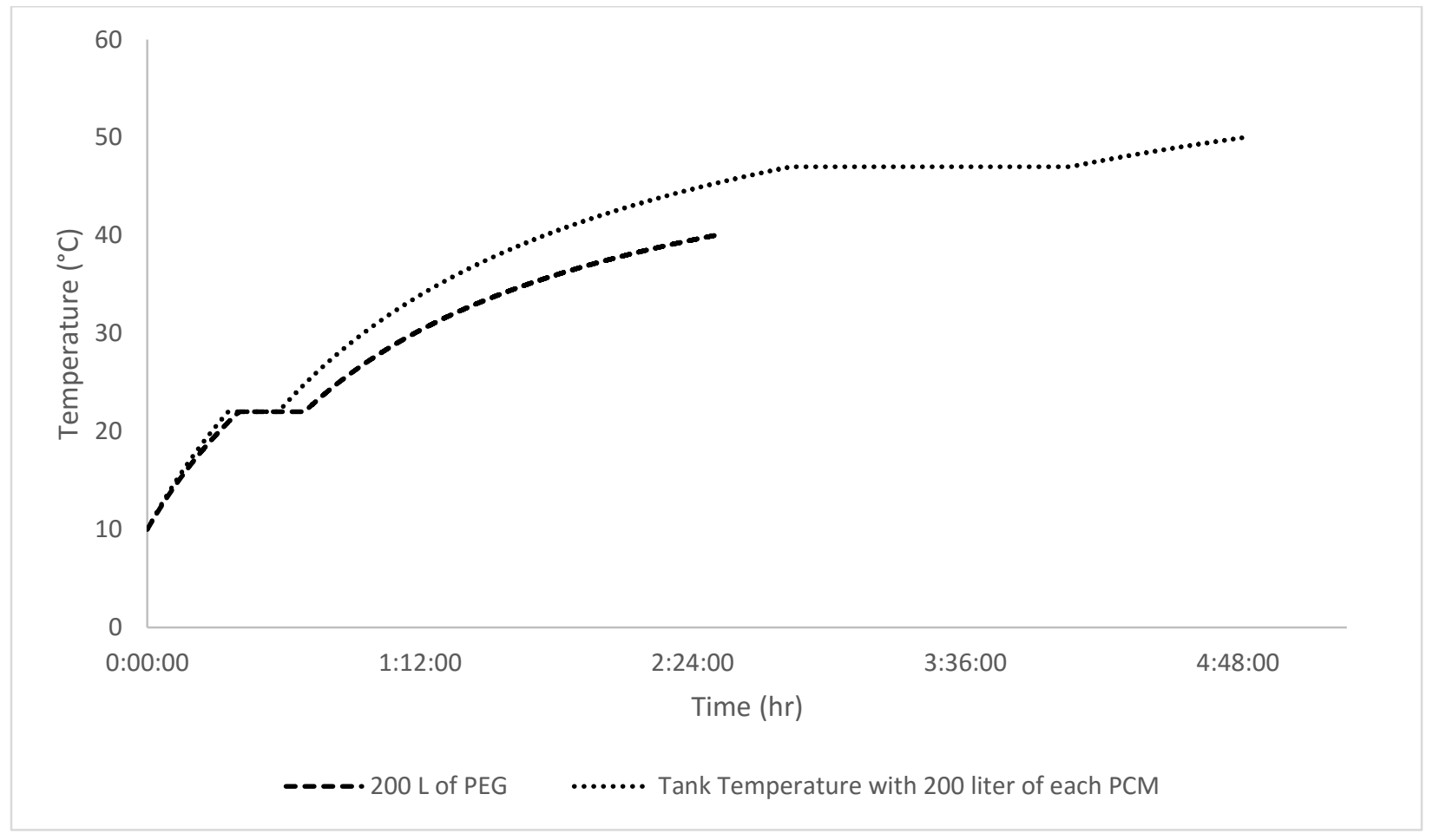

Figure 20: Charging process with bigger PCM blocks

Few sample settings are presented in Table 2 below. PCM1 represents Salt-Hydrate S46 and PCM2 represents Poly-Ethylene-Glycol (PEG) E600. The table shows the coil temperature and volume of each PCM block along with total charging time. Also, melting periods of the PCM blocks are available in Table 2 . The tank temperature set point associated with $65^{\circ} \mathrm{C}$ is at $50^{\circ} \mathrm{C}$ and when the coil temperature is $55^{\circ} \mathrm{C}$ the set point would be at $40^{\circ} \mathrm{C}$. 
Table 2: Various Charging Scenarios

\begin{tabular}{lrrrrrrrr} 
Setting (H:M:S) & $\# 1$ & $\# 2$ & $\# 3$ & $\# 4$ & $\# 5$ & $\# 6$ & $\# 7$ & $\# 8$ \\
\hline PCM1 volume (L) & 100 & 100 & 0 & 0 & 0 & 200 & 300 & 0 \\
\hline PCM2 volume (L) & 0 & 100 & 100 & 0 & 200 & 200 & 300 & 100 \\
\hline Melting time pcm1 (S) & 2211 & 2212 & 0 & 0 & 0 & 4423 & 6634 & 0 \\
\hline Melting time pcm 2 (S) & 0 & 398 & 518 & 0 & 1037 & 796 & 1194 & 398 \\
\hline Coil temp ( $\left.{ }^{\circ} \mathrm{C}\right)$ & 65 & 65 & 55 & 65 & 55 & 65 & 65 & 65 \\
\hline Time to charge (h:m:s) & $4: 30: 48$ & $4: 15: 24$ & $2: 37: 52$ & $3: 40: 45$ & $2: 29: 58$ & $4: 50: 00$ & $5: 24: 35$ & $3: 25: 20$
\end{tabular}

\subsection{Charging Process with Solar Assisted Heat Pump}

Moreover, the tank has been studied to be charged with a solar assisted heat pump. For this study, weather data of a typical winter day such as outdoor temperature and irradiation level was used. Kamel and Fung (2014) developed a building integrated photovoltaic/thermal (BIPV/T) model in TRNSYS. The model calculates the temperature rise and air temperature after the BIPV/T model. This model is based on a $5 \times 5$ roof mounted solar panel array (Figure 21) with 4 inches of the air channel depth between the surface of the roof and the back of the solar collector. The flow rate of the air was set to $1.5 \mathrm{~kg} / \mathrm{s}$ (Kamel and Fung, 2014).

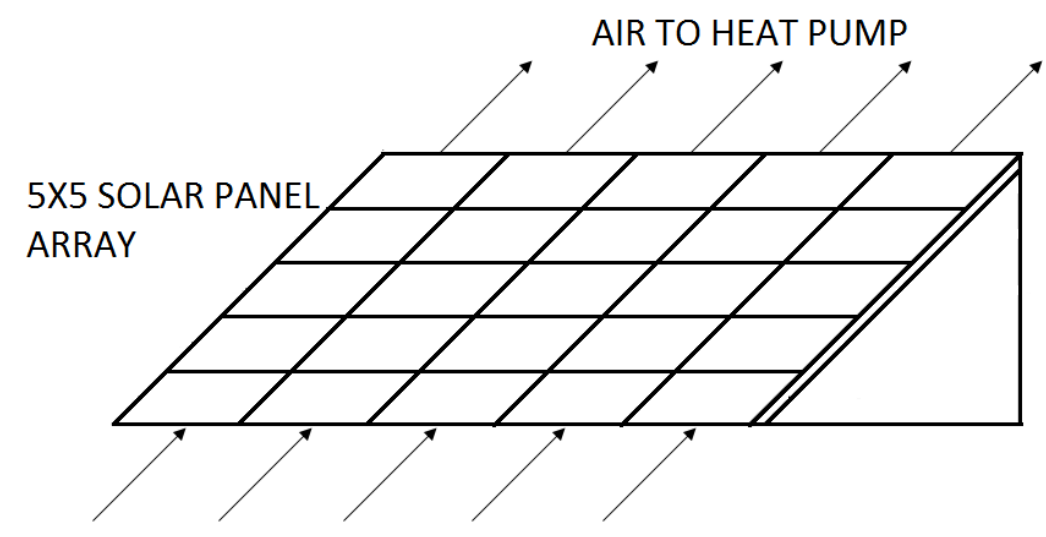

AIR FROM SOFFITS

Figure 21: $5 \times 5$ roof mounted solar panel array (Kamel and Fung, 2014) 
Pre-heated air by BIPV/T then is fed to the heat pump to enhance the performance and COP of the heat pump. It is shown by Safa et al. (2015) that performance of an air source heat pump is directly proportional to the ambient temperature and COP of heat pumps drops as the outdoor temperature is very cold. Therefore, pre-heating the air by connecting a BIPV/T system to the heat pump is beneficial for the heat pump systems and improves the overall performance of the combined system.

In order to find the effect of above mentioned system on charging performance of the water storage tank, both Kamel and Fung (2014) and Safa et al. (2015), model and data were used in this study. Figure 22 shows the ambient temperature and air temperature after the BIPV/T system. Since the hourly data was converted to 10 minutes time steps data, the result is shown as step function, which shows the expected trend of the system.

The data is for two typical winter days as October $26^{\text {th }}$ with maximum radiation of $3553\left(\mathrm{~kJ} / \mathrm{hr} \cdot \mathrm{m}^{2}\right)$ and October $27^{\text {th }}$ with maximum radiation of $2903\left(\mathrm{~kJ} / \mathrm{hr} \cdot \mathrm{m}^{2}\right)$. As shown in Figure 22 although temperature of the second day is higher compared to the first day, higher total radiation throughout the first day along with longer sunny hours results in more temperature difference between two days. As a result the maximum temperature rise on October $26^{\text {th }}$ was $7.42^{\circ} \mathrm{C}$ and $6.28^{\circ} \mathrm{C}$ on October $27^{\text {th }}$. Also, during the night with no available solar energy the temperature does not change after the BIPV/T system. 


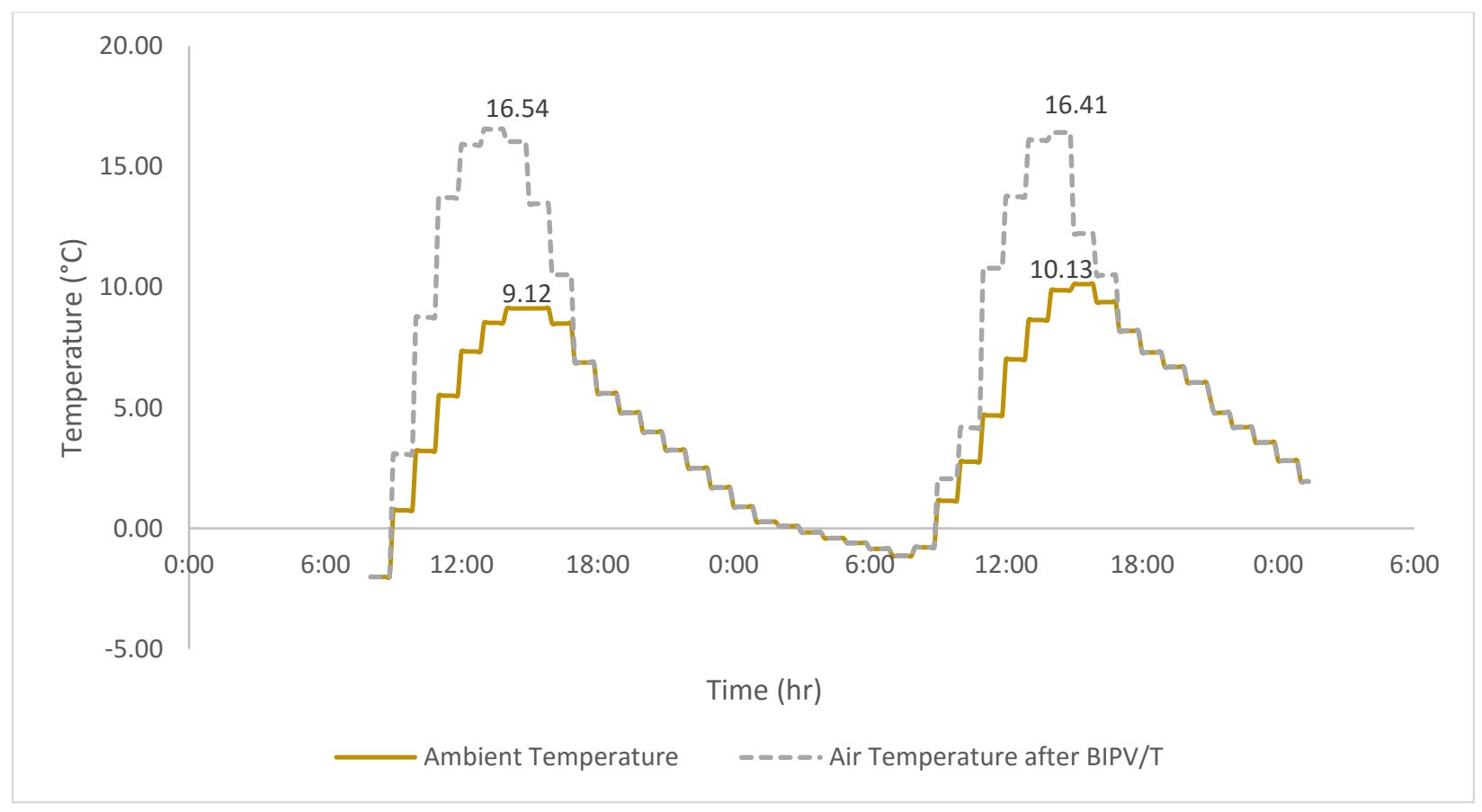

Figure 22: Temperature of air before and after BIPV/T (Kamel and Fung, 2014)

Calculated temperature by (Kamel and Fung, 2014) model then can be used to verify the COP enhancement along with generated thermal energy. To do that, Equation 3 (Safa et al., 2015) was used.

$$
\text { COP }=(0.1158 \times T)+3.7258 \quad \text { Equation } 3
$$

COP of the heat pump system in regards to ambient temperature was calculated and then was compared with the COP of the solar assisted heat pump system. The comparison is shown in Figure 23 with solid lines, which shows the difference between COP of the heat pump with and without pre-heating. As illustrated in Figure 23 the maximum COP of the heat pump increased to 5.64 from 4.78 ( $18 \%$ increase) on October $26^{\text {th }}$ and also improved from 4.9 to 5.63 (14.9\%) on October $27^{\text {th }}$. 
Figure 23 also illustrates associated thermal energy generated by heat pump by dotted lines for each scenario. It is shown that thermal energy generation had a great improvement as well. The maximum generated thermal energy rate rose up to $10.66 \mathrm{~kW}$ from $7.52 \mathrm{~kW}$ ( $41.75 \%$ increase) during the first day and from $7.91 \mathrm{~kW}$ to $10.6 \mathrm{~kW}$ (34\% increase) on the second day.

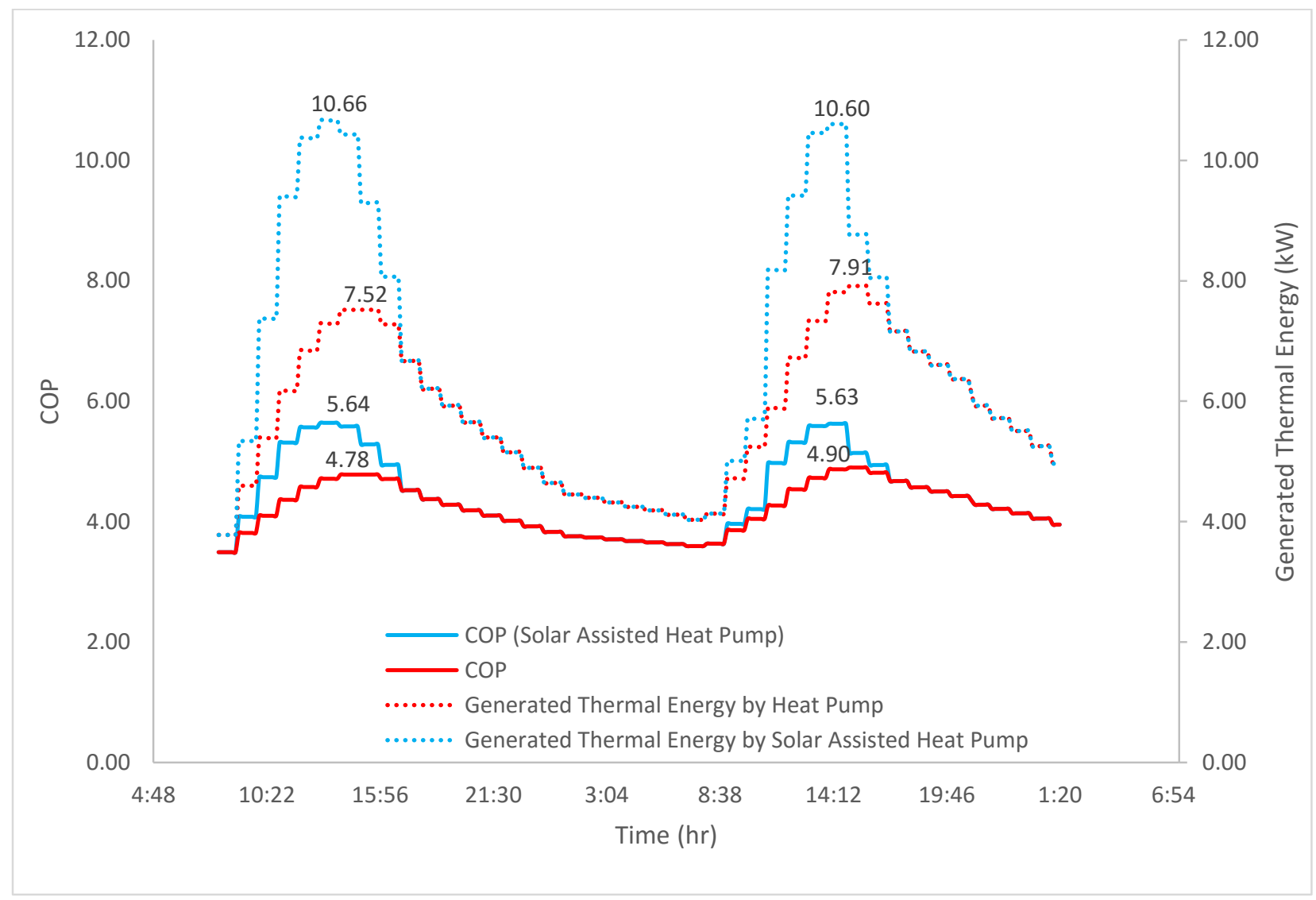

Figure 23: Performance of the heat pump with and without BIPV/T (Kamel and Fung, 2014)

Considering the heat pump performance as a weather dependent factor, the charging process for the tank would be different compared to a heat pump with constant heat flux. A sample of charging process has been shown in Figure 24 which is for October $26^{\text {th }}$. In that day the heat pump started charging the tank at the rate of $3.78 \mathrm{~kW}$ and as the ambient temperature increased during the day the heat pump energy generation rate went up to the maximum of $7.52 \mathrm{~kW}$. In 
this setting the tank was filled with water and a 100 liter block of Salt-Hydrate S46 which took 7.5 hours to be fully charged.

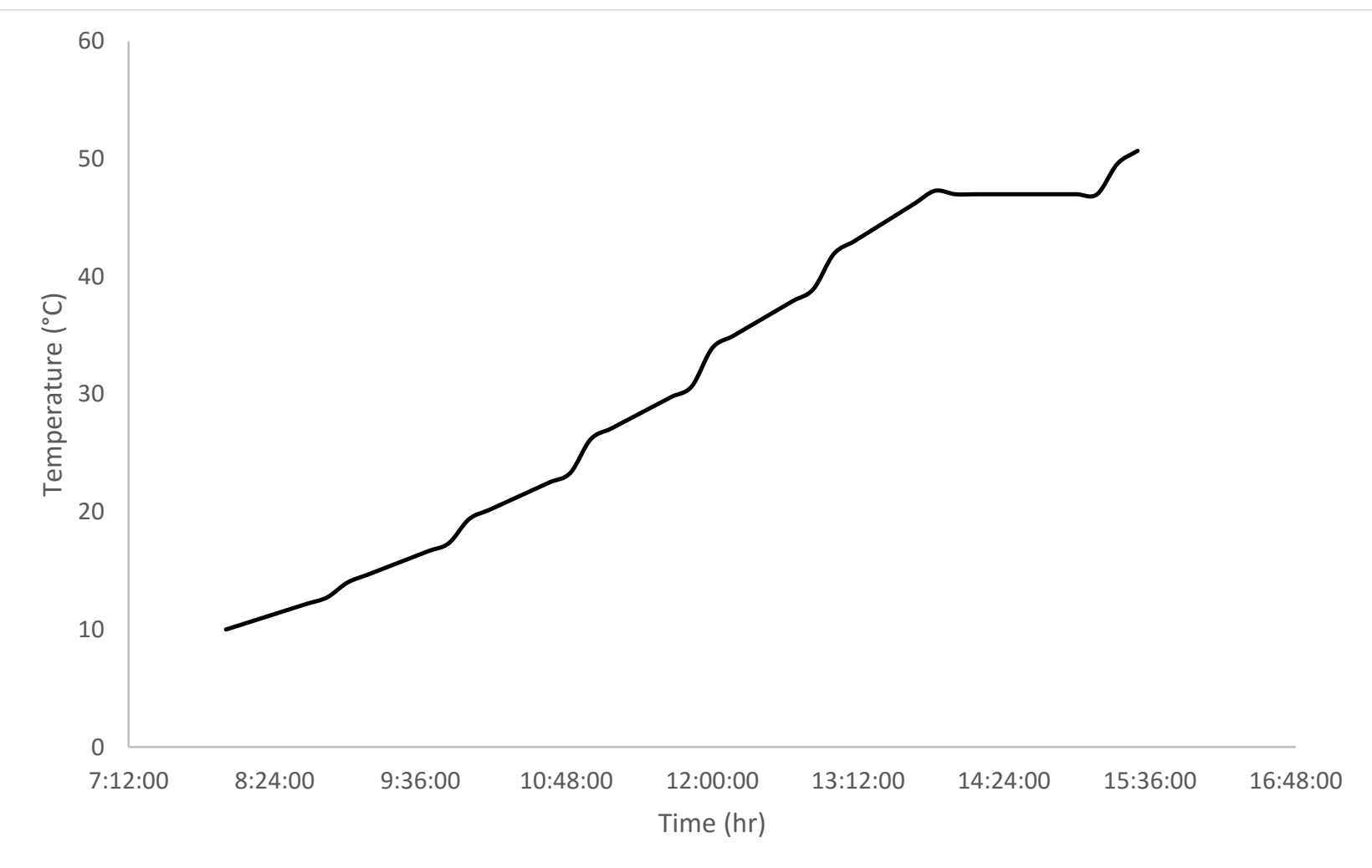

Figure 24: Charging process with a solar assisted heat pump

To study the performance enhancement of the heat pump during the charging process, the same tank was charged with a solar assisted heat pump. Figure 25 shows both scenarios when the tank with a 100 liter block was charged with a heat pump compared to a heat pump with pre-heated air supply. Starting at the same time, the solar assisted heat pump was able to fully charge the tank 2:10 hours sooner than regular heat pump with the maximum thermal energy generation capacity of $10.37 \mathrm{~kW}$ compared to $7.52 \mathrm{~kW}$ of the heat pump only. 


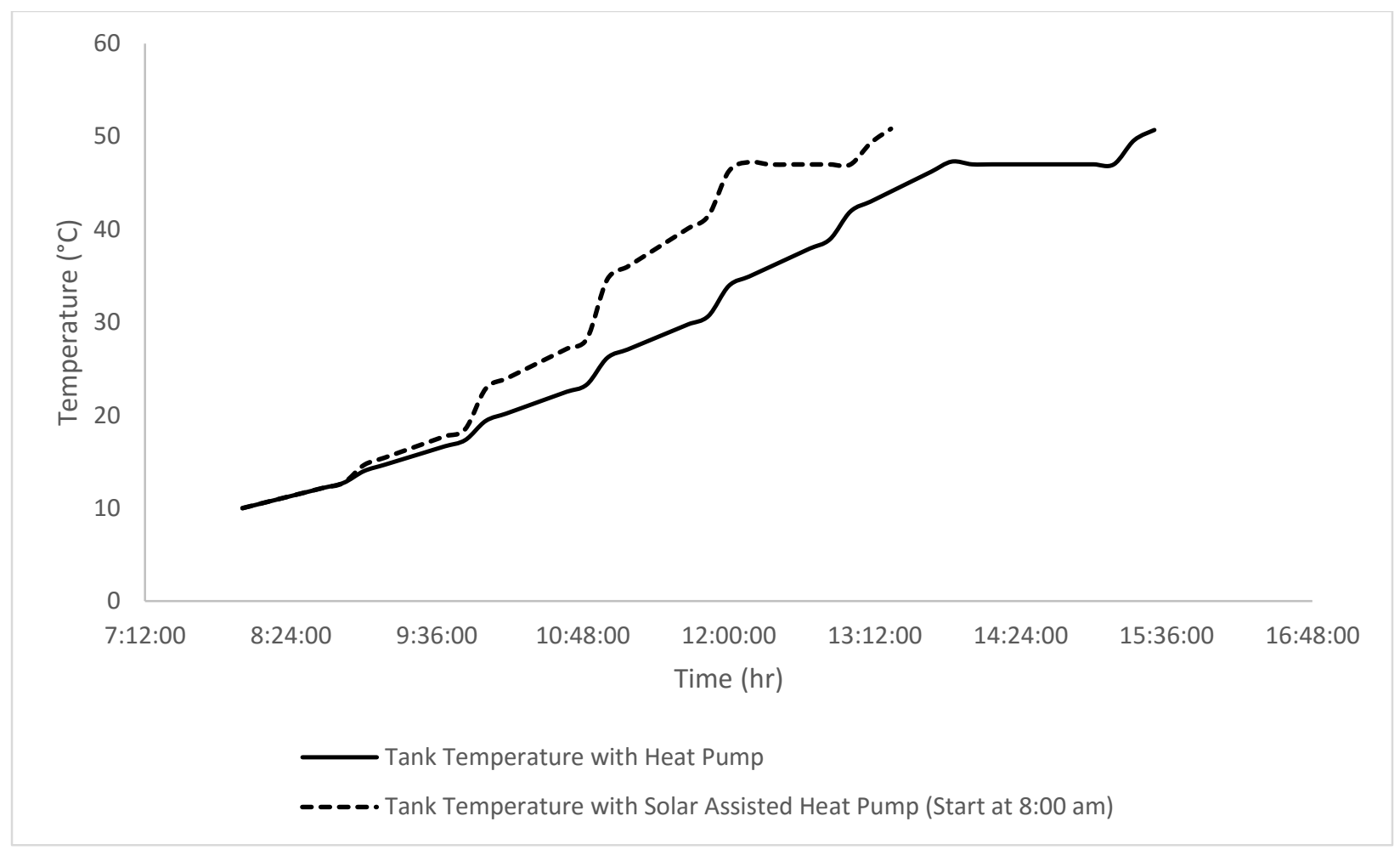

Figure 25: Tank temperature when charged by ASHP and BIPV/T+ASHP

Also data shows that due to solar availability and high radiation, the solar assisted heat pump was able to continue the charging process with higher rate for few more hours. Therefore, Figure 26 was generated to show the difference between charging the tank with solar assisted heat pump while starting at different times of the morning. The tank again is filled with water and a 100 liter block PCM. Figure 26 shows temperature of tank versus time calculated time steps instead of the hours to show different slope of temperature rise. Although, the total charging time for each configuration is within the same range, charging at 10:00 am has a higher slope which makes it a better solution for a charging process when the full charge/full tank is not required. Starting at 10:00 AM with higher radiation level provides $7.37 \mathrm{~kW}$ at the beginning of the process which is almost double compare to starting at 8:00 AM with $3.78 \mathrm{~kW}$. 


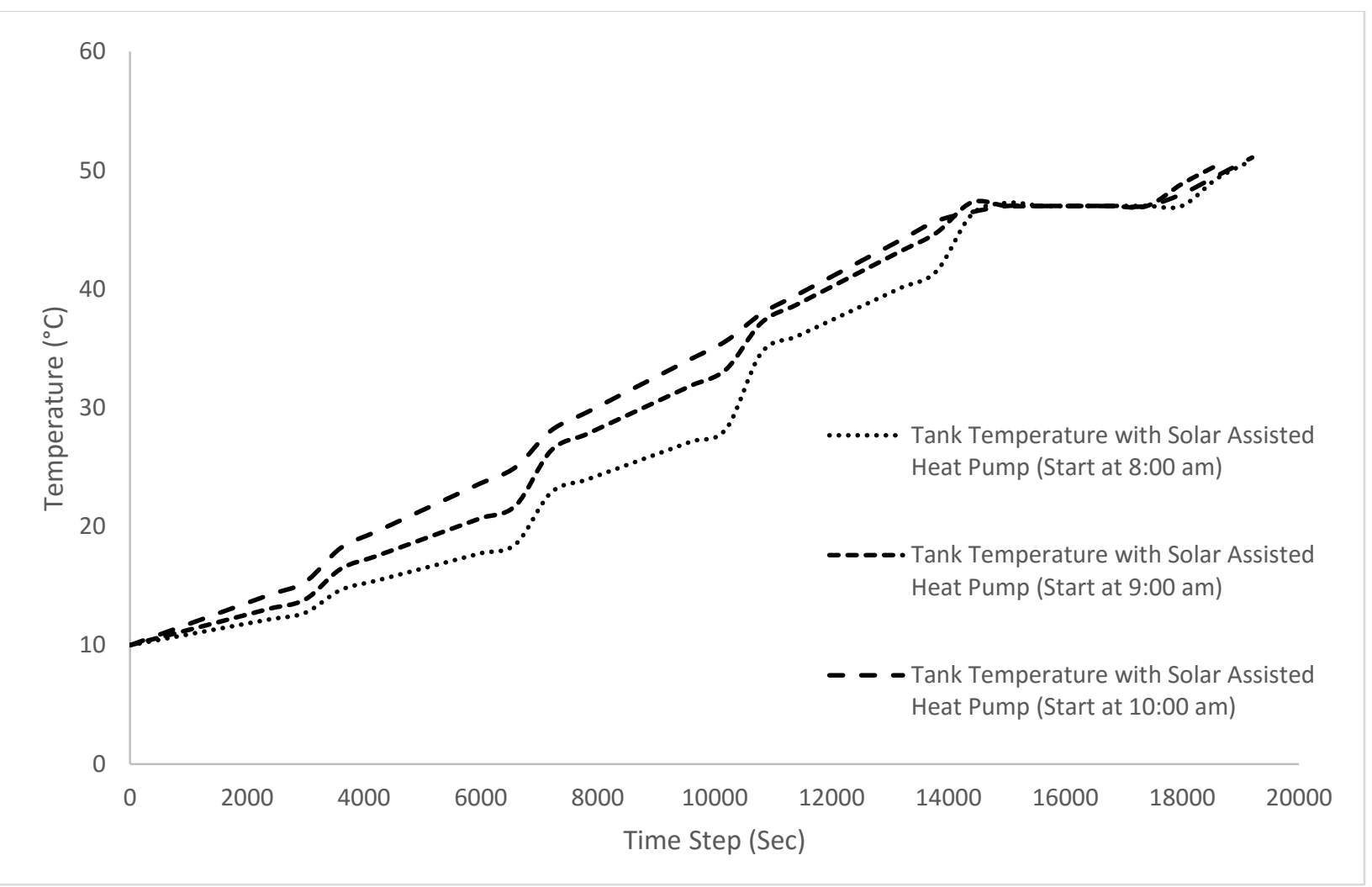

Figure 26: Charging process with various start times

In that regard, charging process was compared in Figure 27 between a regular heat pump and a solar assisted heat pump which starts at a later time (10:00 AM). The advantage of solar assisted heat pump by using pre-heated air is clearly shown in the figure. The charging process with solar assisted heat pump starts two hours later the regular heat pump and charges the tank with a higher rate in a shorter time. Also, comparing the temperature rise slope proves a higher quality charge which would be even more useful for a half charging/incomplete cycle.

In general, it has been shown that pre-heating the air before heat pump in every case is beneficial especially during colder days with higher radiation. However, a control system to set the charging process during more sunny hours is recommended. This control system can postpone the charging to a later time with higher radiation level for a better performance of the overall system. 


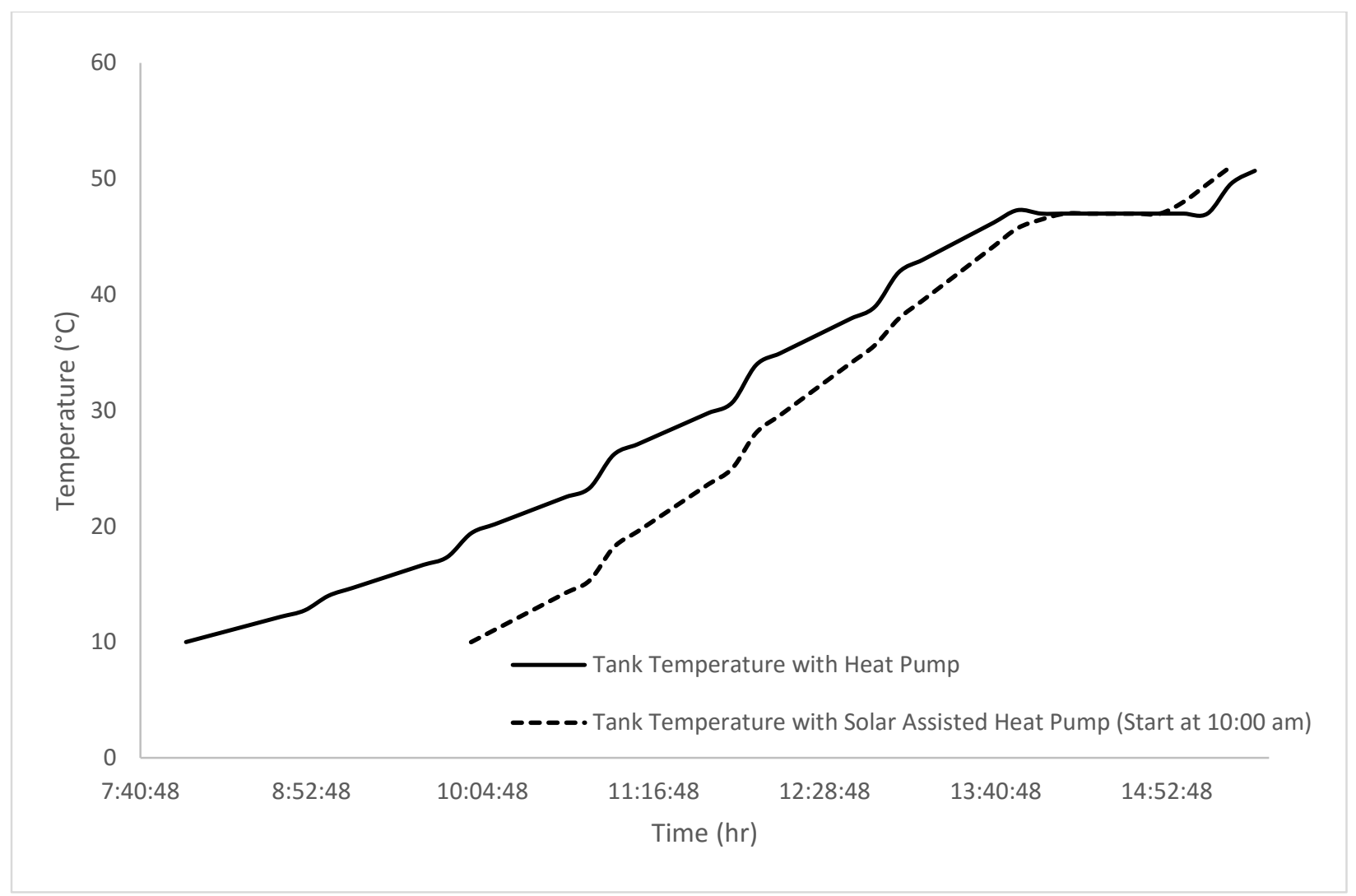

Figure 27: Charging process comparison

Moreover, charging the tank with two different PCM size blocks is shown in Figure 28 while charging with the solar assisted heat pump that started the same day at 10:00 AM. The higher solar radiation improves the charging process for both cases. However, as expected the larger PCM block in the tank takes longer to melt and therefore the whole process takes 30 minutes more compare to a tank with smaller PCM block. 


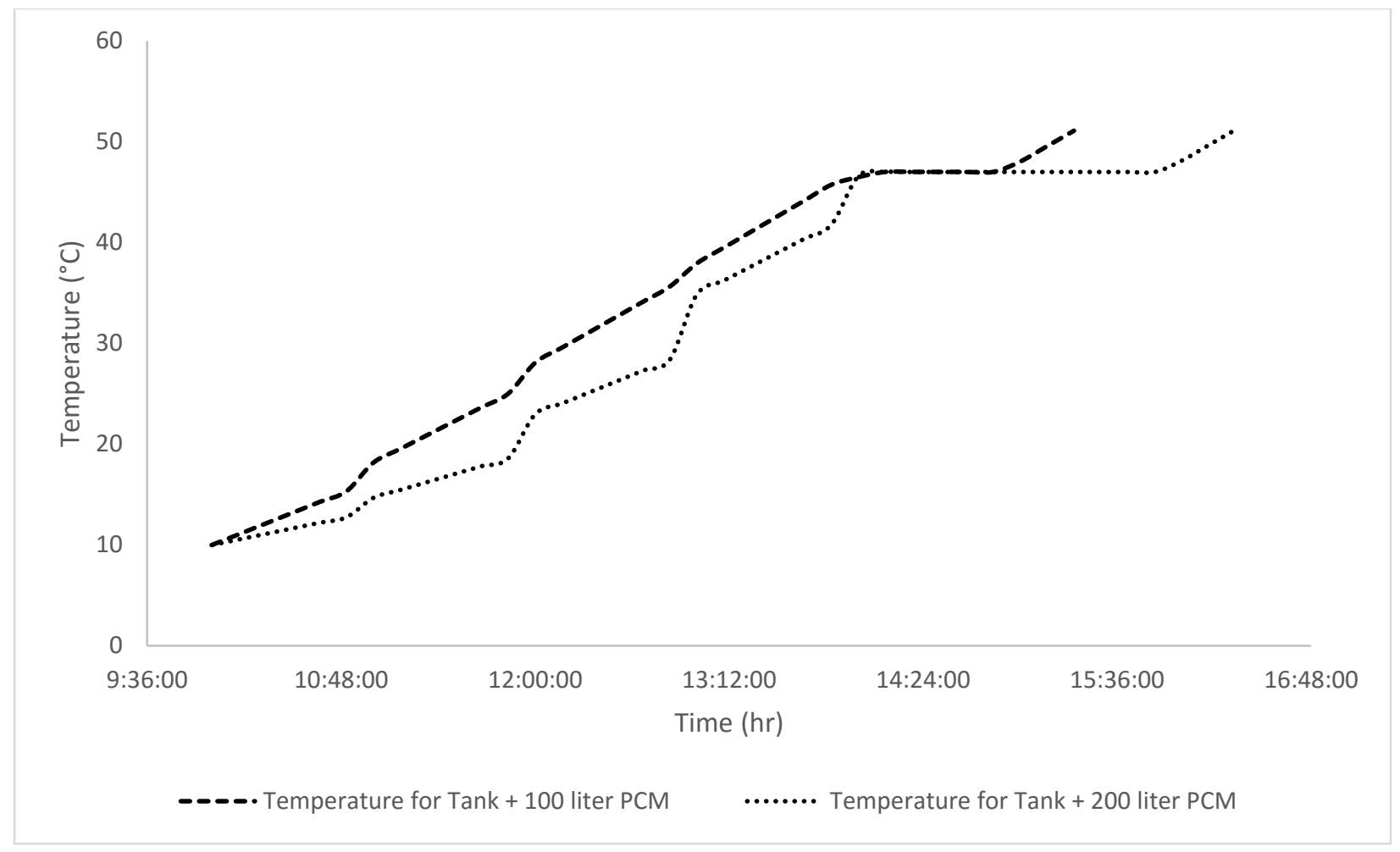

Figure 28: Charging process comparison with various PCM volumes

\section{Discharge Process}

After the detail analysis of charging the thermal storage tank, discharge process was also studied. A fully charged tank with temperature at $50^{\circ} \mathrm{C}$ was discharged based various mass flow rates. The model considers an equal mass flow rate as inlet into the tank when there is a water draw from the storage tank. Meanwhile, the tank receives thermal energy from the coil as either fixed rate or fixed temperature.

Various flowrates of inlet and outlets have been studied. Figure 29 illustrates the tank temperature during discharge process when the mass flow rate is at $0.1 \mathrm{~kg} / \mathrm{s}(1.6 \mathrm{gpm})$ and the inlet flow rate is $10^{\circ} \mathrm{C}$. There is a 200 liter block of S46 PCM inside the tank and the tank is 
receiving thermal energy from a $7 \mathrm{~kW}$ heat pump. It has been shown that a complete discharge take 5.5 hours and the temperature during the first $2: 40$ hrs is higher than $30^{\circ} \mathrm{C}$.

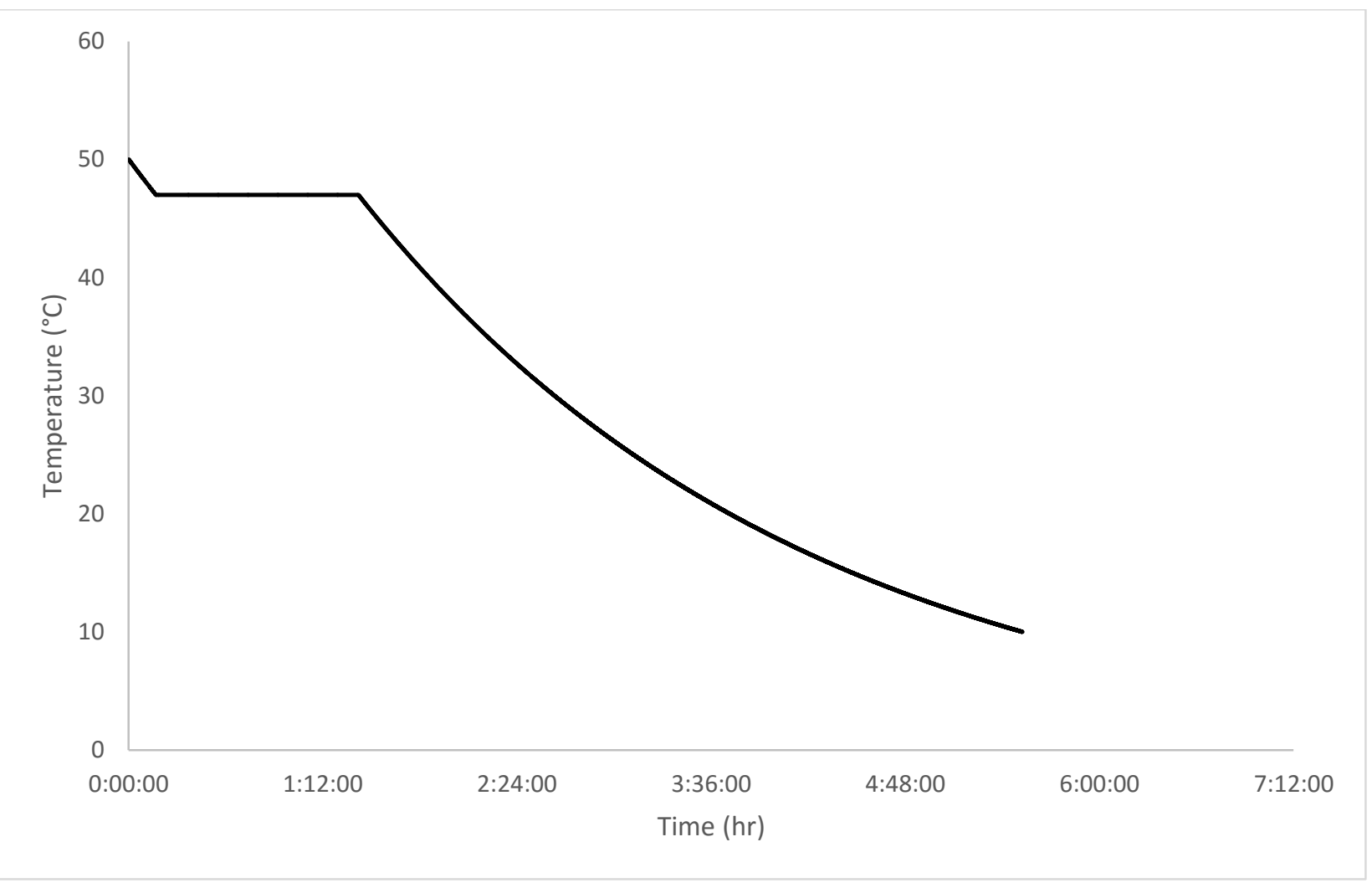

Figure 29: Discharge process

In order to illustrate the effect of mass flow rate for water draw and inlet Figure 30 was generated. The figure compares two other mass flow rates as $0.05 \mathrm{~kg} / \mathrm{s}(0.8 \mathrm{gpm})$ and $0.075 \mathrm{~kg} / \mathrm{s}$ (1.2 gpm) with Figure 29. It has been shown that reducing the mass flow rate would increase the discharge duration which is desirable. However, it depends on the application. When the mass flow rate reduced to half the discharge period was extended for two more hours. This analysis again would be beneficial for developing a control strategy of how and when use the thermal energy storage. 


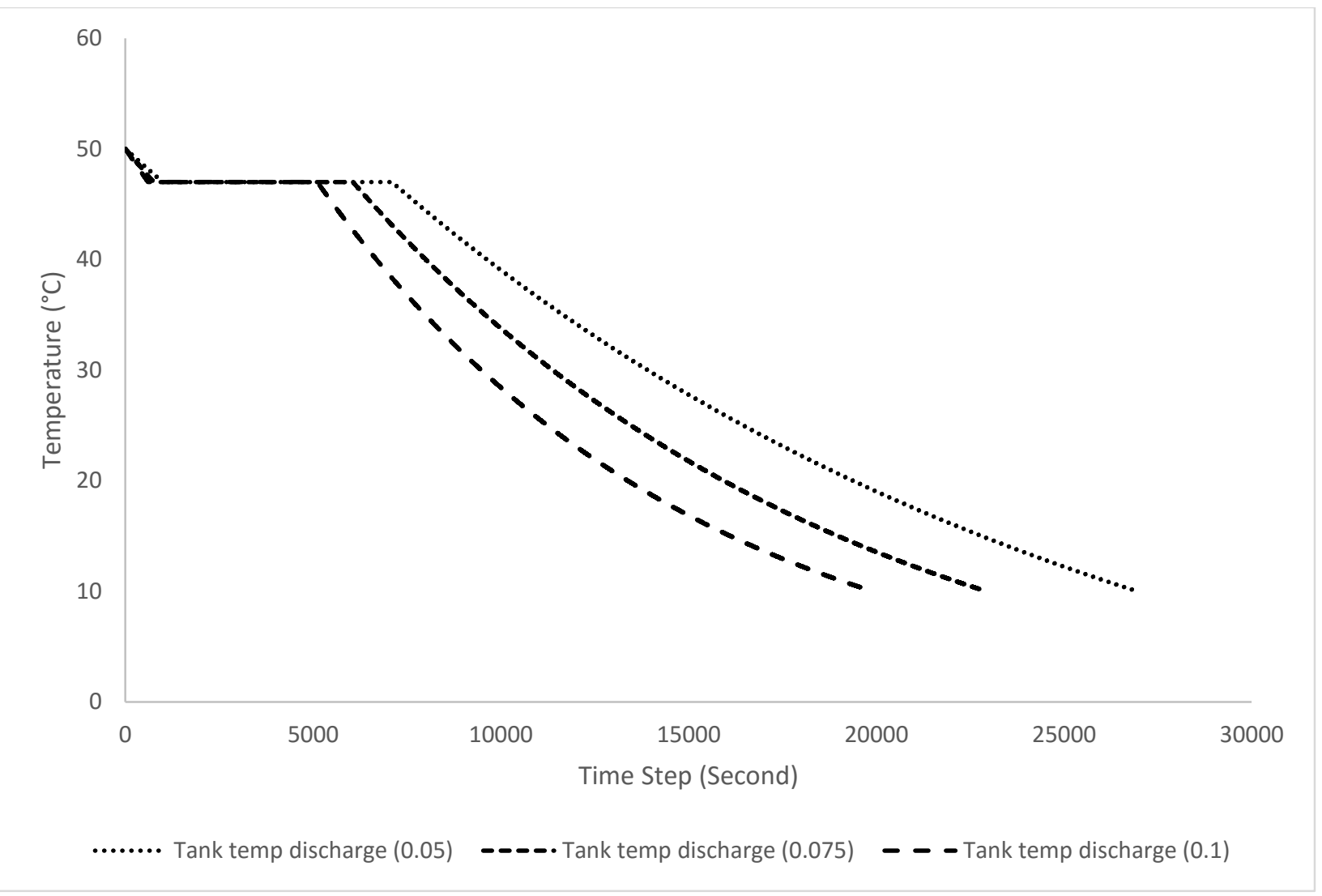

Figure 30: Discharge process with different mass flow rates

Figure 31 shows a full charge and discharge process when the tank is being connected to a heat pump with fixed thermal energy supply. It shows the difference between two processes and how temperature varies in each course. As expected the discharge time is shorter compared with the charging duration. And also it is observed that also tank temperature rises in a linear form due to fixed thermal input but it decreases gradually because of the input mass flow rate and receiving thermal energy. These trend can be used to develop a type in energy simulation software. 


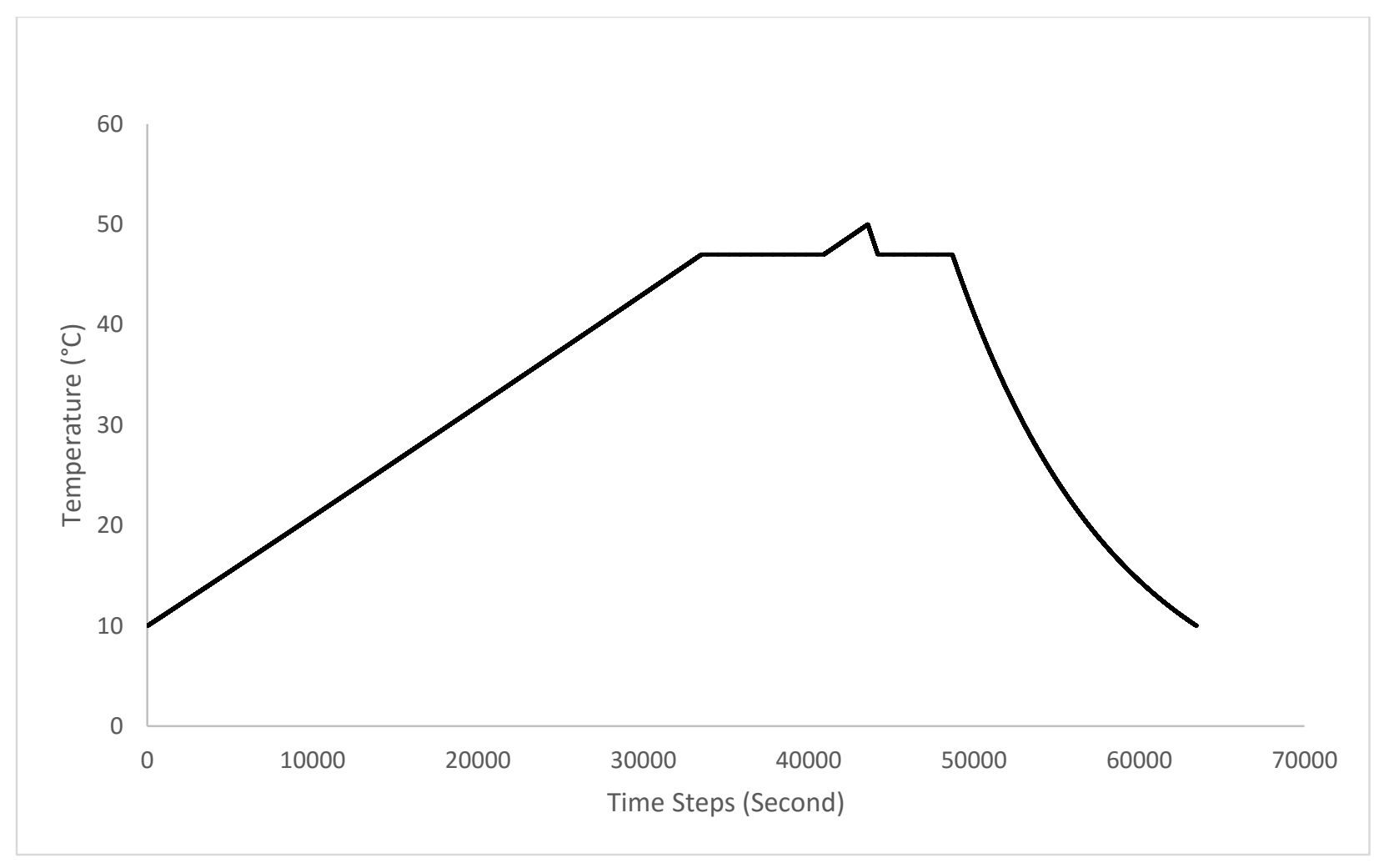

Figure 31: Continuous charging and discharging

After these analysis a comparison between charging time for the tank with fixed heat rate was shown in Figure 32. It is to demonstrate the effect of larger PCM blocks on the charging duration. All three different heat pump that was discussed earlier in this chapter along with three sizes of PCM blocks containing S-46 was shown in Figure 32. A 10 hours variation for different settings has been observed. Therefore, selecting the heat pump capacity and PCM volume play an important role in design and control strategy. 


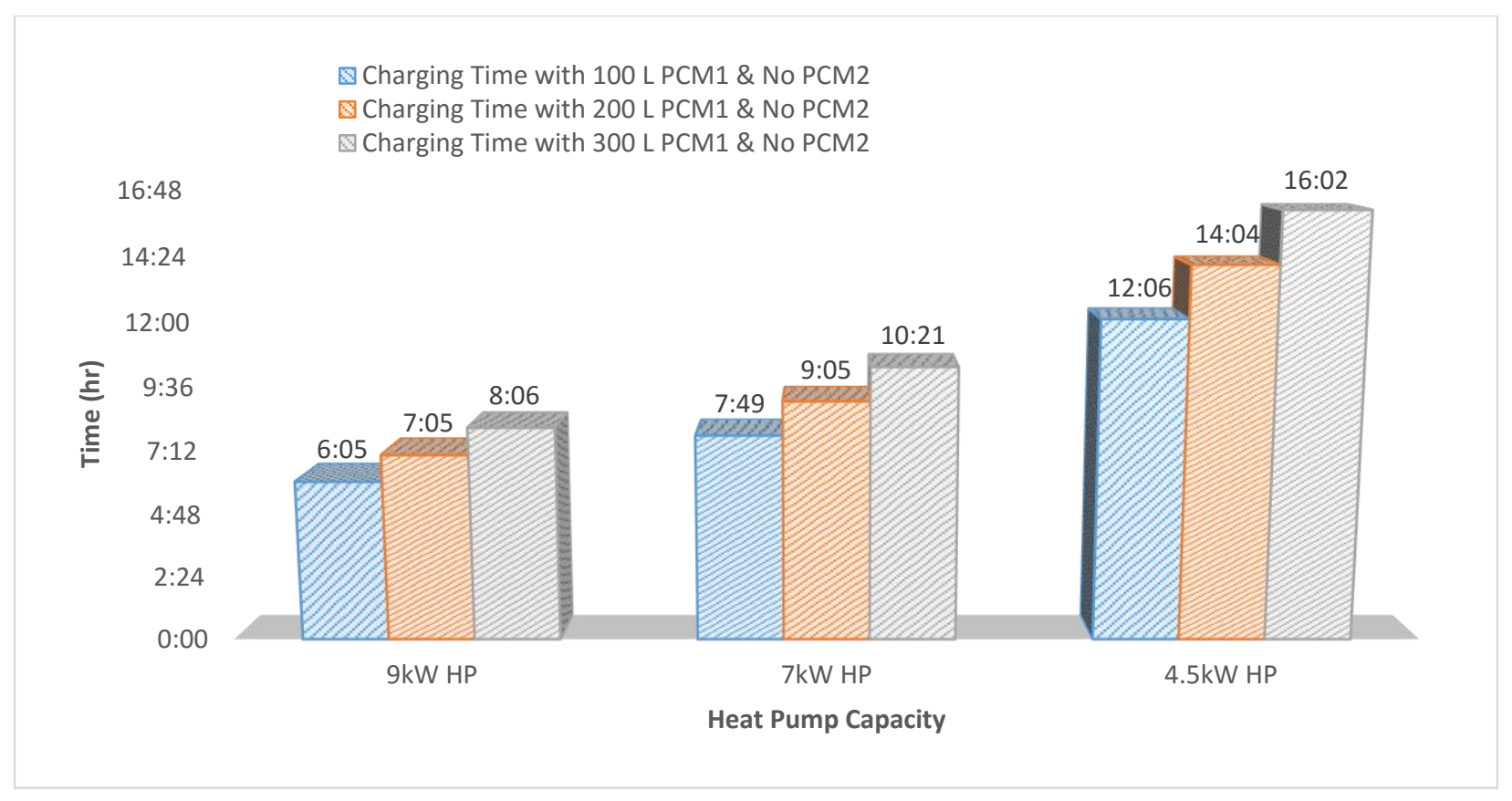

Figure 32: Charging duration for different settings

Moreover, the phase change duration was analyzed and shown in Figure 33. The difference between melting time of a 100 liter block of Salt-Hydrate S46 was compared to a 100 liter PolyEthylene-Glycol (PEG) E600.

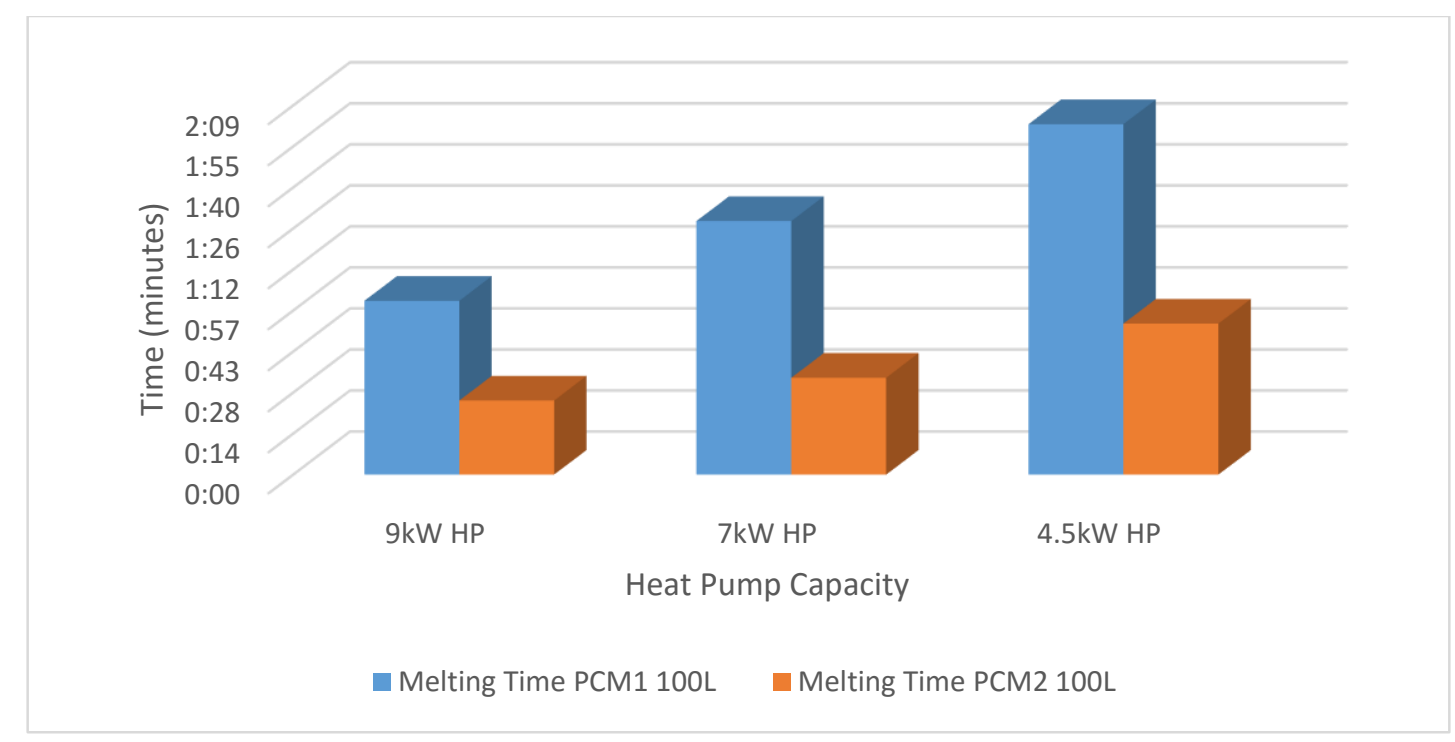

Figure 33: Melting time comparison 


\section{Chapter 4-Summary}

A comprehensive study was conducted to determine how effective a thermal storage tank would be charged and discharged. A numerical model based on the energy balance of the tank was developed. The input thermal energy to the tank is through a coil inside the tank. Hot water produced by heat pump as thermal source will be circulated inside the coil and then transfers thermal energy to the tank. The source of thermal energy can be a heat pump with fixed rate of thermal energy or fixed coil temperature. Also, it could be a solar assisted heat pump, which solar collectors pre-heat the air for heat pump and then heat pump would be able to work more efficiently.

The analysis began with fixed thermal energy rate as input. The pump selection is based on two market available SANYO heat pumps (4.5 kW [SHP-C45DEN] \& 9kW [SHP-TH90GDN]) and a third heat pump was selected as a median between above mentioned heat pumps (7kW). Both SANYO heat pumps have coefficient of performance (COP) of 3.8 Also, the fixed coil temperature method was tested on the model. According to the current heat pumps specifications and output capabilities, coil temperature of $55^{\circ} \mathrm{C}$ and $65^{\circ} \mathrm{C}$ was tested in the model. Later on, a solar assisted heat pump as a heat source was tested also.

The model is able to take into account losses from top, bottom, and sides/walls of the tank. Moreover, the model is designed in a way that can have two phase change material (PCM) blocks embedded inside the tank. 
Volume of the tank and each PCM block can be defined in the model. In all analysis in this study the tank volume was considered as 1000 liter. However, this number can be easily adjusted as per user requirement. Additionally, operational effect of various sizes of PCM blocks $(100,200$, 300 liter) were discussed in this study. For the sake of this analysis, two kinds of accessible phase change materials were defined in the model. These PCMs also can be re-defined in the model as per user requirement. The employed PCMs are Salt-Hydrate S46 and Poly-Ethylene-Glycol (PEG) E600 with the melting temperature of $47^{\circ} \mathrm{C}$ and $22^{\circ} \mathrm{C}$ and heat capacity of 333000000 and $143227200 \mathrm{~J} / \mathrm{m}^{3}$.

For charging process the tank was assumed to be full of water with $10^{\circ} \mathrm{C}$ and no water draw during the process. And discharge process is defined based on equal mass flow rate of inlet and outlet which means that the tank will be filled at the same time of water draw and inlet temperature was set at $10^{\circ} \mathrm{C}$. The inlet water temperature is also can be re-defined by user.

The model is capable of considering water pump work which is neglected in the analysis since the focus of this study was not electrical consumption of the system rather to analyze the thermal response of the tank. 


\subsection{Highlights}

The analysis in this study can be categorized in four sections. First, the tank was charged with a fixed input thermal energy rate. Then, fixed temperature coil was studied. After that, solar assisted heat pump was used as thermal source. The final section is the discharge performance of the tank.

A fixed thermal energy input to the tank resulted in linear temperature rise within the tank up to the melting point of PCM blocks. At the melting point temperature remains constant while the PCM block goes under phase change process. After a complete melting, the tank temperature increase again until it reaches the set point. The set point in this analysis was $50^{\circ} \mathrm{C}$ which is adjustable. The slope of temperature line which corresponds to how fast the tank is being charged is directly related to the heat pump output capacity. It was shown that using a tank with $9 \mathrm{~kW}$ capacity speeds up the charging process compared to smaller heat pumps. Moreover, the melting time of PCM blocks are also proportional to the heat capacity of heat pumps. In this section charging process of the tank with three different heat pumps and using one or two PCM blocks at the same time was studied. The corresponding times and stored energy are discussed as well.

Next, a more realistic charging condition was considered. Providing a constant thermal energy rate might not be a practical way to charge a storage tank. Therefore, a fixed coil temperature was considered in the model. Since the tank temperature is increasing during the charging process, having a fixed coil temperature would result in a variable time dependent input thermal energy. The second section of analysis considered two temperatures for the coil at $55^{\circ} \mathrm{C}$ and $65^{\circ} \mathrm{C}$. 
Again, all previous conditions such as having different sizes of one or two PCM blocks inside the tank were discussed and charging process of the tank was studied. It was shown that the higher coil temperature results in shorter charging period. Also, it was concluded that lower coil temperature is more suitable for applications with low temperature which can be achieved by lower set point temperature of tank. When the coil temperature is close to the set point temperature, the charging is not effective and fast as the beginning of process when the temperature difference is higher. In general, the higher the temperature difference between coil and tank is, the better charging performance would be.

Furthermore, a solar assisted heat pump was used to charge the storage tank. A $5 \times 5$ roof mounted building integrated photovoltaic/thermal (BIPV/T) system which was previously modeled by Kamel and Fung, (2014) was used to calculate the air temperature after the panels. Then heated air was introduced to the heat pump system to upgrade and increase the coefficient of performance of heat pump. After that upgraded heat pump was studied in charging process. This model unlike the other two approaches has variable input thermal energy based on time of the day and radiation level. It has been shown that using a solar assisted heat pump with a welldefined control strategy would enhance the charging process of the storage tank. Again in this approach various PCM volumes were tested and corresponding charging period and stored energies were discussed. The sample results are based on weather data library of typical winter days of Toronto. First day is October $26^{\text {th }}$, a sunny winter day with low ambient temperature and high radiation and second day is October $27^{\text {th }}$, a partly cloudy day with higher temperature and lower radiation. It has been shown that the radiation is more important compared to ambient 
temperature and higher radiation despite the lower temperature has better effect in thermal generation.

Finally, discharge process of a fully charged tank was studied. The effect of water draw mass flow rate was analyzed. As expected the higher mass flow rate, which equal for both inlet and draw, cooled down the tank temperature faster compared to lower flow rates. Also, the solidification period is proportional to the mass flow rate. However, the input thermal energy during the discharge effects the temperature drop inside the tank. 


\subsection{Remarks}

This study shows the charging of a thermal storage tank is possible in different ways. However, each approach has its own advantages and disadvantages. The charging process needs to be defined based on a detail control strategy. Solar availability, time of charge, demand volume, demand time, demand temperature, heat pump capacity, flow rates, etc are elements that need to be considered. In general, it has been shown that PCM blocks are effective in increasing the total energy storage capacity and melting temperature, heat capacity, and specific heat of PCMs are important in charging and discharging processes.

A PCM with lower melting point might be more of use when the demand temperature requirement is lower or when a partially charged tank is required. Also, a lower melting point helps the process when the coil temperature is not high enough. Therefore lower melting point of PCM would keep the temperature difference between coil and tank temperature for a longer time. On the other hand, higher melting point with higher heat capacity is more effective when the tank is being charged with high thermal energy rate.

Moreover, it has been shown that a solar assisted heat pump would effectively charge the storage tank and would be even more effective with a well-organized control system. 


\subsection{Future Works and Recommendations}

This study shows the preliminary results of charging a storage tank with heat pump systems. However, a more detail analysis with building simulation software would provide a more general analysis. Developing the storage tank with and without PCM blocks in TRNSYS or Energy Plus would deliver a whole integrated mechanical simulation. The energy balance in this study would be the stepping stone for developing this new type in building simulation software. Results of the developed type in TRNSYS can then be compared with presented results in this study to be validated. After that the type can be implemented in the whole building simulation and connected to other mechanical components such as heat pump and solar collectors. Based on results presented here, it is recommended that the future TRNSYS type is also better to be developed by flexible volumes for PCM blocks and adjustable mechanical properties in order to provide the user with variety of options for phase change materials. The author also recommends running the simulated model for shorter time steps such as minutely instead of hourly to prevent the step functions in generated figures. This issue specially is more important when the type is being connected to the solar collectors and radiation variation is huge from hour to hour. Therefore, a shorter time step would result in more accurate and a smoother graphs. 


\section{References}

Agyenim, F., Hewitt, N., Eames, P., \& Smyth, M. (2010). A review of materials, heat transfer and phase change problem formulation for latent heat thermal energy storage systems (LHTESS). Renewable and Sustainable Energy Reviews, 14(2), 615-628.

Al-Hinti I, Al-Ghandoor A, Maaly A, Abu Naqeera I, Al-Khateeb Z, Al-Sheikh O. (2010). Experimental investigation on the use of water-phase change material storage in conventional solar water heating systems. Energy Convers Manage; 51:1735-40.

Basecq, V., Michaux, G., Inard, C., \& Blondeau, P. (2013). Short-term storage systems of thermal energy for buildings: A review. Advances in Building Energy Research, 7(1), 66-119.

Bony J, Citherlet S.(2007) Numerical model and experimental validation of heat storage with phase change materials. Energy Build 2007; 39:106572.

Braun, J. E., Klein, S. A., \& Mitchell, J. W. (1981). Seasonal storage of energy in solar heating. Solar Energy, 26(5), 403-411. doi:10.1016/0038092X(81)90219-X

Cabeza, L. F., Castell, A., Barreneche, C., De Gracia, A., \& Fernández, A. I. (2011). Materials used as PCM in thermal energy storage in buildings: A review. Renewable and Sustainable Energy Reviews, 15(3), 1675-1695.

Cabeza, L. F., Roca, J., Ibáñez, M., Nogués, M., Hiebler, S., Solé, C., \& Mehling, $H$. (2006). Use of phase-change materials in solar domestic hot water tanks. ASHRAE Transactions, 112 PART 1 495-508.

Castell, A., Medrano, M., Solé, C., \& Cabeza, L. F. (2010). Dimensionless numbers used to characterize stratification in water tanks for discharging at low flow rates. Renewable Energy, 35(10), 2192-2199. 
Castell, A., Solé, C., Medrano, M., Nogués, M., \& Cabeza, L. F. (2007). Comparison of stratification in a water tank and a PCM-water tank. Proceedings of the Energy Sustainability Conference 2007, 465-470. Castell, A., Solé, C., Medrano, M., Nogués, M., \& Cabeza, L. F. (2009). Comparison of stratification in a water tank and a PCM-water tank. Journal of Solar Energy Engineering, Transactions of the ASME, 131(2), 02450110245015.

Chen, Y., Athienitis, A. K., \& Galal, K. (2010). Modeling, design and thermal performance of a BIPV/T system thermally coupled with a ventilated concrete slab in a low energy solar house: Part 1, BIPV/T system and house energy concept. Solar Energy, 84(11), 1892-1907.

Chen, Y., Galal, K., \& Athienitis, A. K. (2010). Modeling, design and thermal performance of a BIPV/T system thermally coupled with a ventilated concrete slab in a low energy solar house: Part 2, ventilated concrete slab. Solar Energy, 84(11), 1908-1919.

Chu, J. Choi, W. Cynthia A. Cruicks, H. Stephen J.Harrison (2013) Modeling of an Indirect Solar Assisted Heat Pump System for a High Performance Residential House.

Cruickshank, C.A. and Harrison, S.J.: An Experimental Test Apparatus for the Evaluation of Multi-Tank Thermal Storage Systems. Proceedings of the Joint Conference of the Canadian Solar Buildings Research Network and Solar Energy Society of Canada Inc. (SESCI) 2006 Conference, Montreal, Quebec (2006)

Dinçer, I. E., \& Rosen, M. A. (2011). Thermal energy storage: Systems and applications (2nd ed.). Hoboken, N.J.: Wiley.

Dincer, I., \& Rosen, M. A. (2008). Exergetically efficient thermal energy storage systems for sustainable buildings. ASHRAE Transactions, 114 PART 1 98-107. 
Duffie, J.A. and Beckman, W.A.: Solar Engineering of Thermal Processes. John Wiley \& Sons York, N.Y. (2006)

Ekrami, N., Kamel, R. S., Fung, A. S., 2014. Effectiveness of a ventilated concrete slab on an air source heat pump performance in cold climate. In Proceeding of eSim Conference, Ottawa.

Elliot, B. D., 2011, "Evaluation of an Indirect Solar Assisted Heat Pump Water Heater in the Canadian Climate," Master's thesis, Queen's University, Kingston, ON, Canada

Farid, M. M., Khudhair, A. M., Razack, S. A. K., \& Al-Hallaj, S., 2004. A review on phase change energy storage: Materials and applications. Energy Conversion and Management, 45(9-10), 1597-1615.

Fernandez, A. I., Martínez, M., Segarra, M., Martorell, I., \& Cabeza, L. F. (2010). Selection of materials with potential in sensible thermal energy storage. Solar Energy Materials and Solar Cells, 94(10), 1723-1729.

Fisch, M.N., Guigas, M. and Dalenbäck, J.O.: A Review of Large-Scale Solar Heating Systems in Europe. Solar Energy, Vol. 63 (6), 355-366 (1998)

Haji Abedin, A. (2010). Thermochemical energy storage systems: Modelling, analysis and design. (M.A.Sc., University of Ontario Institute of Technology (Canada)). ProQuest Dissertations and Theses, . (808149924).

Helm M, Hagel K, Pfeffer W, Hiebler S, Schweigler C. (2013). Solar heating and cooling system with absorption chiller and latent heat storage - A research project summary, Energy Procedia. 48 (2014)837-849

International energy agency (IEA) task 32, Laboratory prototypes of PCM storage units; 2007.

Kamel, R. S., Fung, A. S. (2014a). Modeling, simulation and feasibility analysis of residentialbipv/t+ashp system in cold climate-canada. Energy \& Buildings, doi:10.1016/j.enbuild.2014.07.081 
Kamel, R. S., Fung, A. S. (2014b). Theoretical estimation of the performance of a photovoltaic-thermal collector (PV/T) system coupled with a heat pump in a sustainable house in toronto. ASHRAE Transactions, 120(1)

Kamel, R. S., Fung, A. S. Solar systems and their integration with heat pumps: A review. Energy and Buildings, doi: http://dx.doi.org/10.1016/j.enbuild.2014.11.030

Kangas, M.T. and Lund, P.D.: Modeling and Simulation of Aquifer Storage Energy Systems. Solar Energy, Vol. 53 (3), 237-247 (1994)

Kousksou, T., Bédécarrats, J., Strub, F., \& Castaing-Lasvignottes, J. (2008). Numerical simulation of fluid flow and heat transfer in a phase change thermal energy storage. International Journal of Energy Technology and Policy, 6(1-2), 143-158.

Lane, G. A. (1980). Low temperature heat storage with phase change materials. International Journal of Ambient Energy, 1(3), 155-168.

López-Navarro A, Biosca-Taronger J, Corberán JM, Peñalosa C, Lázaro A, Dolado $P$, et al., (2014) Performance characterization of a PCM storage tank. Appl Energy 2014; 119:151-62.

Martin V, Setterwall F, Hallberg L.(2008) Development of PCM-based thermal energy storage for solar hot water systems. In: EuroSun conference. Lisbon, Portugal

Mehling H, Cabeza LF, Hippeli S, Hiebler S.(2003) PCM-module to improve hot water heat stores with stratification. Renew Energy 2003; 28:699-711.

Nkwetta, D. N., \& Haghighat, F. (2014). Thermal energy storage with phase change material - A state-of-the art review. Sustainable Cities and Society, 10, 87-100.

Nkwetta DN, Vouillamoz P-E, Haghighat F, El-Mankibi M, Moreau A, Daoud A.(2014) Impact of phase change materials types and positioning on hot water tank thermal performance: using measured water demand profile. Appl Thermal Eng 
Ochs F, Heidemann W, Müller-Steinhagen H. Performance of large-scale seasonal thermal energy stores. J Sol Energy Eng 2009; 131:041005-4.

Pinel, P., Cruickshank, C. A., Beausoleil-Morrison, I., \& Wills, A. (2011). A review of available methods for seasonal storage of solar thermal energy in residential applications. Renewable and Sustainable Energy Reviews, 15(7), 3341-3359. doi:10.1016/j.rser.2011.04.013

Rad, F. M., Fung, A. S., \& Leong, W. H. (2013). Feasibility of combined solar thermal and ground source heat pump systems in cold climate, canada. Energy and Buildings, 61(0), 224-232. doi:http://dx.doi.org/10.1016/j.enbuild.2013.02.036

Sadasivam, S., Zhang, D., Fung, A. S., \& Almeida, F. (2012). Modeling phase change materials with a building simulation code developed in MATLAB. ASHRAE Transactions, 118(PART 2) 610-624.

Safa, A.A., Fung, A.S., Kumar, R. Performance of two-stage variable capacity air source heat pump: Field performance results and TRNSYS simulation (2015) Energy and Buildings, 94, pp. 80-90.

Sharma, A., Tyagi, V. V., Chen, C. R., \& Buddhi, D. (2009). Review on thermal energy storage with phase change materials and applications. Renewable and Sustainable Energy Reviews, 13(2), 318-345.

Speyer E. Optimum storage of heat with a solar house. Sol Energy 1959; $3: 24-48$.

Wang, E., Fung, A. S., Qi, C., \& Leong, W. H. (2012). Performance prediction of a hybrid solar ground-source heat pump system. Energy and Buildings, 47, 600-611.

TRNSYS17, Reference Manual, Solar Energy Laboratory, Univ. of WisconsinMadison, Madison, 2012. 


\section{Appendices}

Appendix A

Table A: Examples of sensible heat storage materials (Agyenim et al., 2010)

\begin{tabular}{|c|c|c|c|}
\hline Material & Operating temperature $\left({ }^{\circ} \mathrm{C}\right)$ & Heat Capacity (J/kgK) & Density (kg/m3) \\
\hline Water & $0-100$ & 4.190 & 1000 \\
\hline Therminol & -9 to 343 & 2.100 & 750 \\
\hline Engine Oil & Up to 160 & 1.880 & 888 \\
\hline Lithium & $180-1300$ & 4.190 & 510 \\
\hline Sodium & $100-760$ & 1.300 & 960 \\
\hline Ethanol & Up to 78 & 2.400 & 790 \\
\hline Butanol & Up to 118 & 2.400 & 809 \\
\hline Octane & Up to 126 & 2.400 & 704 \\
\hline Aluminum & Up to 660 & 0.896 & 2707 \\
\hline Brick & 1000 & 0.840 & 1698 \\
\hline Concrete & 1000 & 1.130 & 2240 \\
\hline Cast Iron & Up to 1100 & 0.837 & 7900 \\
\hline Copper & Up to 1000 & 0.383 & 8954 \\
\hline Sodium Carbonate & Up to 850 & 1.090 & 2510 \\
\hline Limestone & Up to 825 & 0.900 & 2500 \\
\hline Magnesium Oxide & Up to 2800 & 0.960 & 35700 \\
\hline
\end{tabular}


Appendix B

Table B: Examples of organic phase change materials (Agyenim et al., 2010)

\begin{tabular}{llll}
\hline Materials & $\begin{array}{l}\text { Melting point } \\
\left({ }^{\circ} \mathrm{C}\right)\end{array}$ & $\begin{array}{l}\text { Latent heat of fusion } \\
(\mathrm{kJ} / \mathrm{kg})\end{array}$ & $\begin{array}{l}\text { Density } \\
\left(\mathrm{kg} / \mathrm{m}^{3}\right)\end{array}$ \\
\hline Formic acid & 7.8 & 247 & 1226.7 \\
Acetic acid & 16.7 & 187 & 1050 \\
Glycerin & 17.9 & 198.7 & 1260 \\
D-lattic acid & 26 & 184 & 1249 \\
Polyethylene glycol 600 & $20-25$ & 146 & 1100 \\
Cyanamide & 44 & 209 & 1080 \\
Methyl eicosanate & 45 & 230 & 851 \\
Camphene & 50 & 238 & 842 \\
Chloroacetic acid & 56 & 130 & 1580 \\
Trimyristin & $33-57$ & $201-213$ & 862 \\
Bee wax & 61.8 & 177 & 950 \\
Bromcamphor & 77 & 174 & 1449 \\
Durene & 79.3 & 156 & 838 \\
Acetamide & 81 & 241 & 1159 \\
Succinic anhydride & 119 & 204 & 1104 \\
Benzoic acid & 121.7 & 142.8 & 1266 \\
Stibene & 124 & 167 & 1164 \\
Benzamide & 127.2 & 169.4 & 1341 \\
Alpha glucose & 141 & 174 & 1544 \\
Salicylic acid & 159 & 199 & 1443 \\
O-mannitol & 166 & 294 & 1489 \\
Hydroquinone & 172.4 & 258 & 1358 \\
& & &
\end{tabular}


Appendix C

Table C: Examples of inorganic phase change materials (Agyenim et al., 2010)

\begin{tabular}{|c|c|c|c|}
\hline Materials & $\begin{array}{l}\text { Melting temperature } \\
\left({ }^{\circ} \mathrm{C}\right)\end{array}$ & $\begin{array}{l}\text { Heat of fusion } \\
(\mathrm{kJ} / \mathrm{kg})\end{array}$ & $\begin{array}{l}\text { Density } \\
\left(\mathrm{kg} / \mathrm{m}^{3}\right)\end{array}$ \\
\hline $\mathrm{NaNO}_{3}$ & 306 & 182 & 2260 \\
\hline $\mathrm{RbNO}_{3}$ & 312 & 31 & 3685 \\
\hline $\mathrm{KNO}_{3}$ & 334 & 266 & 2109 \\
\hline $\mathrm{KOH}$ & 380 & 149.7 & 2044 \\
\hline $\mathrm{CsNO}_{3}$ & 409 & 71 & 2500 \\
\hline $\mathrm{AgBr}$ & 432 & 48.8 & 1100 \\
\hline $\mathrm{PbCl} 2$ & 501 & 78.7 & 5600 \\
\hline $\mathrm{Ca}\left(\mathrm{NO}_{3}\right)_{2}$ & 560 & 145 & 2113 \\
\hline $\mathrm{LiCl}$ & 610 & 441 & 2070 \\
\hline $\mathrm{FeCl}_{2}$ & 677 & 337.9 & 3160 \\
\hline $\mathrm{MgBr}_{2}$ & 711 & 214 & 3720 \\
\hline $\mathrm{CaI}_{2}$ & 783 & 142 & 3956 \\
\hline $\mathrm{NaCl}$ & 802 & 482 & 2160 \\
\hline $\mathrm{KF}$ & 858 & 468 & 2370 \\
\hline $\mathrm{BaCl}_{2}$ & 961 & 76 & 3856 \\
\hline $\mathrm{PbSO}_{4}$ & 1000 & 133 & 6200 \\
\hline $\mathrm{MgSO}_{4}$ & 1130 & 122 & 2660 \\
\hline $\mathrm{MgF}_{2}$ & 1263 & 938 & 3150 \\
\hline $\mathrm{BaF}_{2}$ & 1320 & 119 & 4890 \\
\hline $\mathrm{CaF}_{2}$ & 1418 & 391 & 3180 \\
\hline $\mathrm{BaSO}_{4}$ & 1512 & 188 & 4500 \\
\hline $\mathrm{SrSO}_{4}$ & 1605 & 196 & 3960 \\
\hline
\end{tabular}




\section{Appendix D}

Table D: Examples of eutectic phase change materials (Agyenim et al., 2010)

\begin{tabular}{|c|c|c|c|c|}
\hline Material Composition (wt \%) & $\begin{array}{l}\text { Melting } \\
\text { temperature }\left({ }^{\circ} \mathrm{C}\right)\end{array}$ & $\begin{array}{l}\text { Heat of fusion } \\
(\mathrm{kJ} / \mathrm{kg})\end{array}$ & $\begin{array}{l}\text { Density } \\
\text { (kg/m3) }\end{array}$ & $\begin{array}{l}\text { Thermal } \\
\text { conductively }(\mathrm{W} / \mathrm{mK})\end{array}$ \\
\hline $\mathrm{NaF}-\mathrm{MgF}_{2}(75+25)$ & 832 & 650 & 4660 & 2.68 \\
\hline $\mathrm{NaF}-\mathrm{MgF} \mathrm{F}_{2}(67+33)$ & 832 & 616 & 4650 & 2.14 \\
\hline LiF-MgF $2(67+33)$ & 745 & 947 & - & 2.63 \\
\hline $\mathrm{NaF}-\mathrm{CaF} \mathrm{F}_{2}-\mathrm{MgF}_{2}(66+23+12)$ & 745 & 574 & - & 1.58 \\
\hline LiF-NaF $\mathbf{F}_{2}-\mathrm{MgF}_{2}(33.4+49.9+17.1)$ & 650 & 860 & 1150 & 2.82 \\
\hline LiF-NaF $\mathbf{F}_{2}-\mathrm{MgF}_{2}(46+44+10)$ & 632 & 858 & 1200 & 2.24 \\
\hline $\mathrm{Na}_{2} \mathrm{CO}_{3}-\mathrm{Li}_{2} \mathrm{CO}_{3}(56+44)$ & 496 & 368 & 2110 & 2.33 \\
\hline $\mathrm{NaCl}-\mathrm{MgCl}_{2}(50+50)$ & 450 & 429 & 0960 & 2.24 \\
\hline $\mathrm{Li}_{2} \mathrm{CO}_{3}-\mathrm{K}_{2} \mathrm{CO}_{3}-\mathrm{Na}_{2} \mathrm{CO}_{3}(31+35+34)$ & 397 & 275 & 2040 & 2.31 \\
\hline $\mathrm{MgCl}_{2}-\mathrm{NaCl}-\mathrm{KCl}(63+22.3+14.7)$ & 385 & 461 & 0950 & 2.25 \\
\hline $\mathrm{NaCl}-\mathrm{Na}_{2} \mathrm{CO}_{3}-\mathrm{NaOH}(7.8+6.4+85.5)$ & 282 & 316 & - & 2.13 \\
\hline LiCl-LiOH $(37+63)$ & 262 & 485 & 1100 & 1.55 \\
\hline $\mathrm{KCl}-\mathrm{NaCl}-\mathrm{CaCl}{ }_{2}(5+29+66)$ & 504 & 279 & 1000 & 2.15 \\
\hline $\mathrm{KCl}-\mathrm{BaCl}_{2}-\mathbf{B a C l}_{2}(24+47+29)$ & 551 & 219 & 950 & 2.93 \\
\hline
\end{tabular}




\section{Background:}

TRNSYS has developed a basic tank model namely TYPE 60. This type considers stratification effects in tank but does not consider the PCM option within the tank. In this model, user can define the number of nodes along with horizontal direction (height) of the tank to find the required accuracy for the stratified method. Also, TRNSYS focuses on the heat exchanger inside the tank and there are four options such as; Horizontal Tube Bank HX, Vertical Tube Bank HX, Coiled Tube HX, and Serpentine Tube HX. A simplified graph of the TRNSYS tank and its nodes has been shown in Figure E1.

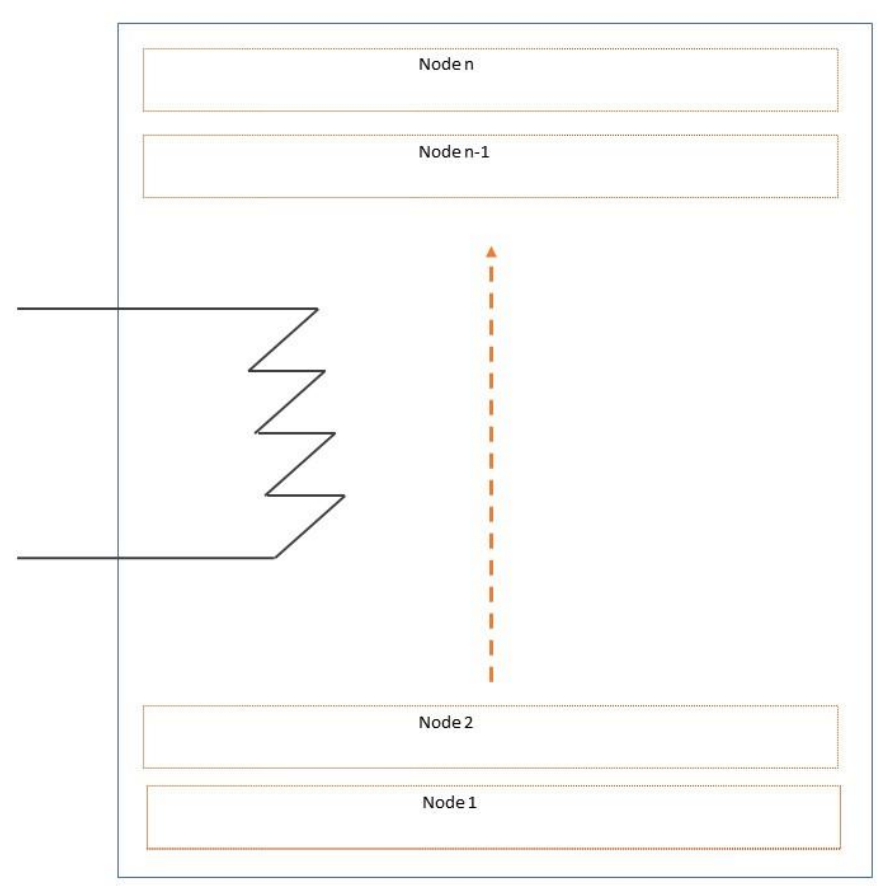

Figure E1: TRNSYS Type 60 (TRNSYS, 2012) 
Additionally, a tank heat storage model with PCM container has been modeled in TRNSYS by IEA Solar Heating and Cooling program - Task 32. This model, which is called TYPE 840, allow user to change the PCM type. However it does not work with two different PCM at the same time. TYPE 840 is modified version of TYPE 60 to implement PCM container in the tank and follows the same approach for transient solution. The schematic of this model is shown in Figure E2.

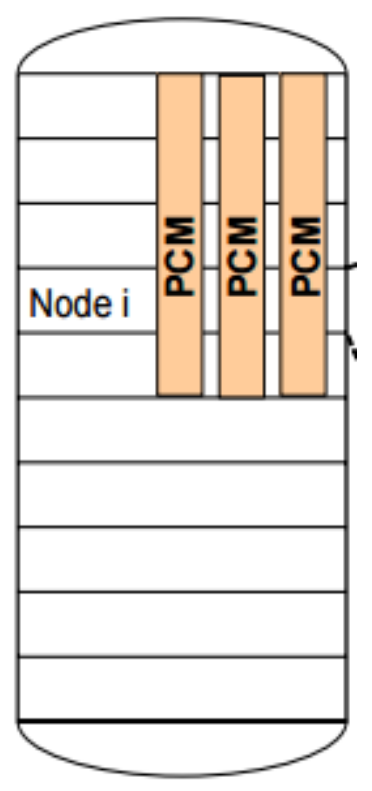

Figure E2: TRNSYS Type 840 (IEA, 2007)

\section{Energy Rate Balance for a Tank with Two PCM}

In this study an energy rate balance for a tank with two different PCM has been developed. However, each PCM can be neglected simply by inserting zero value for its properties. The model considers a general approach of one control volume for the tank including two PCMs and a coil as heat exchanger. The input thermal energy is from the coil and it is considered a fixed value. However, the model can be further developed to define the input energy value as a function of 
water temperature inside the tank, flow rate inside the coil, and supply temperature from the heat pump. A simplified schematic of the tank is shown in Figure E3.

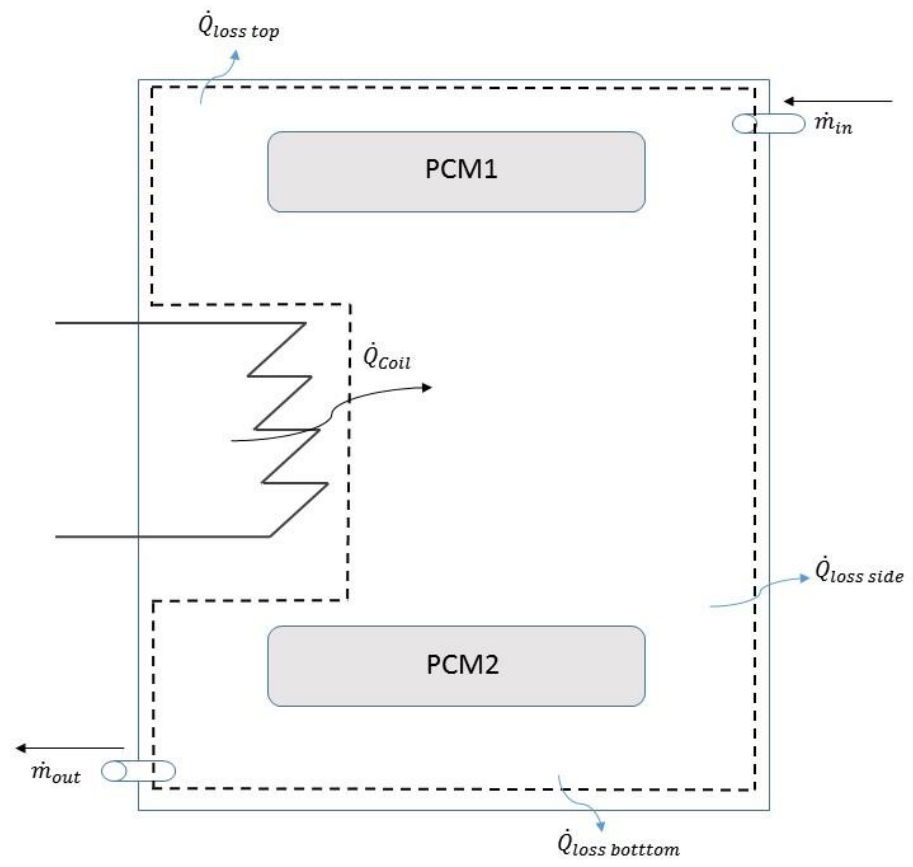

Figure E3: Tank with two PCMs 


\section{Model and Assumptions:}

1. The main significant heat transfer is from the coil. $\left(\dot{Q}_{\text {coil }}\right)$

2. Kinetic and potential energy effects are neglected.

3. The water temperature inside the tank is assumed to be uniform and it only varies as time changes.

4. Losses from the tank are from the bottom, side and top walls.

$$
\left(\dot{Q}_{\text {loss }}=\dot{Q}_{\text {loss bottom }}+\dot{Q}_{\text {loss side }}+\dot{Q}_{\text {loss top }}\right)
$$

5. The power draw rate of the mixer inside the tank is defined as $\dot{W}_{\text {Mixer }}$ which can be a fixed input or neglected.

6. The power draw rate of the pump is defined as $\dot{W}_{\text {pump }}$ which can be a fixed input or neglected.

7. The mass flow rate as inlet and outlet is defined by $\dot{m}$. The inlet and outlet flowrate is assumed to be equal since the tank will be filled at the same time as draw. Therefore, the mass contained within the control volume remains constant. $\quad \dot{m}_{\text {in }}=\dot{m}_{\text {out }}=\dot{m}$

8. Water is incompressible and there is no pressure change.

9. $\dot{Q}_{\text {coil }}$ is defined as a fixed value in this calculation. (However, it can be further defined as a function of $T_{\text {Heat pump }}$ and $T_{\text {Tank }}$ and $\dot{m}_{\text {Heat pump.) }}$ 


$$
\frac{d U_{c v}}{d t}=\dot{Q}_{\text {Coil }}-\dot{Q}_{\text {loss }}-\dot{W}_{\text {Pump }}-\dot{W}_{\text {Mixer }}+\dot{m}\left(h_{\text {out }}-h_{\text {in }}\right) \quad \text { Eq.E1 }
$$

$$
\begin{aligned}
& \frac{d U_{c v}}{d t}=\frac{d\left(m_{\text {water }} u_{\text {water }}+m_{P C M_{1}} u_{P C M_{1}}+m_{P C M_{2}} u_{P C M_{2}}\right)}{d t}= \\
& =m_{\text {water }} \frac{d u_{\text {water }}}{d t}+m_{P C M_{1}} \frac{d u_{P C M_{1}}}{d t}+m_{P C M_{2}} \frac{d u_{P C M_{1}}}{d t}
\end{aligned}
$$

$$
\frac{d u}{d t}=\frac{d u}{d T} \times \frac{d T}{d t}=c \frac{d T}{d t} \quad E q . E 3
$$

$$
\begin{aligned}
& \stackrel{E q . E 2 \Omega E q . E 3}{\longrightarrow} \frac{d U_{c v}}{d t}=m_{\text {water }} c_{\text {water }} \frac{d T}{d t}+m_{P C M_{1}} C_{P C M_{1}} \frac{d T}{d t}+ \\
& m_{P C M_{2}} c_{P C M_{2}} \frac{d T}{d t} \quad E q . E 4
\end{aligned}
$$

water $\rightarrow$ incompressible $\rightarrow$ no change in P (assumption 8)

$\Rightarrow h_{\text {out }}-h_{\text {in }}=c_{\text {water }}\left(T_{\text {out }}-T_{\text {in }}\right) \stackrel{T_{\text {out }}=T}{\longrightarrow} h_{\text {out }}-h_{\text {in }}=c_{\text {water }}\left(T-T_{\text {in }}\right)$ Eq.E5

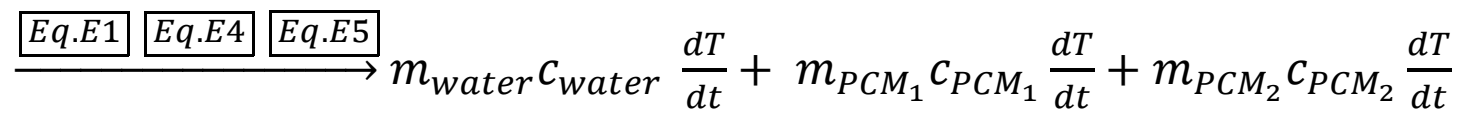

$=\dot{Q}_{\text {coil }}-\dot{Q}_{\text {loss }}-\dot{W}_{\text {Pump }}-\dot{W}_{\text {Mixer }}+\dot{m} c_{\text {water }}\left(T-T_{\text {in }}\right)$

$\rightarrow(\underbrace{m_{\text {water }} c_{\text {water }}+m_{P C M_{1}} c_{P C M_{1}}+m_{P C M_{2}} c_{P C M_{2}}}_{A}) \frac{d T}{d t}$ 


$$
\begin{aligned}
& =\underbrace{\dot{Q}_{\text {coil }}-\dot{Q}_{\text {loss }}-\dot{W}_{\text {Pump }}-\dot{W}_{\text {Mixer }}+\dot{m} c_{\text {water }}\left(T-T_{\text {in }}\right)}_{B} \\
& \Rightarrow A \frac{d T}{d t}=B+\dot{m} c_{\text {water }}\left(T-T_{\text {in }}\right) \\
& \Rightarrow A \frac{d T}{d t}=B+\dot{m} c_{\text {water }} T-\dot{m} c_{\text {water }} T_{\text {in }} \\
& \Rightarrow A \frac{d T}{d t}+\left(-\dot{m} c_{\text {water }}\right) T=B-\dot{m} c_{\text {water }} T_{\text {in }}
\end{aligned}
$$

$\rightarrow$ Solving the first order, differential equation:

$$
\frac{d T}{d t}+\frac{\left(-\dot{m} c_{\text {water }}\right)}{A} T=\underbrace{\frac{B}{A}-\frac{\dot{m} c_{w a t e r}}{A} T_{i n}}_{D} \quad E q \cdot E 6
$$

$$
\mu(t)=e^{\int \frac{-\dot{m} c_{w a t e r}}{A} d t}=e^{\frac{-\dot{m} c_{w a t e r}}{A} t} \quad E q \cdot E 7
$$$$
\left.\begin{array}{c}
\stackrel{\text { Eq.E6 } \times \text { Eq.E7 }}{\longrightarrow} e^{\frac{-\dot{m} c_{\text {water }}}{A} t} \frac{d T}{d t}+\frac{-\dot{m} c_{\text {water }}}{A} \quad e^{\frac{-\dot{m} c_{\text {water }}}{A}} T=D e^{\frac{-\dot{m} c_{\text {water }}}{A}} \\
f^{\prime} g+g f^{\prime}=(f g)^{\prime}
\end{array}\right\} \Rightarrow
$$$$
\Longrightarrow\left(e^{\frac{-\dot{m} c_{\text {water }}}{A}} T\right)^{\prime}=D e^{\frac{-\dot{m} c_{\text {water }}}{A}} t
$$$$
\Rightarrow \int\left(e^{\frac{-\dot{m} c_{w a t e r}}{A} t} T\right)^{\prime} d t=\int D e^{\frac{-\dot{m} c_{w a t e r}}{A} t} d t
$$$$
\Rightarrow e^{\frac{-\dot{m} c_{\text {water }}}{A} t} T=\int D e \frac{-\dot{m} c_{\text {water }}}{A} t d t=D \frac{A}{-\dot{m} c_{\text {water }}} e^{\frac{-\dot{m} c_{\text {water }}}{A} t}+C_{1}
$$$$
\Rightarrow T=D \frac{A}{-\dot{m} c_{\text {water }}}+C_{1} e^{\frac{-\dot{m} c_{\text {water }}}{A} t}
$$ 


$$
\begin{aligned}
& T=\left(\frac{B}{A}-\frac{\dot{m} c_{\text {water }}}{A} T_{\text {in }}\right) \frac{A}{-\dot{m} c_{\text {water }}}+C_{1} e^{\frac{\dot{m} c_{\text {water }}}{A} t} \\
& \rightarrow=\frac{B}{-\dot{m} c_{\text {water }}}+T_{\text {in }}+C_{1} e^{\frac{\dot{m} c_{\text {water }}}{A} t}
\end{aligned}
$$

Considering the initial condition to evaluate $C_{1}$

$$
\begin{aligned}
& \stackrel{C_{1}}{\longrightarrow} \text { at } t=0, T_{\text {in }}=T \\
& T_{(t=0)}=T_{\text {in }}=\frac{B}{-\dot{m} c_{\text {water }}}+T_{\text {in }}+C_{1} \\
& \rightarrow C_{1}=\frac{B}{\dot{m} c_{\text {water }}} \\
& \stackrel{\text { Eq.E8 }}{\underline{\text { Eq.E10 }}} T=\frac{B}{-\dot{m} c_{\text {water }}}+T_{\text {in }}+\frac{B}{\dot{m} c_{\text {water }}} e^{\frac{\dot{m} c_{\text {water }}}{A} t} \\
& \rightarrow T=\frac{B}{\dot{m} c_{\text {water }}}\left(-1+e^{\frac{\dot{m} c_{\text {water }}}{A} t}\right)+T_{\text {in }}
\end{aligned}
$$

By direct substitution the final equation for average water temperature is as follows:

$$
\begin{aligned}
& \rightarrow T=\frac{\dot{Q}_{\text {coil }}-\dot{Q}_{\text {loss }}-\dot{W}_{\text {Pump }}-\dot{W}_{\text {Mixer }}}{\dot{m} c_{\text {water }}}
\end{aligned}
$$

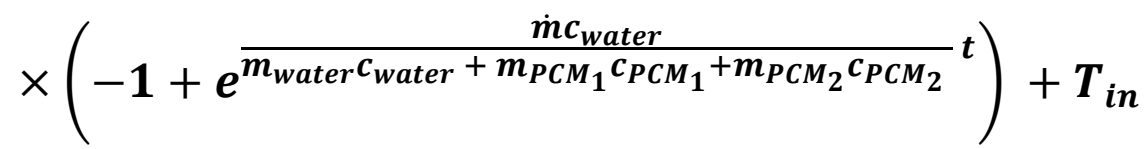

